\title{
Storytelling, Survival, and Child Figures in Contemporary American Life-Writing
}

Yvonne Michelle Swartz Hammond

Follow this and additional works at: https://researchrepository.wvu.edu/etd

\section{Recommended Citation}

Hammond, Yvonne Michelle Swartz, "Storytelling, Survival, and Child Figures in Contemporary American Life-Writing" (2017). Graduate Theses, Dissertations, and Problem Reports. 5745.

https://researchrepository.wvu.edu/etd/5745

This Dissertation is protected by copyright and/or related rights. It has been brought to you by the The Research Repository @ WVU with permission from the rights-holder(s). You are free to use this Dissertation in any way that is permitted by the copyright and related rights legislation that applies to your use. For other uses you must obtain permission from the rights-holder(s) directly, unless additional rights are indicated by a Creative Commons license in the record and/ or on the work itself. This Dissertation has been accepted for inclusion in WVU Graduate Theses, Dissertations, and Problem Reports collection by an authorized administrator of The Research Repository @ WVU.

For more information, please contact researchrepository@mail.wvu.edu. 
Storytelling, Survival, and Child Figures in Contemporary American Life-Writing

Yvonne Michelle Swartz Hammond

\author{
Dissertation submitted \\ to Eberly College of Arts and Sciences \\ at West Virginia University \\ in partial fulfillment of the requirements for the degree of \\ Doctor of Philosophy in \\ English
}

\author{
Kathleen Ryan, Ph.D., Chair \\ Ryan Claycomb, Ph.D. \\ Cari Carpenter, Ph.D. \\ Rosemary V. Hathaway, Ph.D. \\ John Ernest, Ph.D. \\ Department of English
}

\begin{abstract}
Morgantown, West Virginia
2017
\end{abstract}

Keywords: Family, Child, Survival, Storytelling, Contemporary American Literature

Copyright 2017 Yvonne Hammond 


\section{ABSTRACT \\ Storytelling, Survival, and Child Figures in Contemporary American Life-Writing}

\section{Yvonne Michelle Swartz Hammond}

My dissertation explores strategies for survival primarily related to acts of storytelling, and more specifically storytelling with the tacit agreement for measures of truth, what I refer to in my title as life-writing. The term "life-writing" refers broadly to literary and theatrical works that are connected to the lived-experience. The texts I examine, all written in the U.S. after 1990, consider the impact of traumatic and unjust pasts through sweeping, epic narratives. Each of these texts tells a separate story about injustice through stories that reveal children as victims of discursive and/or actual violence arising out of conflict between and within institutional and family identities. Instead of viewing these texts as isolated and unrelated, my dissertation places these stories in conversation with one another to ask what we can learn about the child and survival. Childhood in these texts is an act of performative grieving, mourning the loss of a self that either never was or a self that was lost quickly to experiencing or witnessing trauma.

I argue that Gerald Vizenor's term "survivance" offers a perspective for understanding these survival stories as active resistance to make a cultural analysis that focuses on narrative devices and patterns. Breaks in the written story or theatrical performance testify to experiences that threaten the stability of a single narrative about the child or family, while demonstrating survivalist strategies for understanding family as a source of pain and strength. In my dissertation I am closing in on the power of testimony and witnessing as means for recovering the voice and perspective of the child. My definition of the child begins with what I understand as the child figure. The child figure is a written self accessed through memories and experiences of a childhood used to represent an emotional past. The child figure frequently signals loss or a sense of absence. As a link between survival and presence, survivance provides a way to name the feel of these stories, an assertion of persistence and hope from within stories riven by violence. 


\section{Acknowledgments}

As with all of life, the credit for a grand accomplishment must be shared by many. I cannot imagine having tried to make this dissertation happen without personal and professional support, and though an acknowledgement is not nearly enough gratitude, it has certainly been earned. The following list is likely incomplete — many had a stake in my survival — but I have tried to remember and include all those who continued to remind me as often as possible (especially in moments when I could not tell myself) that this study needed to happen.

To my children, Eion and Rion, and my sister, Rhiannon, for moving (yet again) away from family and the beautiful Montana Rocky Mountains, for creating a new life and home in West Virginia, for living in the mire and muck of a $\mathrm{PhD}$ in process, for growing up in graduate school—-for all of this and more, thank you.

To Katy Ryan, for adopting me and opening so many doors, for trusting me and my process, for kindly listening to my tearful rants, for making me feel safe enough to weep, for always caring about me before the dissertation, for advocating for me (most especially in moments when I felt incapable of advocating for myself) — for all of this and more, thank you.

To John Ernest, Ryan Claycomb, Cari Carpenter, and Rosemary Hathaway, for finding ways to make my time at WVU successful, for allowing me to be me and showing me how to appreciate my strengths, for reading my work and pushing me to be a better writer, for helping me realize my potential—-for all of this and more, thank you.

To my mom, Marian, and my dad, Lee, for lifting all of my things in one of the worst summer heats on record, for helping me buy a home too far away for your comfort, for answering my calls and saying the things that children always want to hear: you are loved, you are special, you can do this - for all of this and much, much more, thank you.

To my brother, Christopher, and my sister, Heather, (and their families including some rather cute nephews new on the scene), for all of the phone calls and visits and efforts to understand what seemed like a crazy, mixed-up idea, for painting graduation cards and business cards, for beautiful flooring my house, for all the odds and ends that you have picked up, for being okay with missing a sister when you needed her-for all of this and more, thank you.

To the dogs, Zoe and Rusty, for the walks and love and the warm snuggles, I thank you even if you can't read.

To Kwabena Opoku-Agyemang, who has been one of my best friends since my first day at WVU, who has shared in heart-ache and celebration, who has watched my children and helped raise them, who always had my back, I thank you.

To Rebecca Thomas and Shane Stricker, who have shared lives with me for seven years, who have supported my children, watched my pets, watered my plants, and celebrated all the changes that seven years can bring, I thank you. 
To Teresa Persching, who read much of my work before and after the dissertation, and who provides excellent feedback and a sound, calm mind when I start to veer into the radical, I thank you.

To Katie Vogelpohl, who swooped into my office and held my hand and read my work at a time when I needed a new set of eyes, who allowed me to whine and never once judged, I thank you.

To Mike Buso, who always keeps an eye out for opportunities - the best travel spots, the best places to eat, the best conferences, and even the chance of a job or publication-I thank you for being a kind colleague and a good friend.

To Cara Snider, now Williams, for being the big sister I never had, who encouraged me simply by inspiring me, talking to me, and helping me (or at least trying) to see myself in kinder ways. For this and so much more, thank you.

To Kelsey Liebenson-Morse, who never let me not be her friend, who loved foodie adventures as much or more than me, who loved and embraced all the mess of me and my life with a smile, I thank you.

To Lisa Weihman, who made time for me even though I was not her student, who understood being in the trenches of raising boys, who always took the time to listen and who always made me think harder about perspective, I thank you.

To Francille Sussott (Swartz), who admired me enough to send me money for over two years and insisted I save for something special for myself, I thank you.

To Derek Stanley and Allegra Browne, two outstanding students who provided incredible (and beyond the call of duty) help so that I had the time to finish this dissertation in time- thank you.

And finally, to all my friends at large, friends from high school, friends from college, friends from the military, friends from grad school, and friends from Morgantown-I thank you. I especially want to thank: Amy Phillips, Amy Emerson, Brenda Van Mil, Neil Timmons, Tiana Childers, Angela Charbonneau, and Mike and Robin Ducharme, all of whom have insisted on making sure I stop and enjoy life. 


\section{Table of Contents}

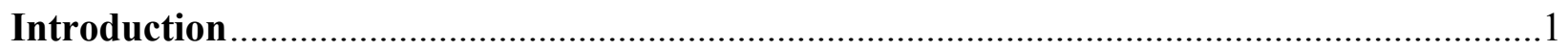

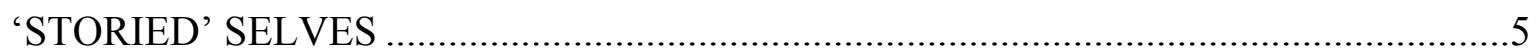

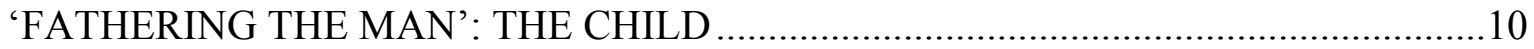

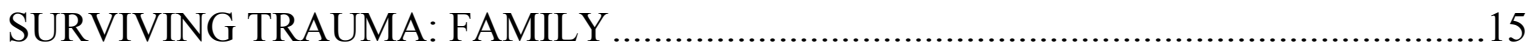

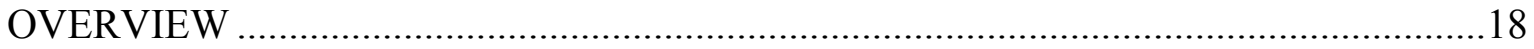

\section{Chapter One:}

The Myth of Childhood Innocence: Visualizing Native American Survival ..........................26

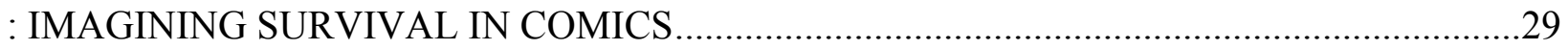

HARD LESSONS: POVERTY \& THE CHILD ...............................................................

A PART-TIME INDIAN: BOYHOOD \& IMAGINED FUTURITY .................................50

\section{Chapter Two:}

Rescuing Girlhood: Didactic Storytelling and Surviving the Legacy of Poverty....................70

'WHITE' TRASH: REGIONAL HISTORIES \& THE SHADOW OF POVERTY ............74

'YOU KNOW HOW YOUR MAMA GETS': ALLISON \& CHILDHOOD .......................83

TRUTH-TELLING: WALLS \& ADULT CHILDREN ……………………………........92

TWO OR THREE THINGS: DIDACTIC PERFORMANCE \& STORYTELLING .........98

\section{Chapter Three:}

Missing Children: Secret Pasts, Haunted Silences, and Revising Family History ...............105

LIFE-WRITING AND TRUTH TELLING............................................................112

'FEELING MISSING': ISOLATION \& ABSENCE .....................................................119

FILLING IN THE BLANKS: LEGACY \& STORYTELLING.....................................128

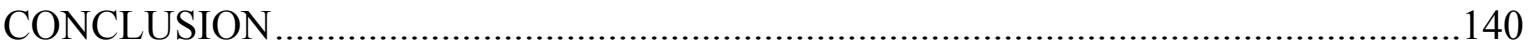

\section{Chapter Four:}

The Adult Child: Reviving the Father in Recycled Performances.....................................143

THE WEST: HISTORY \& FATHERHOOD .............................................................147

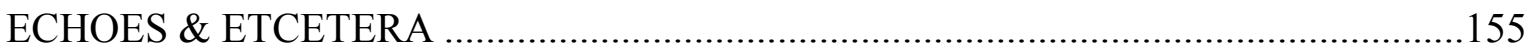

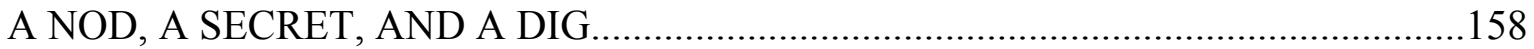

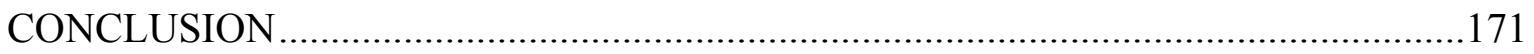

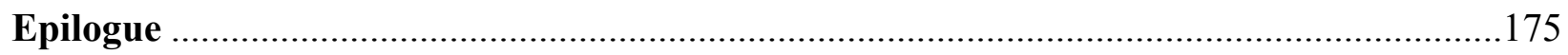

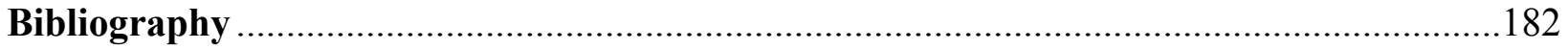




\section{Introduction}

Time moves in one direction, memory in another. - William Gibson ${ }^{1}$

So is it now I am a man;

So be it when I shall grow old,

Or let me die!

The Child is the father of the Man-William Wordsworth, $1802^{2}$

I'm only suppose to tell one story at a time, one story. I don't do that. I never do. -Dorothy

Allison (Trash 39)

When Alex Kotlowitz, a journalist and Chicago resident, approached LaJoe Rivers about writing a book about her sons, Lafeyette and Pharoah and other children living in the Henry Horner Homes, a housing project on the west side of Chicago, she responded favorably, but followed quickly with a warning: "you know, there are no children here. They've seen too much to be children" (x). Twelve-year-old Lafeyette and nine-year-old Pharoah, two of eight children, had developed strategies for surviving a neighborhood where "one person every three days" was "beaten, shot at, or stabbed" (32). Crime in the area was reported at a level nearly twice the average rate in Chicago despite the short distance between the neighborhood and a bustling downtown Chicago (26). In contrast to River's claim that the environment had disappeared

\footnotetext{
${ }^{1}$ Gibson, William. Distrust That Particular Flavor. New York: Berkely, 2012, 51. Print.

${ }^{2}$ Wordsworth, William. "My Heart Leaps Up When I Behold." The Complete Poetical Works by William Wordswoth. London: Macmillan \& Co., 1888. Web. Bartleby. 2 Feb. 2017.
} 
childhood, Kotlowitz admits in the epilogue of the text that he could not remain detached from Pharoah and Lafeyette (though he tried) because "in the end [he] had to remind [himself] that [he] was dealing with children" (309). Kotlowitz's work writes against common assumptions about childhood, revising an epic narrative to include two young black boys' surviving life in the west side of Chicago.

As Kotlowitz and Rivers show, ideas about childhood differ based on varied and diverse circumstances, with some situations stressing the exchange of innocence for experience. The terms for "child" and "family" have widespread cultural and political impacts even though the definitions often rely on cultural narratives driven by a fantasy child and childhood. The child has important impacts in society and in literature, but often remains ill defined. Reading across disparate contemporary stories, I find that the child, shaped by familial and state sponsored influences, tells a precarious story about power and secret pasts. My dissertation examines nonfiction survival narratives in which a child, who has witnessed or experienced trauma, emerges as a figure for historical memory.

I argue that Gerald Vizenor's term "survivance" offers a perspective for understanding these survival stories as active resistance in which storytelling provides the means for exposing inequitable childhoods. To make this cultural analysis I focus on narrative devices and patterns. Breaks in the written story or theatrical performance testify to experiences that threaten the stability of a single narrative about the child or family, while demonstrating survivalist strategies for understanding family as a source of pain and strength. As a link between survival and presence, survivance provides a way to name the feel of these stories, an assertion of persistence and hope from within stories riven by violence. Survivance is a feeling produced in the moments when stories seem to start falling apart. 
I am interested in strategies for survival primarily related to acts of storytelling, and more specifically storytelling with the tacit agreement for measures of truth, what I refer to in my title as life-writing. The term "life-writing" refers broadly to literary and theatrical works that are connected to the lived-experience. Definitions for autobiography (and biography) have long roots, going back to St. Augustine's Confessions. Reflecting the "great man" genre conventions, autobiography and biography began as life performances designed to model better ways of living. The genre has always been linked with notions of truth and truth telling because its subject matter is "real" life. Augustine's work calls attention to the genre as not just a tool for teaching, but also a tool for confession or testifying; autobiographical works are proof of life. Though originally dominated by the "great man" works, life-writing also includes marginalized voices, such as women's diaries and memoirs and slave narratives. In my dissertation I am closing in on the power of testimony and witnessing as means for recovering the voice and perspective of the child.

My intervention into childhood studies begins with looking at the child in life-writing. While literary and social science scholars have studied fictional works written by adults and children, little to no scholarship exists discussing the role and voice of the child in life-writing. Unlike familiar child narrators, such as Scout in To Kill a Mockingbird, Huck Finn, or Maisie in Henry James' What Maisie Knew, the child in life-writing resists a coherent voice, instead the child figure's voice becomes mingled with and fractured by narrative perspectives of memory, story, and adult efforts to reconcile past and present lives. Though the child in fiction and the child in nonfiction works share commonalities, in the end I argue that the nonfiction child-a child that existed in a certain time and place—-leaves traces that are impossible for a fictional child to create. My definition of the child begins with the literary childhoods summoned in five 
pieces of life-writing and is informed by what I understand as the child figure. The child figure is a written self accessed through memories and experiences of a childhood used to represent an emotional and unresolved past.

The texts I examine, all written after 1990, consider the impact of traumatic and unjust pasts through sweeping, epic narratives. Sherman Alexie's The Absolutely True Diary of a Parttime Indian (2007), Jeanette Walls' The Glass Castle (2005), Dorothy Allison's Two or Three Things I Know for Sure (1995), Mikal Gilmore's Shot in the Heart (1995), and Suzan-Lori Parks's The America Play (1993), reveal children as victims of discursive and/or actual violence arising out of conflict between and within institutional and family identities. Each of these texts tells a separate story about injustice, and rather than insisting on a singular definition for contemporary child and childhoods, these works are resist the suggestion that there is a common child or childhood. These texts are representative in their persistent exceptionality. And while these stories might normally contribute to a perception that "different groups of ordinary people in this country live in their own world and have experiences that are wholly separate from each other," I argue that the differences allow for a broader study of childhood (Taylor).

Instead of viewing these texts as isolated and unrelated, my dissertation places these stories in conversation with one another to ask what we can learn about the child and survival. Childhood in these texts is an act of performative grieving, mourning the loss of a self that either never was or a self that was lost quickly to experiencing or witnessing trauma. Mindful of the storied-self, specifically the story of the child and childhood in America, these texts reveal childhood as process of public mourning that highlights unresolved experiences and ideas about what it means to be a child.

\section{‘STORIED' SELVES}


All of my texts explore the limitations and usefulness of authorial versions of history, offering varied notions of the "real" story—a story based on documents, real events, individual testimonies, memories, interviews, photos, and/or previously established histories. In these works, family stories and individual histories expose secrets that challenge the stability of a monolithic, often institutionalized, truth. Conversely, the authors draw from the genre conventions for autobiography that depend on implicit assumptions of truth and what Phillipe Lejeune calls "le pacte autobiographique," a "form of a contract between the author and reader in which the autobiographer explicitly commits himself or herself not to some impossible historical exactitude but rather to the sincere effort to come to terms with and to understand his or her own life" (ix).

Most if not all scholarship about autobiography admits that the genre "cannot really be defined" (Adams 2). James Olney writes that autobiography is the "simplest of literary enterprises and the commonest," but is also the "most elusive of literary documents" (3). Critics of autobiography struggle with definitions that are either so inclusive that all writing becomes autobiographical, or are so limiting that they become self-serving definitions. Olney avoids directly confronting the definition of autobiography and instead argues that regardless of structuralist, post-structuralist, or deconstructionist discussions about the language of auto-biographe or its deep-lying structures, "what they are still troubling about is the self and consciousness or knowledge of it" (23). Paul de Man skirts the definition trap by rejecting the notion that autobiography should be treated as a literary genre. De Man's argument complicates the boundaries between all writers and writing, such that even literary criticism could be autobiographical. Rather than attempting to define autobiography as a genre or mode of writing, de Man places all of the emphasis on audience and contends that autobiography is a "figure of 
reading or of understanding that occurs, to some degree in all texts" (921). Conversely, Paul John Eakin's emphasis on the self, or rather the impossibility of a non-fiction self, claims that all writing is fiction. Eakin, an advocate for LeJeune's notion of the autobiographical pact, argues that the autobiographical ' $I$ ' is itself a fictive self in a fictional world. Instead of fixed reference, Eakin contends that the self evolves through the creative process.

Timothy Adams offers what is perhaps an appropriately complicated (but still broad) definition of autobiography, a concession that the only way to define autobiography is to accept the "inescapable conclusion" that the terms used to define autobiography are: "complicated, ambiguous, inseparable from other terms, and finally paradoxical" (3). Adams locates this impossibility in the function of design (genre) and tension between truth and lie. Although “autobiography is synonymous with lying” critical efforts have widely ignored lying as a focus (Adams 4). According to Adams, autobiographical writing possesses a

particular kind of truth through a narrative composed of the author's metaphors of self that attempt to reconcile the individual events of a lifetime by using a combination of memory and imagination — all performed (emphasis added) in a unique act that partakes of a therapeutic fiction making, rooted in what really happened, and judged both by the standards of truth and falsity and by the standards of success as an artistic creation (3).

Adams' definition stresses the relationship between the author and reader, much the same way performance scholars call attention to the connection between the stage and the audience.

Adams points out that the "truth" of autobiography — a tacit agreement between readers of life writing and their audience — is not found in the "facts" of the story itself, "but in the relational space between the story and its reader" (12). Adam's description of truth as space 
aligns with my own notions of the autobiographical as a performance. I believe that the texts share more in common with stage; they are performances of lives that shows traces, slips, and shades $^{3}$ of the real. Drawing from theatrical scholars, such as Elin Diamond, Peggy Phelan, Carol Martin, and Bertolt Brecht, helps me consider the political aspects of an autobiographical performance, specifically the play between truth and lie, or what Leigh Gilmore summarizes as the culture of confession and testimony.

Reading limit-cases for autobiography (texts that challenge formal definitions of the genre), Gilmore stresses that when self-representation involves the representation of trauma, the "autobiographical paradox of representativeness is intensified" (19). Gilmore's exploration of trauma narratives leads her to understand autobiography as a politicized narrative, one in which the public self-representation reproduces the conditions of confession. Trauma, she writes, "names an unprecedented experience" and results in a conflicting set of demands: "how can one tell the truth, the whole truth, and nothing but the truth, when facts, truth and memory combine in the representation of trauma to undermine rather than strengthen representativeness" (19)? Confessionals and testimonies participate in the secret, official discourses that merge with selfrepresentation "such that any self-representational act is fully burdened by its public charge to disclose a private truth" (14). Linda Anderson argues that autobiography is the "text of the oppressed," providing both the testimonial for oppression and the empowerment through "cultural inscription and recognition" (97). The private truth often redirects conversations about truth that not only intervenes in historical or institutionalized conversations about commonly held perceptions, but also emphasizes the spectacular aspects of performing truth. According to Jennifer Griffiths, testimonies, particularly those representing trauma, depend on a "relationship

\footnotetext{
${ }^{3}$ I am inspired by Parks's discussions in Elements of Style, and I am more broadly interpreting her definitions for stage figures.
} 
and a process between the survivor and the witness, as memory emerges and reunites a body and a voice severed in trauma" (2). Testimony, she writes, is a "public enactment of memory" (5).

I am reading performance through a body of writing that confronts historical truth with survival stories that reveal alternative perspectives. In the attempt to reach toward the real, to assert historical presence, the textual performances of memory through testimony serve to highlight the performative aspects of history, which confront the limitations of authorial truth paradoxically through truth-telling. In general the texts in my dissertation weigh the balance between recorded history and familial storytelling, drawing attention to absences, what Parks directly names the "Big Hole" of history. Institutionalized histories create big holes, but so do memories. The texts are also family stories exploring the role of memory and inherited familial histories.

I am drawn to the small gestures of love and endurance within these epic stories. The moment when Mikal Gilmore, in Shot in the Heart, cherishes an evening with his brother Frank while wrestling with the impact of their brother Gary's execution. The evening becomes even more poignant when Gilmore watches that brother walk away for the last time. The moment when Jeanette Walls, in The Glass Castle, parts with a summer nanny job so that her sister Lori can escape a derelict clapboard house. The moment when two boys are pictured as comic book superheroes whose powers are drawn from their friendship. The moment when Allison sits with her niece and attempts to push away the "sullen look of a not quite adolescent girl who knew too much" by pushing her hair to the side and telling her that she's "going to be something special" (83). The moments when Brazil, in The America Play, continues to dig, even when he not longer must. In these moments especially, I argue, we see what Gerald Vizenor calls "survivance." 
Rather than focusing on the traumatic event and the unbearable weight of history, Gerald Vizenor (Anishanaabe), a postmodern Native American storyteller and scholar, chooses instead to offer the term survivance to understand legacies of dominance, tragedy, and victimry. Survivance, in its most basic form, means presence plus survival. Vizenor emphasizes that survivance is active, an "active sense of presence over absence." Survivance is the "action, condition, quality, and sentiments of the verb survive, 'to remain alive or in existence,' to outlive, persevere with a suffix of survivancy" (19). Vizenor's work contributes to a larger effort to combat the Vanishing Indian narrative (a narrative that anticipates the absence of a Native population through assimilation, dominance, or eradication). Instead of falling victim to absence, Vizenor instead turns to story as a means of testifying presence. "Survivance stories," he argues, "are renunciations of dominance, detractions, obtrusions, the unbearable sentiments of tragedy, and the legacy of victimry" (1). Vizenor's work helps maintain a hope in readings that might otherwise fall prey to an almost inevitable tragic response - in too many family stories childhood cannot be separated from witnessing and/or experiencing trauma.

In his development of the term "survivance," Vizenor emphasizes that the practice of survivance establishes a "storied presence of a fourth person ", " a "testimony" and a "visual reminiscence" for Native presence (1). The term "storytelling" seems antithetical to notions of truth-telling; stories are assumed to be opposite to histories, yet the epic narrative has long roots connected to both performance and storytelling in oral traditions. In my dissertation I do not just see survivance in the stories themselves, but also in the act and performance of the story. Though Native scholars tend to focus on Native authored texts and Native theory is usually read in context with Native texts, I want to argue that it might be possible to use Native scholarship to

\footnotetext{
${ }^{4}$ The storied fourth person is a narrative voice created in Native oral traditions, most often associated with animism. However, Vizenor also suggests that oral history can (at times) be a "fourth person," particularly when the oral story performs the role of history.
} 
read texts written by non-Natives and offer new ways to think about texts. I believe that survivance emphasizes the power of hope.

I chose Vizenor's term survivance because it seems opposite to the US myths of linear progression and boot-strap workaday success that might otherwise minimize individual efforts to oppose institutions. I have also selected a purposeful range of genres — autobiography, a play, young adult fiction, and memoirs — designed to interrogate the way form influences the telling/staging of family history. My selection is also multiethnic. I realize I risk losing a deeper analysis and discussion of the significant cultural heritage connected to more racially specific histories and experiences, of homogenizing the experiences of Jeanette Walls, a white West Virginian, with Arnold, a Spokane Indian. However, my argument is invested in the idea that Native American scholarship can and should inform literary analysis outside of non-Native works. The comparison I offer in this work should not suggest that I am diminishing culturalspecific experiences, but instead identifying sources of strength within and across diverse cultural experiences, an accounting for how these literatures provide necessary tools for living.

\section{'FATHERING THE MAN': THE CHILD}

Like genre, definitions for the child (and by extension family) shift depending on a variety of contexts and purposes. Michael Warner, Lauren Berlant, Pat Califia, and Lee Edelman all highlight the relationship between public regulatory policies and national fantasies that dependent on the child as a monolithic and nostalgic emblem for elevating a "sanctified nationality" (Warner and Berlant 550). Queer studies have been particularly vigilant in exposing public use of the child as the "bearer of heteronormativity" (Bruhm and Hurley xiii). James Kincaid indicts a society that tells stories fixated on a fluid child that at eighteen-years old can be portrayed as child victim and at six-years old can be portrayed as an adult perpetrator (20). He 
notes that our culture has "enthusiastically sexualized the child while denying just as enthusiastically that it was doing any such thing" (13). Public institutions have coopted the real child and forwarded policies that reify racial and economic divides under the guise of saving the mythical child, a child that Sherman Alexie argues is always white.

Scholarship in childhood studies shows that definitions for the child are complex and contingent, most often highlighting a dependence on social constructions of innocence and lack of experience or knowledge. Steven Mintz author of Huck's Raft credits a "series of myths" about the carefree child living in a child-friendly society for clouding public thinking about the history of American childhood (2). He concludes that in the US we are "deeply ambivalent about children" (2). As opposed to imaging childhood as a biological phenomenon or a monolithic status "transcending class, ethnicity, and gender," Mintz contends that childhood should be understood as a "life stage whose contours are shaped by a particular time and place" (2). Like Mintz, Marianne Hirsch offers a cultural definition of child based on uncertainty, noting that "at the end of the twentieth century and beginning of the twenty first, the figure of the 'child' is an adult construction, the site of adult fantasy, fear, and desire" (162). She emphasizes that our culture is deeply invested in children's innocence and vulnerability—and yet also their "exoticism and knowledge" such that "children invite multiple projections, and lend themselves to universalization" (162).

Explanations of the child in childhood studies seem to be divided along disciplinary lines, which Karen Coates relates (in part) to trouble integrating a truly interdisciplinary statement. Coates believes that social scientists are inclined to essentialize the child, while literary critics want to disassociate the study from real children. Social definitions of the child tend to emphasize the child as incomplete. Claudia Castañeda says that "assumptions about the child as 
an adult in the making" are "embedded in the conceptualization of the child as potentiality rather than an actuality, a becoming rather than a being: an entity in the making" (1). The child is a person, but not yet a whole person.

Humanities scholars shift between polemic definitions for the child and childhood studies, citing evidence for a contingency-based understanding or suggesting the absence of the child and childhood altogether. Looking at the forever child, Peter Pan, Jacqueline Rose says that the child in literature is the "result of an impossible relationship between the adult and the child" (1). "The child," she writes "is [...] something of a pioneer who restores these worlds to us and gives them back to us with a facility or directness which ensures that our own relationship to them is, finally, safe" (9). Conversely, Susan Honeyman claims that "we impose 'childhood' on those we define as children according to biased standards of adult nostalgia and desire," adult anxieties creating projections of childhood insistent on maintaining childhood as "innocent (or ignorant in the Puritan tradition), pre-sexual, irrational, and unschooled" (2-3). Projections of childhood create a "strange cultural phenomena," according to Robin Bernstein, used to invoke the image of the past and childhood, which, she argues, exists with a paradoxical tension between the forgotten past and the traces that retain past practices (3). Bernstein's definition of childhood stresses performance, particularly the act of surrogation, an "endless attempt to find, fashion, and impel substitutes to fill a void caused by the loss of a half-forgotten original" (23). Childhood, Bernstein writes, is best understood as an "act of surrogation that compensates for losses incurred through growth" (24).

Scholarship about the child tells us this: children are defined through a narrative of innocence, futurity, desire, anxiety, memories of the past, and potentiality. Children are the cyphers, the bearers of culture, and the legacy of family. For my own definition of the child, I 
return to Suzan-Lori Parks, a playwright who asserts that her stage figures are not characters and that to call them so is an "injustice" (12). Instead Parks argues that her stage figures are “figments, ghosts, roles, lovers maybe, speakers maybe, shadows, slips, players maybe, maybe someone else's pulse" (12). Divorcing character and stage presence divides the performance from materiality and emphasizes the ethereal quality of the action as well as the importance of gestures. Much of what Parks lists — figments, ghosts, shadows, slips — are phenomena used to describe momentary notions of presence in absence. They are phenomena that leave inexplicable traces. The terms for performance help ground my understanding of the child as both a physical being, positioned as young and innocent but not unknowing or inexperienced. In my perspective the child is a written child, a necessarily metaphorical concept tied to varying individual and social concepts about the child and childhood in certain times and places.

Ruptures in the children's identities often precipitate ruptures or breaks in my texts, moments when the text appears to fall apart or when the story drops abruptly, which I connect to expression of unease about futurity. As noted by Lee Edelman and Judith Halberstam, heteronormative narratives fixate on the production of children to assure futurity, enforcing gendered identities to reinforce heteronormativity. Using the example of tomboyism, Halberstam shows that childhood can be a period of limited gender fluidity; however, after the age of puberty women are expected to assume a recognizable feminine gender and extinguish signs of male identification. Halberstam alludes to the violence witnessed by children in passing through childhood to adulthood; "adolescence, she says is a lesson in 'restraint, punishment and repression"' (6). Though the stories in this study provide testimonies to survival, the narrative breaks reveal ongoing efforts to reconcile past traumas. 
The use of the child figure in life-writing differs from fictional works if only in the tacit agreement for truth (however unstable). Yet, child narrators in fiction, such as Scout or Huck Finn, mediate adult worlds through the perspective of a child not wholly different from the written child in life-writing. An important distinction between the two should be the experience of the "real" child, the lived experience; however, the role of memory in distinguishing truth from fiction presents certain challenges. Critics like Richard Coe contend that looking back is impossible. He argues that the former self as child is as foreign to a writer as it is to the reader and therefore, the margin between non-fiction and fiction thins (1-3). Conversely, historian Dominick LaCapra elevates the role of memory, maintaining that memory is a crucial component of history (19). In looking backward, through the memory of a child, the child figure adopts a narrative perspective used to negotiate between the past and a futurity shaped by the writer's autobiographical performance. The child exists in life-writing, in part, to verify the past through a lived experience of childhood. The texts' testimonials depend on the memories of a child witness filtered through adult reflections capable of understanding, explaining, and reflecting on the past. Ultimately, the difference between the child in fiction and the child in life-writing lies not in the child, but in the adult writer invested in truth-telling about the past and the traces of the real child written into the text by the now adult, former child.

While it may seem that my dissertation distances the real (or rather living) child from the written child, it has not been my intention to suggest that the child does not exist. In fact, my choice of texts purposefully draws from a genre with roots in truth-telling. The child is an important part of this truth-telling. In the varied definitions of child it is not hard to find words like "innocent," "naïve," or "unknowing," all of which signal a certain untainted or truthful perspective. Children are believed to tell it like it is. However, I would like to emphasize that the 
child doesn't write the book nor is childhood the only time period represented. The child and childhood are the means by which the author crafts a trajectory towards the future, a motion between what has already happened as an explanation for what will happen or what will help explain an unsettled adulthood. For example, Allison, Walls, and Gilmore's stories benefit from a chronological organization that opens with childhood and ends with the impacts of history. In defiance of this seemingly natural course their stories remain haunted by interruptions, which often circle back to the child to signal what remains unresolved. The ghost of the child and absence resulting from missing childhoods cannot be silenced. In Alexie and Parks's works this looks like recycled histories and retellings of the "official" story with the inclusion of raced voices and perspectives. Thus while the child may not always be represented, the child is always (in a sense) present.

Though the child is real the presence of the child in life-writing cannot be real because the child cannot author his or her own story except through memory. The child figure is therefore a performative child, tied to storytelling about the past. Conversely, the child is a necessary aspect of life-writing because the child provides evidence of having experienced and survived trauma. Thus while the child is not real, the experience of childhood is real; children experience what the adult writer witnesses in autobiographical performances emphasizing survivalist narratives.

\section{SURVIVING TRAUMA: FAMILY}

Survival stories seem to inevitably turn back to trauma, drawing attention to crisis and what Cathy Caruth identifies as both the unbearable nature of an event and the unbearable nature of survival (7). I am exploring the origin of individual strength and thinking about how people learn to live with inhuman acts of violence and injustice, particularly those acts committed in the 
service of institution. For most of the families in my study, history reveals acts of violence committed by the state in an effort to demand a homogenized, wealthy state. Children (and families) inherit traumatic pasts wrought through colonization, enslavement, and/or imprisonment. Despite the diverse background, each of the texts is held together by a shared experience of poverty and compulsory movement. More importantly though, each story notes feeling absent from the institutionalized histories and cultural narratives tied to Americanness. For Brazil in The America Play this means taking on the role of Lincoln, a father of America, to experience the violence of murder over and over again. For Jeanette Walls in The Glass Castle or Dorothy Allison in Two or Three Things I Know for Sure, it means reconciling familial neglect and abuse that cannot be separated from the white poverty leftover from historic fiscal exploitation.

Despite the irreparable effects of trauma, people do survive. And often this survival is in spite of and because of family. All of the works in this study illustrate the complex and paradoxical conditions families create; family provides both the founding for and asylum from institutional identities. For example, the child figure Arnold in The Absolutely True Diary of a Part-time Indian describes a Christmas scene that speaks to the pain of poverty and the effects of alcoholism. Arnold's father disappears for almost a week around Christmas, leaving behind a family with no tree and no presents. When he finally returns home, still drunk, he pulls off his boot and hands his son a $\$ 5$ bill. Arnold, though still angry and saddened by his father's state, knows that it must have taken great willpower for a man on a drunk to save that money. This is survival.

Scholarship in family studies tends to pair the study of the child and the family with trauma. The cornerstone definition for trauma has been developed by Caruth who explains that 
trauma and its symptoms are best described as an "overwhelming experience of sudden or catastrophic events in which the response to the event occurs in delayed, uncontrolled repetitive appearances of hallucinations and other intrusive phenomena" (11). Caruth's definition depends on understanding trauma as a psychic event, which suggests the possibility of recovery. However, my primary texts seem to suggest that there are ways in which recovery is never possible; in fact, Mikal Gilmore plainly states: "It will never be okay." Though my project doesn't focus on trauma, I do think it's important to state that my understanding of trauma develops from the notion that trauma is ongoing. I define trauma not as a single act, but as a condition of being that makes one vulnerable to repeated witnessing and experiences of physical and emotional instability. In other words, trauma irreparably changes normalcy.

Family studies is a newer field of study, coming out of the 1980's rise in life-writing, particularly memoir writing. Like childhood studies, the field is necessarily interdisciplinary, drawing from social work, sociology, and psychology, among other fields of discipline to understand the complex institution of family. My dissertation turned to a varied set of sources to explore family. Historical investigations, such as Philippe Ariès's Centuries of Childhood or Lloyd de Mause's The History of Childhood, helped to trace the development of family, whereas Shannon Jackson's Lines of Activity inspired me to think about the role of social work as both an extension of paternal whiteness as well as a source for advocacy. The families in my study vary in size, geographic location, race, and temporal location; however, they all share one commonality_all of the families are poor. The state of poverty invites varying institutional governance - from at-home child services visits to repeated policing to various types of encounters with public school — all of which attempt to provide a version of paternalism, a substitute for what seems to be lacking in terms of "parenting." Ironically, in spite of varying 
degrees of familial dysfunction, public institutional intervention does little to provide a stable, loving environment — policing the poor in these works does not result in creating loved selves.

I want to maintain that family institutions are complicated, problematic and potentially complicit in the damage inflicted upon individual identity development, and yet I also want to maintain the idea that family and community can also provide the support necessary for survival. Families are institutions even if families also provide haven from state and social institutions. Ultimately, I am mostly interested in examining how individuals cope with the weight of historical and ideological injustice. I see epic texts as gestures toward (and within) the ongoing process of negotiating with institutional histories and the identity performances they demand. Epic texts help ensure the survival of the individual without sacrificing a connection to community. In the literature that guides my dissertation, history is a performance of the real, a mimesis where the texts reflect and refract the real for recuperation and catharsis—-stories are sources of strength and the result of persistent survival.

\section{OVERVIEW}

In the end all we ever have are stories. Hayden White defines storytelling as a "natural" way to provide events meaning. White argues that the act of storytelling is so "inevitable" that "narrativity could appear problematic only in a culture in which it was absent" (1). Stories often look back, reflecting on family and family histories for answers about the individual, and the literary texts that I have examined in my dissertation take this type of historical approach, but also depend on versions of the child to help process and give voice to the weight of history.

Not all children are equal, and arguably, the child that haunts the text is not the privileged child living a childhood fantasized for sociopolitical interests, but instead the forgotten child, the child impacted by direct and indirect forms of institutional violence. Authors like Piri Thomas 
show that as a whole "society does not give a crap about" the children of the poor (335). "When we hear society expressing that "the children are our future," Thomas writes, "many of us ask, 'Whose children and whose future?'” (335). Rather than image children through lack-lack of agency, knowledge, or experience-Thomas asserts that children are "not stupid" but are "born with innate intelligence and the spirit of discernment" (335). Every child is "born a poet and every poet is born a child" (335). Every child is "born of earth and universe," and Thomas asks readers to consider how any child could be "considered unimportant and dehumanized, relegated to being a minority, a less than?" (335).

In chapter one, I begin by looking at the child figure as a narrator for other children in Sherman Alexie's young adult novel The Absolutely True Diary of a Part-time Indian. The story traces Arnold's freshman year of high school as he decides to leave Wellpinit High School on the reservation and attend the predominantly white high school in Reardan, WA, a move that invites comparison between Arnold's life on the reservation and life outside of his Native community. The text suggests that Arnold's survival hinges on his ability to find a new "tribe" off the reservation, despite the fact that cosmopolitanism also isolates him from both communities. Underscoring Arnold's relatively successful efforts to escape poverty and violence is the story of his best friend Rowdy, whose story is more akin to the future expected for poor Indians.

Part of the work of survivance in this diary is to make available the realities of reservation life in order to "disrupt widespread historical amnesia" (Johnson 227). Alexie confronts Native stereotypes in his writing - the image of the drunk Indian, the hopeless Indian, and the sad, useless Indian - exposing what mainstream audiences might expect to see. Even readers unfamiliar with Native American peoples will recognize the historical racism written into scenes with Mr. P, a reservation teacher, or in the frank use of racial slurs. Alexie's portrayals of 
"truth" have drawn criticism from Native scholars and writers like Louise Owens and Elizabeth Cook-Lynn, who have said that Alexie's characters "reinforce all of the stereotypes desired by white readers: his bleakly absurd and aimless Indians are imploding in a passion of selfdestructiveness and self-loathing" (Owens 79). Alexie rejects the term stereotype, arguing instead that the stereotype is the real, lived experience. "People thought I was writing about stereotypes," he says "but more than anything I was writing about my own life" (152). He adds that Indian writers don't "have the luxury of being called autobiographical writer," because Indian writers end up "writing for the whole race" (152).

At the heart of Alexie's work lies a story about Native education, which cannot be separated from the child figure's efforts to know himself as an individual. Arnold's choices have been limited by historical racism, particularly poverty and violence endemic to reservation life. Arnold witnesses tragic deaths in his family and community due, in part, to the living conditions - specifically the hopelessness that drives alcoholism. Off the reservation, Arnold faces a community conditioned to view Natives through colonial constructions, which often deny the presence of a living, dynamic culture. In opposition to this denial, Arnold creates a visual presence through comics that use humor as a way to mitigate racism and poverty.

Alexie's text challenges mythologized (privileged) childhoods, exposing childhoods impacted by violence and the damaging effects of poverty. He is writing against the presumption of childhood innocence. The culturally specific "suffering" he creates with Native American child figures interrogates the ways in which whiteness assumes childhoods free from want and the experiences common to reservation life, such as poor healthcare or food insecurity. Survivance is best demonstrated in Arnold's efforts to write his friend into history, remembering a boy, a child, and a childhood that might otherwise be lost. The two versions of childhood- 
Arnold and his friend Rowdy_-both represent the "real" Indian; however, in imagining Arnold's future off the reservation, Alexie makes a claim for futurity based on new definitions for Indianness.

Like Alexie, Jeanette Walls and Dorothy Allison expose childhoods impacted by poverty. However, while Alexie's work maintains a certain distance in half-hearted admissions of the story's connection to his own youth, Walls and Allison's work fall into the traditional memoir genre. Alexie's effort to create a fictional child draw from his own experiences, which keeps the text grounded in the real if only in the feeling that Alexie creates about what it means to be a poor Indian. Walls and Allison also acknowledge uncommon childhoods, exposing their conflicted efforts to reconcile and resist their experiences of Appalachian impoverishment.

The deep hunger that Jeanette Walls describes in her 2005 memoir The Glass Castle parallels that of Dorothy Allison in her 1995 memoir, Two or Three Things I Know for Sure. Both texts explore the effects of chronic poverty, which cannot be separated from complicated relationships with their "white trash" families, especially mothers who remained in volatile and unstable situations. Allison and Walls' memoirs depend on stories that construct the past using memories and the perspectives of a child to understand the impact of their relationship with their parents and institutional poverty. Shadowed by sadness, both writers seem to suggest that girlhood was not just interrupted, but lost for having witnessed and experienced repeated scenes of gendered violence and neglect.

Rather than reservation poverty, Allison and Walls are impacted by the longstanding, geographical poverty of the Appalachian region. Born into working-class families, history predestines the Walls and Boatwright families for specific roles. Gendered scripts for marriage and motherhood further complicate Walls and Allison's social movements. To control erratic and 
traumatic pasts, Allison and Walls use storytelling to circle back through history while interrogating the social and historical discourses that limited their agency. Like Arnold's comics that show what it means to be a poor reservation Indian, Allison and Walls are teaching their audiences what it meant to survive a lifetime of feeling like trash. In telling the story of Appalachian poverty, these women use didactic performances in which narrative breaks disrupt and call attention to the act of storytelling as a necessary means for survival.

Though Walls and Allison teach audiences what it means to survive their backgrounds, they also reveal the instability of race as a signifier for success and wealth. Allison repeatedly asserts that the name "white trash" enacts a specific type of racism, one that both takes advantage of whiteness by purposely separating "white" trash from "black" trash and marks the "white" trash body as unworthy of whiteness for being "trash." Walls echoes this sentiment in scenes that return to the family's dependence on trash for food, for household goods, and even for money. Trash becomes a metaphor for childhoods carelessly tossed away.

In this chapter I am looking at texts that stress the failures of defining childhood as a period of innocence. In these stories, childhood continues to feel unresolved, suggesting that children continue to feel "missing." Despite the recognizable child figure in their memoires, both Allison and Walls' descriptions of the conditions of their childhood create unease about the presence of the child. Poverty (coupled with abuse) invalidates notions of childhood defined by innocence and calls into question the role of parents in determining the boundaries between child and adult. Both Allison and Walls show that poverty demands responsibility commonly assigned to adults, which limits the opportunity for childhood free from the type of experience signaling adulthood. Survival depends on the women's efforts to realize agency while accepting their complex pasts, even if it means that they might never escape the legacies they have inherited. 
Despite the contradictions they expose, both women return to their family as a source for healing and strength.

Alexie, Allison and Walls depend on child figures written through the adult memories of the past; however, for Mikal Gilmore childhood was defined paradoxically through the memories of the relationship he shared with his father and a lasting detachment from the siblings with whom he should have shared childhood. Socially accepted definitions of childhood presume the child's dependence upon family, particularly mothers and fathers as the means for assuring the child's survival (and hopeful futurity). Allison, Walls, and Gilmore counter this assumption in stories of childhoods impacted by the failures of the adults upon which they depended.

Part memoir, part reflection, Gilmore's autobiography (somewhat) responds to Lawrence Schiller and Norman Mailer's The Executioner's Song, an effort to understand Gary Gilmore (Mikal's brother), a man best-known for begging to die by execution. B, the work also attempts to account for the loss and sorrow experienced by Gilmore. Although spared his father's ire, Mikal was no more able to escape the institutional violence in the Gilmore home than Gary, and while Gary expressed his anger outwardly, physically, Mikal writes of haunted houses, nightmares, and the psychological impact of feeling "missing" from family photos. Like Alexie, Allison, and Walls, Gilmore emphasizes the ways that trauma disappears the feel of childhood.

Gilmore's work is necessarily historical; he works to reconstruct a family widely unfamiliar to him. In his study he juxtaposes such disparate histories as Mormon settlement and the bloody conflicts with Native Americans against family stories that suggest a lineage to Harry Houdini in an attempt to "get at" the missing boy in the family photos_-himself. The text exploits unlikely sources for truth and truth-telling, most notably his dreams. At odds with the efforts to chronicle history are narrative breaks, dream sequences that seem counter to the truth- 
telling in the rest of the text. These dream sequences expose Gilmore's troubled relationship with his family, particularly his father, with whom he shared a loving relationship counter to that of his brothers.

In Gilmore's text the child figure is defined in relation to parents, which extends the influence of childhood through adulthood. In his text, child figures witness trauma, but fail to recover a feeling of having survived. The child figure, captured most often in Gilmore's dreamscapes, is an emotional response to feeling absent from the family, a feeling of lack driven by missing shared history with his brothers. In the dream sequences Gilmore seems to recycle the past in an effort to rectify his absence from family history. Rather than rejecting the "tormented and hyperbolic family mythology," the history of verbal and physical abuse, or the constant upheaval and transient existence, Gilmore imagines survival lies in accepting the messaccepting that things will never be alright (116).

In the final chapter, I turn, unexpectedly, to look at life-writing as a theatrical performance to understand how the stage unsettles truth between the child, on the one hand, and familial and state history, on the other, using Suzan-Lori Parks' The America Play. Similar to Gilmore, Suzan-Lori Parks also explores the adult child, a child shaped by what it means to be the child of America. The play opens with the Lesser Known, a black man who dresses as Abraham Lincoln to be shot over and over and over again by those willing to pay for the privilege. However, the second half of the play reveals the family left behind when the Lesser Known takes his show out West. Left alone to manage the family's grieving business, Lucy, the Lesser Known's wife and a keeper of secrets, and Brazil, their son, must cope with the impact of the Lesser Known's loss. 
Emphasizing cyclical time, the play re-cycles histories in a performance repeatedly interrupted by gunshots and a hustle to dig up the truth. Parks' "makes strange" the history of Lincoln by interrogating not only the commodification of race through the Lesser Known's act, but also the ways in which the idolization of Lincoln impacts black history. Despite passing the Amendment abolishing slavery, an act that seem to infer greater equality, the Lesser Known and his family are forced to move further West in order to discover the idyllic past promised to them. For Brazil this means coping with historical legacies about race as well as the familial legacy his mother and father have determined for him—-he does not just inherit his father's box of beards, his speech, and manners - he inherits a string of significations. The child of the Lesser Knownand by extension the child of America—Brazil must adopt the garb of his father's role and continue to repeat the death of Lincoln in order to lead the country through the act of mourning a past constructed on fantasy. In this final chapter, survival is understood as legacy, a continuation of the Lesser Known through the act of Lincoln, which repeats and revives the past with a hopeful nod to the future.

\footnotetext{
${ }^{5}$ See Bertolt Brecht and the politics of epic theatre.
} 


\section{Chapter One:}

\section{The Myth of Childhood Innocence: Visualizing Native American Survival}

"A poor Native American faces more hurdles than a poor anybody." Sherman Alexie, "A

Dialogue on Race"

"And now I write books for teenagers because I vividly remember what it felt like to be a teen facing everyday and epic dangers. I don't write to protect them. It's far too late for that. I write to give them weapons - in the form of words and ideas—-that will help them fight their monsters. I write in blood because I remember what it felt like to bleed." Sherman Alexie, "Why the Best Kids Books are Written in Blood"

Scholarship historicizing American childhood very rarely includes the experience or perspective of Native American children. Two exceptions include Joesph Hawes and N. Ray Hiner's Growing Up in America (1985) and Joseph Illick's American Childhoods (2002), both of which historicize a specifically American understanding of the child's experience and briefly acknowledge the diversity of experiences based on race, class, and geographical location. Hawes and Hiner $^{6}$ acknowledge that many Native children face chronic deprivation and discrimination; ${ }^{7}$ worsened by established colonial structures and paternalistic governance at odds with indigenous

\footnotetext{
${ }^{6}$ Hawes and Hiner's research tends to provide a colonial viewpoint of childhood that, on the one hand acknowledges a childhood before colonization, one slightly romanticized and idyllic, and on the other hand, recognizes the influence of colonialism in creating the conditions that led to poverty and deprivation.

${ }^{7}$ One of the difficulties in comparing mainstream Euro-American childhood to Native childhood is the diversity in experience and tribal culture. The lifestyle and resources available to each group varied according to region. Cultural contact varied as well: in the Southwest the Navajo and Apache met Spaniards and in the Northeast the Pequot and Massachuset met the Pilgrims, for example. Contact with Europeans varied as well, but for the purposes of this work I will tend to consolidate my observations to look primarily at the adoption of Imperial British policies, such as reservations and the use of education for assimilation.
} 
lifestyle and education. Twentieth century America witnessed a series of acts designed to swiftly remove Native Americans. One of the more insidious policies for cultural genocide used institutional education to steal generations of Native children. Progressive reformers imagined schools and schooling as a way to convert Native children to Euro-American religious and cultural values, emphasizing the development of vocational skills, farming, Christianity, and a nuclear family life. The civilizing project included academic education in Euro-centric language, history, science, and politics with the hope that Native children accustomed to Euro-American lifestyles would not return to their own culture. Though some Native groups felt that a white education offered benefits, knowing that opportunities to fight white encroachment would happen in legal battles and treaty making, others resisted, particularly as the schools increasingly turned more militaristic. Col. Richard Henry Pratt's Carlisle Indian School in Carlisle, Pennsylvania boasted a slogan that demanded full assimilation: "Kill the Indian," Pratt said, "save the man."

At the heart of Sherman Alexie's The Absolutely True Diary of a Part-time Indian (2007) lies a story about Arnold Spirit (Junior) and Native education, which cannot be separated from Arnold's efforts to understand his connection to Indianness. Alexie adopts the voice and perspective of a fourteen-year-old teenager living on the Spokane Indian ${ }^{9}$ Reservation to trace Arnold's freshman year of high school after he decides to leave Wellpinit High School on the reservation and attend the predominantly white high school in Reardan, WA. A meta-narrative

\footnotetext{
${ }^{8}$ Small, Albert H. "Kill the Indian Save the Man.” Smithsonian. Smithsonian, 13 November 2009. Web. 15 August 2016.

${ }^{9}$ Throughout this chapter I will be shifting between the term Indian and Native American. Though Alexie rejects the term Native American in favor of Indian, arguing that the term Native American is "guilt-ridden liberal coinage," other Native writers and scholars feel different. Gerald Vizenor, for example, argues that the term "Indian" lack signification; it "represents the false homogeneity of the dominant culture, namely the Western white culture" (Yu 90). For my own stake in the argument, I give preference to the term Native American only in so far as it reduces confusion between U.S. Indians and citizens of the country of India. However, when appropriate, I have chosen to use the term Indian when Native scholars and writers use the term in their own individual work.
} 
about education in public school institutions, the move invites comparison between the life Arnold lives on the reservation and life outside of his Native community, paralleling stories about basketball teams and family, isolation and adolescent awkwardness, and best friends, both white and Native. At Wellpinit High School, students continue to feel the effects of colonialism in what Arnold recognizes as lessons in how to be poor-and nothing else. Arnold believes that escaping the reservation assures a more hopeful future even though he quickly realizes that too many people in his new community view him through the lens of a racist, colonial past. Arnold's cosmopolitanism isolates him from both communities, but it also leads him to reimagine Native identity and become a modern "warrior."

Arnold's exceptionality places him at odds with the stories he witnesses on the reservation even though he continues to live with the effects of racism, poverty, and violence. Despite such indicators as having an alcoholic father or a jobless family, Arnold resists the stereotypical Indian by revealing his passion for reading, his ambitions for school and basketball. The "real" Indian in Diary emerges as a story about a child who does not tell his own storyRowdy. Rowdy, with his drunken father and "savagery," both voiceless and ready to vanish, is poised as the stereotypical Indian. After the two separate in anger, Arnold creates comic images to maintain a connection with Rowdy. The ongoing effort to reconcile two children produces an anxious and ambivalent narrative about Native futurity; one Indian is poised to disappear physically, the other culturally. However, Diary wants to recover Native futurity through boyhoods memorialized in comics. After a discussion of survival found in the comic images and an analysis of the text's hard lessons in poverty and race, I argue that Arnold's comic images help assure Rowdy's survival in story and maintain a visual presence in opposition to mainstream narratives denying Native American presence. 
In making Native lives visible, Diary uses Arnold's culturally specific "suffering" to demonstrate the ways in which the term "child" assumes whiteness, relative wealth, and most importantly, innocence. Arnold cannot assume whiteness, yet the text hints that his future survival depends on his ability to assimilate. The relationship between the real and the constructed image of Indians is often symbolized in Arnold's friendship with Rowdy. Arnold's futurity is linked to a continued connection between himself and his best friend Rowdy, who is also a "real" Indian, the type of Indian destined to disappear. However, while the "real" Indian we know best is Arnold, I maintain that Rowdy's story provides an authenticity in addition to the one found in Arnold's story. The actual lived experience, according to Alexie, cannot be captured without the overused stereotypes because the stereotypes draw from real, lived experiences. The dialectic between real and fantasy Indian recycle colonial constructions of Indian identity, especially in moments when Arnold draws attention to stereotyped Native lives.

\section{SECRET-KEEPERS: IMAGINGING SURVIVAL IN COMICS}

Although the plot of Diary focuses on Arnold's education, Alexie uses narratological tools, most notably visual performances in comics, to frame Arnold's experiences as pedagogical for readers. Arnold's attempts to reconcile his individual identity with that of a community struggling to come to grips with historical racism, poverty, and conflict are visualized in shifts from text to comics, images that draw attention to racial constructions of Indians Arnold faces on and off the reservation, ${ }^{10}$ to teach readers about Native presence. Comic images draw attention to stereotypes, but comics also provide the means for writing Rowdy and other Indians in Arnold's life into history; the images of survival of a child, for a child. Unable to be a child, Rowdy's "visual presence" (and not documentation as normally discussed in autobiographical writing) in comics

\footnotetext{
${ }^{10}$ I am using Scott McCloud's definition in Understanding Comics, which defines comics as "juxtaposed pictorial and other images in deliberate sequence, intended to convey information and/or to produce an aesthetic response in the viewer" (9).
} 
suggests a precarious futurity. ${ }^{11}$ A ritual continued in a private gesture shared between Arnold and Rowdy, the comics represent Arnold's ongoing, albeit fantasized, conversation with his friend. Arnold's visual stories bridge the past and present, not only memorializing a life that Rowdy does not see, but also assuring Rowdy (and other Indians in Arnold's life) a visual survival.

Though recently comics have gained more traction in mainstream culture, traditionally comics tended to rely on marketing to children or (after 1970s) "nerds," depicted as infantilized adults. Comics create a fantasy world in which Arnold's memories define the past, not unlike the autobiographical narrations that supply the necessary contexts for understanding family photos. Life-writing texts frequently provide family photographs, a strategy that seems tied to the genre as truth-telling; however, Alexie uses comics instead, a move that offers an interesting challenge to representation. In the afterward of Diary, Ellen Forney, ${ }^{12}$ the illustrator of the text, shares that the comics were inspired by the original manuscript and lists written by Alexie (np). Thumbnail sketches started conversations between Alexie and Forney, and she says that, "about a third of the graphics were Sherman's ideas, a third were real collaborations, and a third were my ideas

\footnotetext{
${ }^{11}$ The term life-writing provides a better way to understand the way Alexie is using autobiography. Life-writing, as I argue in the introduction, is based on lived experiences but does not necessarily make promises for truth or accuracy assumed in autobiographical genres. Though Alexie has said Diary is based on his life, the book maintains connections to fiction as well. Alexie has recently released Here, he says he's "done with the bullshit that my whole career hasn't been autobiography. I've been lying for 25 years and everyone knows I'm lying. This memoir has completely eliminated that thinly constructed facade" (Smith).

${ }^{12}$ The edition used in this study includes an interview with Forney that shares her process for working with comics and the collaboration work with Alexie. Highly acclaimed for her own semi-autobiographical work, Marbles, Forney admits that collaborative work in comics is rare ("A Tiny Sense of Accomplishment"). Though the work began illustrating the ideas that Alexie imagined, Alexie notes that by the end Forney understood the character and text well enough that she could anticipate the how to illustrate without direction ("A Tiny Sense of Accomplishment"). Forney's work, as reflected on her personal website and discussed in her public blog, exemplifies performative storytelling by using comics to visualize inner monologues, challenges audiences to reimagine abstract concepts and feelings with which they may be unfamiliar. For example, in Marbles, Forney tries to explain what is means to live with bipolar disorder. Rather than using the common wave metaphor for mood swings, Forney choose a carousel. In another image she tries to represent the categories of mania. In an interview with Huffington Post, she explains: "It was satisfying to wrestle something unwieldy like mania into categories and tidy descriptions. I was also hoping to remind other bipolars who miss their manias - especially if they're tempted to go off their meds - that mania can be terrible, too. It's hard to describe, and my impression is that there's a lot of misunderstanding of what mania is" (Klein).
} 
that struck me as I read the text” (np). Alexie's images reverse Marianne Hirsch's mythologizing process $;{ }^{13}$ instead of looking at the images to verify history, Forney and Alexie look at the story to create a visual presence. Though Alexie says that his story is heavily autobiographical, the comic images used to visualize his presence mock the ritualized family photograph and draw attention to the way we imagine self and the performative aspects of photographic representation. In her work, Marianne Hirsch draws attention to the dialectic between family photographs and the fantasies they produce. She argues that family is "structured by desire and disappointment, love and loss," and that photographs as the "only material traces of an irrevocable past" derive power from imbedded "rites of family life" (5). Hirsch continues by tying the ideology of modern family to the family photo, which displays the "cohesion of family" as an "instrument of its togetherness" by chronicling and constituting family rituals (7).

Isolated from the text, photographs from life-writing texts provide visual confirmation of the text and offer only a limited story of their own. The comics in Diary, however, could be viewed in isolation and the images would still tell Arnold's story. Rather than looking back at the past, these images establish presence by reinforcing the text with a visual performance, forcing the reader to see what Arnold believes to be invisible, unknown, or unfamiliar. Alone in his basement, Arnold says he spends much of his time reading and drawing comics. Drawing, he

\footnotetext{
${ }^{13}$ In her definition of the familial gaze, Marianne Hirsch approaches the family photograph as a product of postmodern displacement through which narratives about the past become verified in photographic fragments of a "real" life lived. In documenting the real life, the genre of the family photo has helped create an American family romance built on the illusion that a photograph can simply record a pre-existing external reality, frozen in time. However, family photographs cannot supply the necessary context, she stresses, and instead occupy the space "between the myth of the ideal family and the lived reality of family life," perpetuating a stereotyped family as "stable, united, static, and monolithic" $(8,11)$. In contrast to the images of family, life writing offers narratives (sometimes) at odds with the images seen in photographs; a counternarrative that rescues the individuals from the photographic representation of a family naturalized by images, but potentially in conflict with memory. Hirsch offers Art Spiegelman's work in Maus as an example, demonstrating the tension between the lived experience of World War II and the inheritance of historical trauma in photographs of the dead and missing persons. Photographs help foster postmemory, a term she uses to describe the second generation removed from the trauma event. The images provide a path for descendants of the survivors to "witness" and connect to the previous generation's "remembrances of the past" so strongly that they can "identify that connection as a form of memory" even though they can only remember by means of stories, images and behaviors among which they grew up ("Generation" 5).
} 
says, allows him to "talk to the world" (6). If the images in Diary offer a prevailing message, they offer a story about survival. At the beginning of the text, Arnold tells readers that he spends most of his time alone, reading and drawing comics. He writes:

I draw because I want to talk to the world. And I want the world to pay attention to me. I feel important with a pen in my hand. I feel like I might grown up to be somebody important. [...] I So I draw because I feel like it might be my only real chance to escape the reservation. (6)

Comics provide Arnold a presence he does not otherwise feel in his world; the images assure his survival by providing visual proof of his world through his perspective. He begins with a self-portrait, a caricature of himself emphasizing the aspects he feels separate him from his community and peers. In the image his pupils are obviously two different sizes, his hands and feet are equally over-sized and drawn in awkward positions, with a speak bubble that stutters "the rain in Spain" with a lisp. The title sarcastically notes: "me in all my glory" (5). The image creates a tension between what he imagines as glorious, the opposite of all that he has described, and the reality of his life, emphasizing what Alexie has already written in the text.

Alexie's various forms of commentary-both in and outside the comic - create a break in the narrative that draws attention to the performative

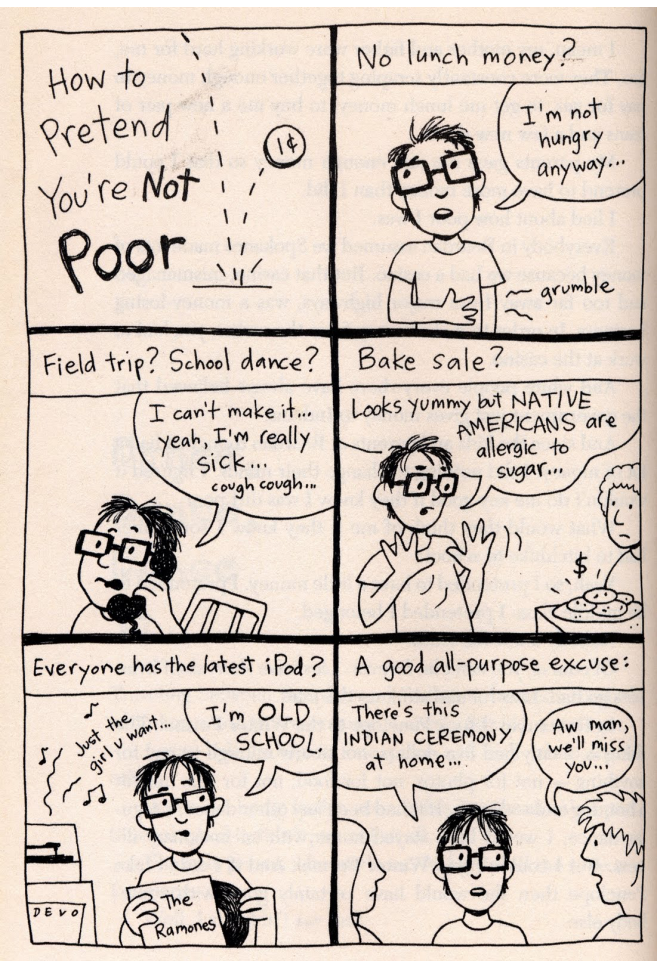


aspects of the narrative akin to Bertolt Brecht's sense of breaking the fourth wall. ${ }^{14}$ Among the best examples of his narratological breaks are moments when the comics supply information not found in the surrounding text. Written in comic panels, these moments present a dialectical look at truth and fabrication that help Arnold negotiate difficult situations he encounters with individuals unfamiliar with his reality, moments where he struggles to survive the realities of poverty, alcoholism, and grief. In the panel "How to Pretend You're Not Poor," Arnold provides a variety of excuses for common questions. The answers, though sometimes humorous, offer a dark look at the ways the poverty has affected Arnold's life. Arnold's explanations in comic panels typically explore different versions of answers he might provide when confronted with questions about uncomfortable, embarrassing, or shameful situations. Comics draw attention to the words not said as well as the missing stories. Arnold redress this loss by ensuring survival through an adapted version of the family photo.

Comics that depict Arnold's family and

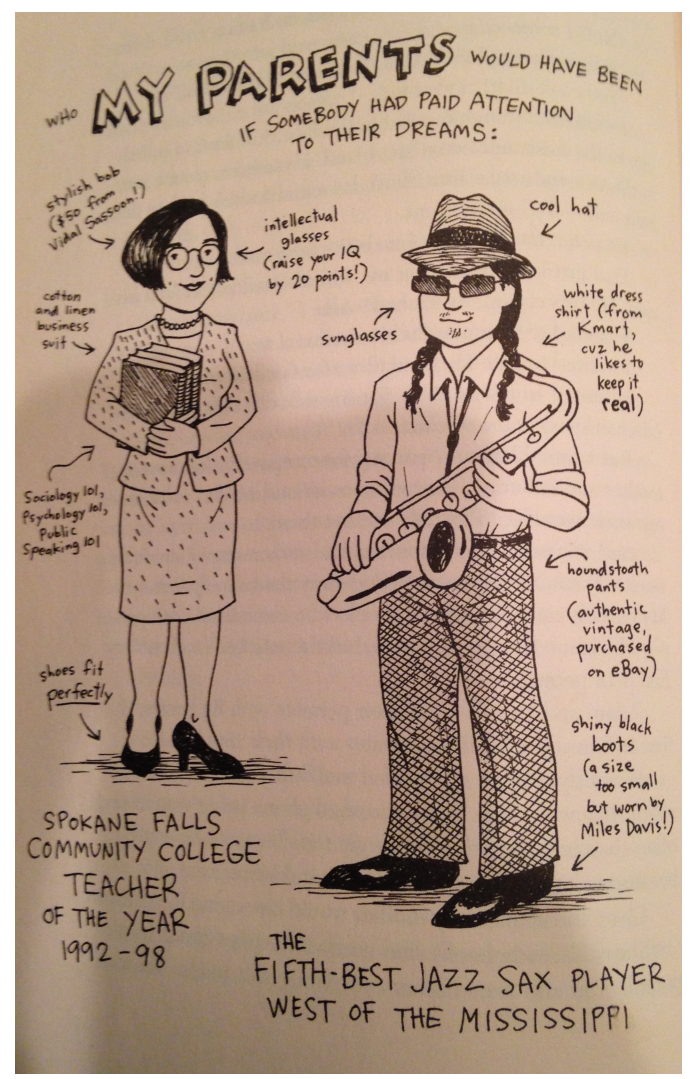
community provide race-based commentary that interrogates the limited possibilities for

\footnotetext{
${ }^{14}$ Bertolt Brecht's theories about epic theatre use his understanding of gestus and alienation to examine experiences that "make strange." Contesting the mechanical production of war, Brecht's theories return humanity by empowering audiences to think more critically about what happens on the stage. He shifts responsibility from an abstract "human-nature" to expose those in control of the decisions that resulted in massive destruction and poverty. Brecht's understanding of gestus and alienation as part of the processes of "making strange" draw attention to the performance as a performance, using discomfort to make audiences more aware of social situations and environments. His definition of epic theatre helps redefine Alexie's work through a performance lens as defined by a representation of reality not overly emotional, corresponding to a sociological situation, appealing less to feelings and more to an audience's reason (23).
} 
Spokane Indians with narratives about stymied lives. This is best exemplified in a comic Arnold draws of his parents imagining who they might have become under different circumstances. Arnold's imaginary constructions of his parents (lack of) future are notably imbued by cultural assimilation. Small details in the image, such as his mother becoming a community college instructor (and thus symbolically joining an off-reservation education system) or his father becoming a jazz musician who would wear the shoes of one of the great African American jazz musicians, Miles Davis, complicate the representation of what might have been. Even in the imagined space of an unfulfilled dream, Native Americans can only hope to mimic or integrate into mainstream society. In contrast to the possibilities he imagines for his parents, Arnold describes his sister in the present, acknowledging that she "froze" after high school (26). In the comic, Mary Runs Away stands arms akimbo with "acne scars that somehow make her look tough and pretty at the same time," a "tie-died T-shirt (shoplifted from The Gap)," "distressed jeans (shoplifted from Macy's)," and "Birkenstock sandals (stolen form the feet of an

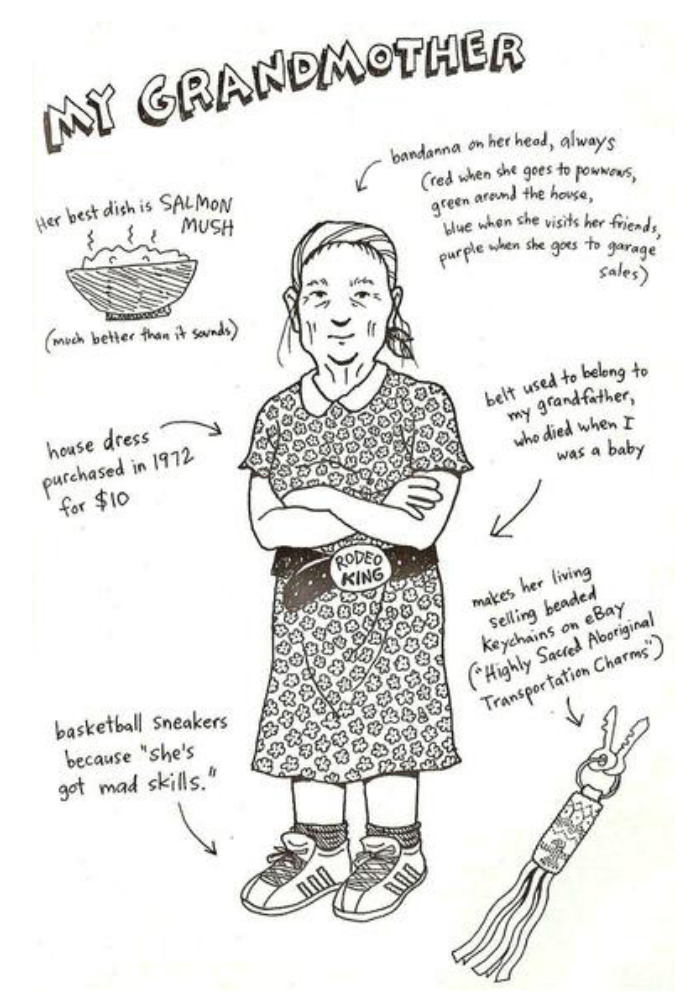
unconscious white pot dealer and poet)" (127). His commentary admits both poverty and theft.

Ironically, Arnold's description of his grandmother appears less static than that of his parents and sister. In a subtle gesture of hope, Arnold points out that his grandmother takes advantage of white stereotypes by "making her living selling beaded keychains on eBay," what she calls "Highly Sacred Aboriginal Transportation Charms" (69). Not unlike her children and granddaughter, Arnold's grandmother 
depends on a certain level of the anachronistic Indian to sell her wares, a fantastical Indian-ness born from a tribal identity and the imagination of Euro-American colonizers. Arnold's depiction of his grandmother, which comes later in the text, helps reflect back on the ways in which his mother and sister might also be subverting mainstream culture. Arnold imagines his mother becomes a teacher, perhaps as a result of Arnold's poor experience with reservation education as well as a hopeful nod to the intelligence and resilience that lies relatively untapped in his community. Like her grandmother, Arnold's sister is strong. She too rejects capitalism and mocks elite fashion with shoplifted clothing. However, not unlike family photos, the comics provide visual cues for certain stories, but much remains unexplained.

Arnold's comics, particularly those depicting family members, mock the rites and rituals of family with commentary that notes how Indians fail to fulfill the fantasies about family, shifting the emphasis instead to survival. Juxtaposed to images of the people in his life are comics that repeatedly stress the hopelessness of reservation life. Reservation direction signs that lead away from home, towards hope, or Arnold's head buried in an ant hill with the word "hope?!!??” reveal a dark humor imbedded in the comic form $(43,47)$.

Arnold's images also tell a story about those who don't survive, like his sister. Early in the book, after hearing for the first time that his sister used to write romance novels, Arnold draws a picture of a book cover. Titled Savage Summer (or Apache Heat or Lummi Lust or Yakama Yearning), the comic shows a shirtless Indian with "huge half-breed muscles" attempting to kiss a woman whose hair is "blowing in the breeze" (38). A repetition of this image appears again after his sister moves to Montana. This time the book is called The Stranger from Montana and the man is clothed. An arrow points to the woman on the cover, beside it Arnold 
writes "My Only Sister" (91). His sister seems to respond saying, “Think YOU'RE so tough, Junior?!" (91). An excerpt from the book mocks the romance genre:

'I want to have ten babies and live here forever and ever!' exclaimed Mary Runs Away.

'Darling!' gushed what's-his-face. Their beer-smelly mouths met in a big kiss, until what's-his-face had to burp. 'Bleeap!' (91)

In the final romance cover image Arnold completes the story using the romance cover again to think about his sister's death. The title is Burning Love and the cover shows his sister and her husband surrounded by flames, their trailer is in the background and his sister says: "Thanks a lot, Junior" (213). The text reveals Arnold's guilt; he believes if he had not left the reservation, his sister might not have left either. Perhaps he traded his own future for her future. In contrast to diary forms that use pictures to ritualize togetherness, this series interprets Arnold's relationship with his sister through romance novel book covers, a commentary that calls attention to the failure of romantic fantasies. The series provides a dark reminder about those who don't survive and those who must survive in spite of death.

While the text lacks photographic images, certain comics draw from the portrait style and adopt a greater realism in artistry. These images often demonstrate Arnold's deep love for people in his life. The first time readers see this type of art Arnold is describing his friendship with Rowdy. Rowdy "loves" Arnold's cartoons, and Arnold admits that he draws cartoons to make Rowdy happy, to "give him other worlds to live inside" (23). Comics also represent Rowdy's dreams, dreams he only talks about with Arnold (23). In the image Rowdy is laying down reading a comic, his face is angry and scribbled, and he yells at Arnold—-"What're you drawing??" (23). In the margins Arnold explains that Rowdy is reading the latest issue of Casper 
the Friendly Ghost and that Rowdy hates it when Arnold draws him and "never lets him finish" (23).

Much like the images of his sister's romance novels, this illustration links visual presence with loss and absence. Arnold suggests that without his comics Rowdy might never leave the reservation and by extension he might never be known by the outside world. Other realistic illustrations verify different loves — a portrait of his first impression of Penelope (Arnold's girlfriend), an image of Penelope and Arnold's desire to escape symbolized by a bird called an Arnelope, and a portrait of Gordy, a Reardan student who teaches him how to navigate white

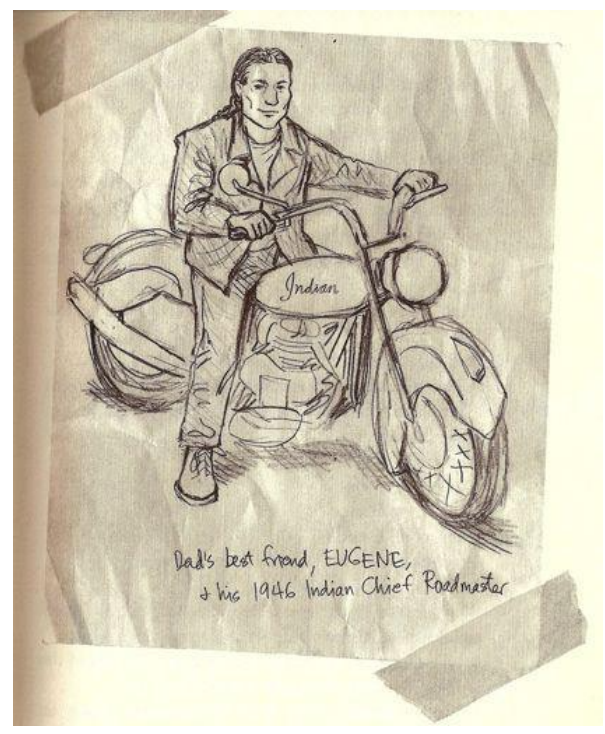
schooling $(112,113,117)$. While most of the realistic images belong to Arnold's friends, there is also a portrait of his dad's friend Eugene riding his motorcycle. Eugene helps Arnold travel to and from school, and he is one of the few reservation Indians who doesn't judge Arnold's choice to attend Reardan. He tells Arnold it's "pretty cool, you doing this" and that he could never do it because he is a "wuss" (71-72). The image also foreshadows loss since it is the only realistic illustration of an adult, and Eugene dies in a drunken brawl.

Photographic images seem to anticipate loss and change, capturing a moment in time that quickly passed. In the final image of the text readers see Arnold jumping into Turtle Lake holding hands with Rowdy, a photographic-like image that notes, "boys can hold hand until they turn nine" (218). In the chapter that

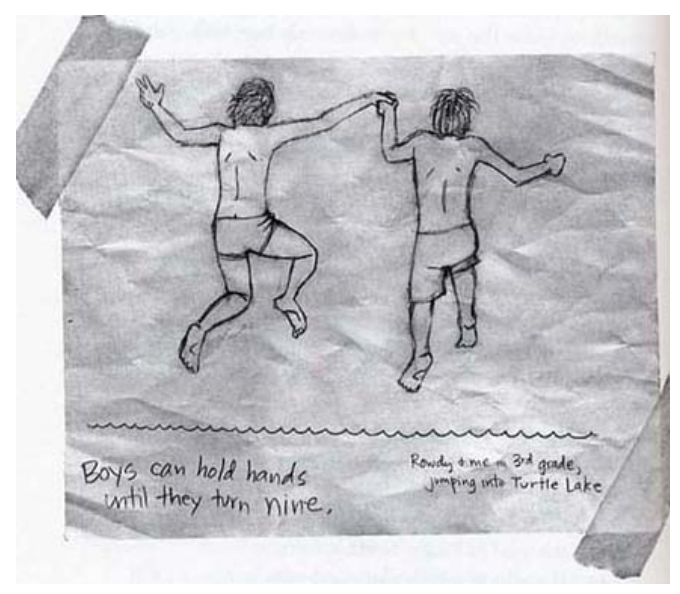


follows Arnold begins by stating that the reservation is "beautiful" and full of pine trees that are "ninety feet tall and more than three hundred years old;" older, he says, than the United States (219). Some of them were alive, he says, when "Abraham Lincoln was president," and when "George Washington was president," and when "Benjamin Franklin was born" (220). Arnold says that "maybe you can take pine trees for granted" (219).

The contrast of one moment showing Arnold and Rowdy's happiness and love with the old reservation pine trees exemplifies a connection of presence. In spite of the changes, Arnold knows that he needs his friend and the two return to Turtle Lake to climb the same tree that they used to climb and share their dreams about someday. Grounded in the past by history, by the tree, and by the events of their lives, both boys think about the future. Arnold acknowledges that he would "always love and miss" his grandmother, his sister, and Eugene, that he would "always love and miss" his reservation and his tribe, and that he "hoped and prayed that they would someday forgive" him for leaving (230). Rowdy knows Arnold will leave, and Arnold knows Rowdy will not, and rather than anticipate what they believe they know will come, both choose a perpetual delay of the present.

\section{HARD LESSONS: POVERTY \& THE CHILD}

Being a reservation Indian means growing up without the type of innocence mainstream society uses to define the period called "childhood." Instead, Arnold documents stories about his family and community that reveal violence, death, and extreme poverty. Counter to notions of childhood as a time of innocence, reservation childhood erases the boundary between adult and child, in effect suggesting the absence of childhood. While mainstream definitions of the child and childhood seem to infer lack of experience (or innocence) as an inherent condition of childhood, Robin Bernstein asserts that the performance of childhood is steeped in political 
positions that appear "natural, inevitable, and therefore justified" (4). Bernstein's term "racial innocence" calls attention to this dynamic in recognition of the shift from the doctrine of original sin to innocence, a shift that was notably "raced white" (4). Arnold shifts between public (and private) educational systems help teach readers what it means to be a reservation Indian.

Arnold's lessons in being Indian and being poor begin at birth. Born with a "water on the brain," Arnold struggles throughout his childhood with several health-related problems including seizures, vision impairment, and an abnormal number of teeth (likely contributing to his lisp). ${ }^{15}$ Arnold's trip to Indian Health Services for extraction so he "could eat normally, not like some slobbering vulture" ends with the removal of his ten extra teeth in one procedure because Indian Health Services only funded major dental work once a year (2). The dentist only uses half the Novocain because "our white dentist believed that Indians only felt half as much pain as white people did" (2). Already marked by his physical impairments (huge hands and feet and a head "so big that little Indian skulls orbited around it"), Arnold must also accept the only style of eyeglasses offered by the once a year eye care: "ugly, thick, black plastic ones" that made him look like a "three-year-old Indian grandpa" (3). Only three, Arnold has already skipped childhood and become elderly. At an early age Arnold learns that being a reservation Indian means that you don't get "chances or choices;" being a reservation Indian means that you don't get to realize dreams (11). "We're just poor," he says, "That's all we are" (11).

Institutional poverty necessitates a different type of "schooling," one that Arnold says “doesn't give you strength or teach you lessons about perseverance," but "only teaches you how to be poor" (11-12). Arnold reiterates these lessons in scenes where he describes what it means

\footnotetext{
${ }^{15}$ Bryan Crandall writes specifically about Arnold's disabilities arguing that Alexie uses the character to make a larger claim about survival. He writes: "Acknowledging that The Absolutely True Diary of a Part-Time Indian is autobiographical, Alexie promotes literacy as a means for survival. He does not allow the labels placed on Arnold as "different" to overpower Arnold's literacy practices and success in school" (Crandall np).
} 
to be hungry and to be sad. He explains that the worst thing about being poor is being hungry: "Poverty =empty refrigerator + empty stomach" (8). Poverty means that when Oscar, an "adopted stray mutt" and the "only living thing that [he] could depend on," becomes ill he must be shot because "a bullet only costs about two cents, and anybody can afford that" $(9,14)$. Though Oscar taught him “more than his teachers ever did," poverty means that there isn't any money for visits to the veterinarian (9). Poverty teaches Arnold that Christmas means that his father will be absent because when the holidays arrive there isn't any money for presents, so his "Dad does what he always does when we don't have enough money"- he runs away to "get drunk" (150). When he returns, January $2^{\text {nd }}$, with an “epic hangover," his father lays in bed for hours, and yet Arnold still tries to protect his dad's feelings by accepting his apology knowing that it wasn't okay. He had learned how to be the child of an alcoholic.

Despite his conclusion that poverty doesn't teach lessons about perseverance, Arnold vacillates between images of profound, hopeless poverty and images of the beauty found in simple gestures. In contrast to the ugliness, Arnold sees beauty in the only gift his father gives him that year:

"I got you something," he said.

"What?"

"It's in my boot." I picked up one of his cowboy boots.

"No, the other one," he said. "Inside, under that foot-pad thing."

I picked up the other boot and dug inside. Man, that thing smelled like booze and fear and failure. I found a wrinkled and damp five-dollar bill. "Merry Christmas," he said. 
Wow. Drunk for a week, my father must have really wanted to spend those last five dollars. Shoot, you can buy a bottle of the worst whiskey for five dollars. He could have spent that five bucks and stayed drunk for another day or two. But he saved it for me. It was a beautiful and ugly thing (151).

Even though his family "misses a meal and sleep is the only thing we have for dinner" in a "weird way, being hungry makes food taste better" (8). He claims that there is "nothing better than a chicken leg when you haven't eaten for (approximately) eighteen-and-a-half hours" (8). A recognizable dark humor emerges from the scenes described, a tragic humor based on an effort to represent what Heldrich calls the "unspeakable" (34). Heldrich writes that Alexie's dark humor “addresses absurdity predicated upon such problems as unemployment, poverty, alcoholism, drug abuse, diabetes, the uncertain future, and eroded cultural traditions" (25). Dark humor, he argues, provides an effective strategy for pointing out "historical and present conditions of inequity create by white hegemony and convey conflicts generated by assimilation" (25).

Arnold's experience of poverty displaces his connection to the reservation by stealing any hope or innocence presumed to be a part of childhood and trading it for paternal institutions invested in prolonging colonial ideologies. For example, Arnold's education on the reservation was no less racially contentious than at Reardan. Federally funded and managed, reservation schools adopted a civilizing mission pursuant with the US policy of assimilation and extinction of Native peoples and cultures. Alluding to Col. Pratt's famous "kill the Indian, save the man," Mr. P, Arnold's geometry teacher at Wellpinit High School, admits that he "hurt a lot of Indian kids"- he "might have broken a few bones" (35). In a conversation turned confessional, Mr. P explains: "that's how we were taught to teach you. We were supposed to kill the Indian to save the child" (35). Alexie's slight adjustment to Pratt's statement, specifically his use of "child," 
highlights an important distinction between colonial definitions and perspectives about childhood and the way Alexie imagines (through Arnold) he felt about his childhood. Col. Pratt, founder and superintendent of the Carlisle Indian School, chose children because he imagined a future without Indians best created by assimilating children, who would be malleable and would grow into adulthood a good sense of Indian culture. Through the voice of Arnold Alexie is able to reflect his childhood and his encounters with colonialism, emphasizing the impact of an education aimed at erasure. Further stressing the metaphorical death, Arnold misunderstands Mr. P's story; he believes Mr. P literally killed Indians. Mr. P tells him that they didn't kill Indians, but instead they "were supposed to make you [Indians] give up being Indian. Your songs and stories and language and dancing. Everything" (35). "We were trying to kill Indian culture," he tells Arnold (35).

While some Native students were sent to boarding schools, others remained on the reservation to be educated by teachers willing to relocate to reservation lands and live in what Arnold calls "prison work-farm" conditions. Arnold explains that the tribe houses all of the teachers on a compound in "one bedroom cottages and musty, old trailer houses behind the school" (29). You can't be a teacher, he notes, without living on the reservation. Those willing to relocate to poor reservation living conditions also faced poorly funded schools. In the early pages of the book, Arnold becomes enraged when he opens his textbook and sees his mother's name written inside - thirty years later. Reservation schools attracted what Arnold calls "liberal, white, vegetarian do-gooders and conservative, white missionary saviors" (30). Far from benign, Arnold registers their self-serving agendas as vacillating between fetishizing imagined perceptions of Native life and versions of Pratt's "kill the Indian." He notes "some of our teachers make us eat birdseed so we'll feel closer to the earth, and other teachers hate birds 
because they are supposedly minions of the Devil" (30). He concludes: "It is like being taught by Jekyll and Hyde" (30). Arnold explains that Mr. P sometimes forgets to come to school and students must be sent to housing compound to "wake up Mr. P who is always conking out in front of his TV" (29). The kids "dig" Mr. P because he "doesn’t ask too much," which Arnold concludes is related to a lack of respect: "how can you expect your students to work hard if you show up in your pajamas and slippers?" (29).

Arnold's conversations with Mr. P frequently highlight the ways in which formal education for Native children created a point of conflict that demanded choice between tribalism and a futurity based on adoption of contemporary white culture (an argument that remains debated today). In learning to assimilate, Native Americans faced the loss of culture and traditions, which in turn affected the way Native peoples learned to know themselves, trading cultural knowledge and growth for a life stymied by poverty. In interviews Alexie emphasizes that reservation poverty exceeds expectations. Conditions are beyond third world or fourth world poverty, he argues. In a 1998 roundtable discussion about race in the U.S., Alexie stresses that he didn't have running water until he was seven years old and tells former President Clinton, "I still remember when the toilet came" (“A Dialogue"). ${ }^{16}$ In Diary Arnold tells readers:

It sucks to be poor, and it sucks to feel that you somehow deserve to be poor. You start believing that you're poor because you're stupid and ugly. And then you start believing that you're stupid and ugly because you're Indian. And because you're Indian you start believing you're destined to be poor. It's an ugly circle and there's nothing you can do about it. (11-12)

\footnotetext{
${ }^{16}$ Based on his birth in 1966, this would have been sometime in 1973.
} 


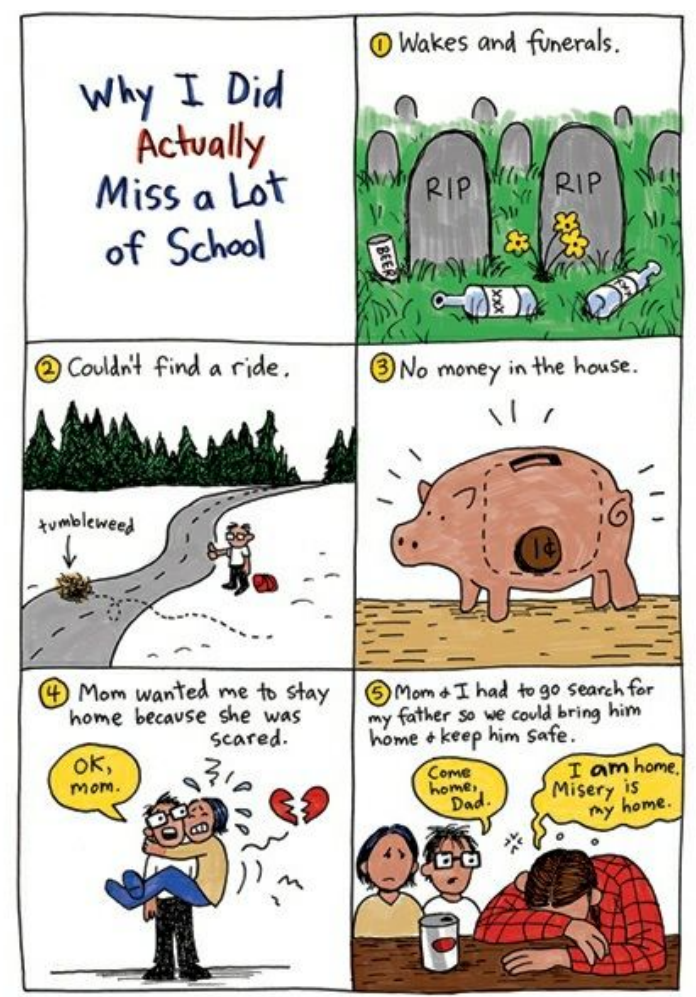

Childhood on the reservation means growing up with economic insecurity, food insecurity, and the nagging feeling that no one cares because you are just an Indian. Off the reservation Arnold continues to carry the trauma of poverty, which affects the way he relates to other young adults.

"Reardan was the opposite of the rez," he notes (56). It was the "opposite of my family" and it the "opposite of me," Arnold says and both he and the other students knew "didn't

deserve to be there"- “Indians don't deserve shit" (56).

Unable to identify with his Reardan peers, Arnold recuperates the "real" story in comic images that reveal what hasn't been told. These panels provide an almost pedagogical element to the text, visualizing the "real” Indian life. In "Junior Gets to School," Arnold chronicles his efforts to get to school for a week (88). In "Why I did Actually Miss a lot of School" Arnold lists the real reasons he misses school after a series of deaths in his family. The list begins with the familiar - wake and funerals - moving to "couldn't find a ride," to "no money in the house," to more emotional explanations which show Arnold taking care

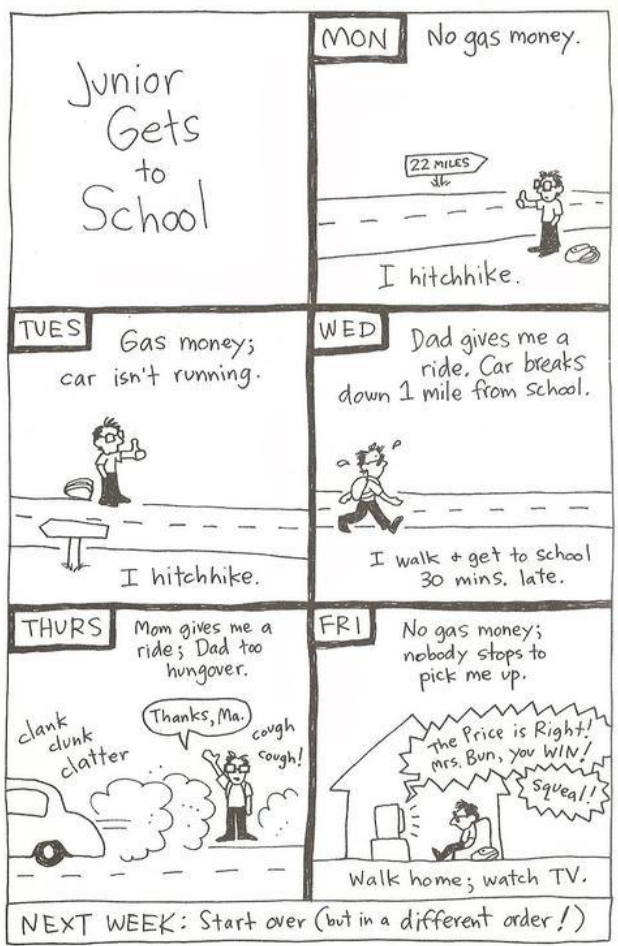


of his grieving parents (174). Shifting attention to the untold stories further highlights the unsaid, and seemingly unknown, aspects of Indian life; however, in one panel Arnold addresses the assumed in a panel titled "How to Get the Last Sip of Wine from the Bottom of the Bottle" (170). This panel combines Arnold's imaginative efforts to understand the death of his father's friend Eugene. The series illustrates a dark humor, pointing out that love, guilt, and sacred traditions can persuade a friend to give up the last bit of alcohol. But, the last panel, ending with a gunshot, belies the humorous tone, confronting the very real violence Arnold knows but does address directly.

Complicating Arnold's lessons in poverty are new lessons in what it means to be poor off the reservation, which not only increases Arnold's isolation, but also demonstrates the instability of terms for innocence. Penelope lacks experiences with poverty and violence - an innocence in terms of experience-whereas Arnold lacks experience with girls—also an innocence in terms of experience, but a very different type of experience, one more commonly associated with growing into adulthood. During Halloween Arnold attends school dressed as a homeless "dude": a "pretty easy costume" for a poor kid (77). Penelope also dresses as a homeless person, but she was the "most beautiful homeless woman who ever lived" (77).

Arnold and Penelope's differences continue to surface as Penelope tells Arnold that her costume is meant as a political statement, protesting the treatment of homeless people. She tells Arnold that she is going to collect spare change instead of candy. Arnold follows her lead telling her that he too is protesting, but he is protesting the treatment of homeless Native Americans. Later, collecting money, Arnold thinks it was a "pretty stupid idea," even though many people give him spare change and candy when he trick-or-treats, because a "lot more people" called him names and slammed the door in his face (79). On the way home three guys jump him, shoving 
him to the ground, kicking him, and spitting on him. He says he "felt like an insect; like a slug" (79). Devastated by the loss of ten bucks, it wasn't much, but it had made him feel good about himself despite being a "poor kid raising money for other poor people" (79). The next day Arnold tells Penelope that he was attacked and shows her the bruises. She feels sorry for him, innocently asking if he went to the doctor. Arnold falls more in love with her gentle touch and promises to put his name on the money she plans to send to the poor. Unable to risk the tentative relationship he creates with Penelope, Arnold prefers to continue the charade that he creates, a narrative created in part by the assumptions he allows Penelope to make based her lack of understanding.

Much of Arnold's time at Reardan is spent learning how to hide his poverty and the effects of reservation life, while trying to learn how to function in white culture. For example, in one set of images about poverty, Arnold imagines possible responses to the question "are you poor" (128)? With each answer Arnold becomes increasingly anxious, first denying poverty, then admitting poverty, then purposely misinterpreting the word as "pore," then delaying his response through social context, and finally running away (128).

Unable to explain to confront the truth and even less capable of explaining what reservation poverty looks like, Arnold chooses to run away.

Conversely, reservation life taught Arnold not to run away from a fight. On the reservation Arnold had learned about violence, about how to fight, and the rules for fighting which include "if somebody

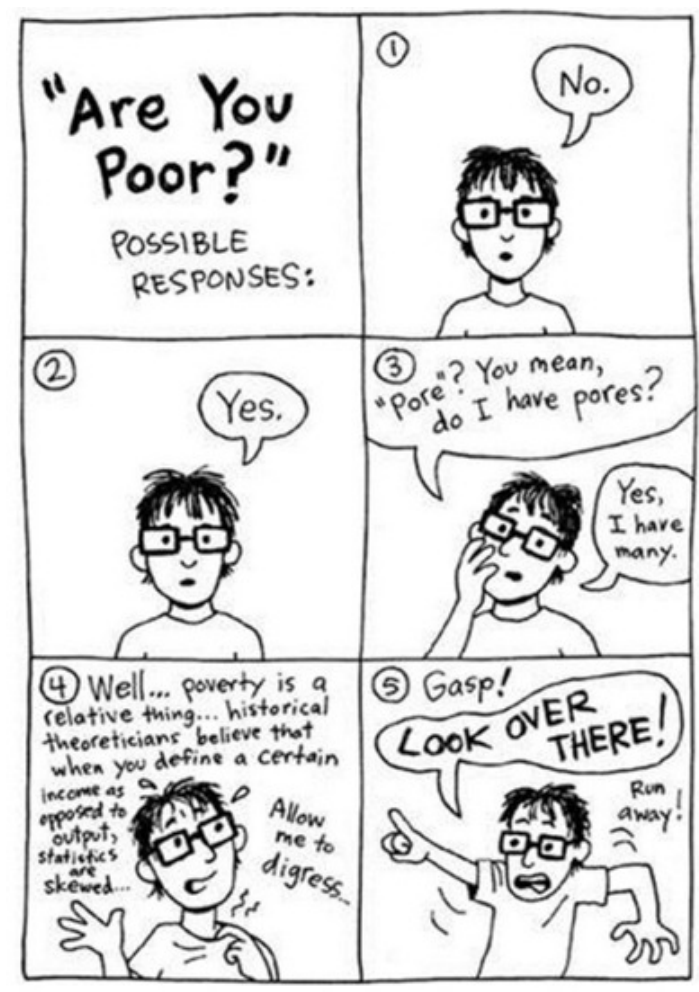


insults you, then you have to fight him" (61). In a comic aside, Arnold lists the "UNOFFICIAL AND UNWRITTEN (but you better follow them or you're going to get beaten twice as hard) SPOKANE INDIAN RULES OF FISTICUFFS" that seem to return to one rule: you have to fight (61-62). Throughout the novel Arnold repeatedly talks about moments where he is hit—by strangers, by his friend Rowdy, by Reardan jocks, by his tribe, and by community. However, at Reardan Arnold's reservation lessons about how to fight don't help and in fact, because the larger student body has not experienced hunger or beatings (at least as far as the narrative includes), Arnold must figure out how to hide his pain. While most students at Reardan ignored Arnold, a few of the "big jocks" paid "special attention," and threatened to beat him up and called him names (63). Despite the threats, Arnold "wins" the only fight that actually materializes. In the end Arnold is able to find allies at Reardan, all of whom help mitigate Arnold's isolation as a poor Indian. Gordy, one of the few students willing to talk to Arnold, tries to talk to Arnold about books; Roger helps him with basketball and the occasional ride home. Penelope teaches him about love.

Alongside Arnold's attempts to hide the pain and embarrassment of poverty are his observations about what he did not expect to see-_white pain." In one scene Arnold escapes a boring history lesson by going to the bathroom. Next door he hears a weird noise that sounds like someone vomiting and he tries to help. Eventually Penelope leaves the bathroom and under Arnold's stare she assures him that she is not anorexic — she is bulimic (106). Arnold is disgusted and thinks it's strange that there are a bunch of "anorexics who are PROUD to be skinny and starved freaks" (107). Penelope's defense of her bulimia reminds Arnold of his father's alcoholism: "I'm only an alcoholic when I get drunk," his father says in nearby comic. Arnold concludes that there are "all types of addicts;" we "all have pain" and look for ways to "make the 
pain go away" (107). Penelope throws up her pain and his dad drinks his pain. The recognition of the slim margin of white privilege shifts the narrative to consider the absence of childhood more broadly, and casts a shadow on whiteness as a guarantee for a successful future.

In finding a way to make pain relevant Arnold is also able to see how his own perspectives about whiteness were tied to his assumptions about race; however, despite finding a way to identify with Penelope's pain, Arnold is equally aware that her feelings reveal selfcenteredness. As Penelope complains about the limitations she faces because of her "perfect" life, Arnold listens and hears her repeat herself about beauty, intelligence, and popularity; he notes that the "girl has an ego" (108). Though he remains attracted to her, in spite of her ego, Arnold knows that their friendship shocks the school, particularly given that her father is openly racist. The first time he meets her father, Earl, he tells Arnold:

Kid, you better keep your hands out of my daughter's panties. She's only dating you because she knows it will piss me off. So I ain't going to get pissed. And if I ain't pissed then she'll stop dating you. In the meantime, you just keep your trouser snake in your trousers and I won't have to punch you in the stomach.

While his deeply misogynist lecture might be considered a normal paternal reaction, he follows the lecture by telling Arnold that if he impregnates his daughter with "charcoal babies" he will disown her (109). Unlike Penelope, Arnold faces childhood as experienced through hostile racial terms that limit the opportunity for him remain innocent of history, of prejudice, and of violence.

Reservation life provides little opportunity for economic stability, creating an environment shadowed by effects of violence and poverty, an effect that offers little chance for surviving childhood with any measure of innocence. Arnold's beatings can usually be tied to 
being sensitive, disabled, and quiet; the more he cries the harder people hit. Arnold tells Mr. P that he doesn't like to cry because other kids beat him up when he cries and sometimes they make him cry just for an excuse to beat him up. Worse, however, is Mr. P's response: “I know. And we let it happen. We let them pick on you" (41). Rowdy, on the other hand, "is the toughest kid on the rez" (15). Rowdy is "long and lean and strong like a snake" with a heart as "strong and mean as a snake, too" (15). But Rowdy's toughness and his anger do not save him from beatings.

Arnold explains at the opening of the book that Rowdy is "having one of the worst summers of his life" because "his father is drinking hard and throwing hard punches, so Rowdy and his mother are always walking around with bruised and bloody faces" (16). Rowdy protects Arnold, but he also seems always ready for a fight. "Whenever he came to school with a black eye," Arnold says, "Rowdy made sure to give black eyes to two kids picked at random" (41). Rowdy perpetuates the violence he experiences at home, violence stemming from alcoholism, limited opportunities, and hopelessness. Mr. P tells Arnold that Rowdy is "just going to get meaner and meaner" (41). Rowdy takes pride in his bruises, calling them "war paint," and telling Arnold that they "just make [him] look tougher" (16). Rowdy's comments cleverly link Native history with violence, drawing pride from a long tradition of having to fight colonialism, but also demonstrate the damaging effects of a people sentenced to disappear. Rowdy's bruises provide proof of persistence while telling a much darker tale about the expense of survival, suggesting, at least in part, that should Rowdy stop fighting he might disappear altogether.

Though Arnold and Rowdy both experience reservation violence, Rowdy is the character that seems destined to disappear. Both characters have parents who are alcoholics, but Arnold says that his parents are just neglectful. "My mother and father are drunks, too," Arnold says, 
"but they aren't mean like that. Not at all. They sometimes ignore me" (16). Rowdy's parents hurt him. One morning Rowdy limps into Arnold's house with a sprained knee and a bandaged ear. Arnold asks what happens and Rowdy tells him: “'Dad said I wasn’t listening. So he got all drunk and tried to make my ear a little bigger'” (16). Unlike Arnold, Rowdy is always angry; he begins life fighting. His first fistfight was in kindergarten — he "took on three first graders during a snowball fight because one of them had thrown a piece of ice" (18). Then he punched the teacher who tried to break up the fight. Rowdy fights everyone and everything, even the weather (18). Arnold is the only person who believes in Rowdy and his capabilities. He tells his friend that he is going to play for the NBA or Seattle (221). He asks him to come with him to Reardan, but Rowdy avoids the question, or rather avoids the answer, unable to survive outside of his anger.

\section{A PART-TIME INDIAN: BOYHOOD \& IMAGINED FUTURITY}

Criticism of Diary tends to focus on community/tribalism themes ${ }^{17}$ to emphasize the cultural dichotomy between Euro-American and Native traditions, particularly in terms of the text's efficacy in teaching young adult audiences about common issues in adolescence. For example, Dawn Thompson recognizes the role of context in teaching Diary, notably in terms of the way the "reader situates the narrative" in regard to what it means to leave "place" (65). In her experience she has found that non-Native readers tend to misunderstand and misinterpret tribal values, which sometimes has the effect of homogenizing American childhood. More troubling, however, are reviews of the text that fail to highlight the cultural significance of Native life. Allison Porizio tells readers that Junior is a "character with whom teens can relate," and his

\footnotetext{
${ }^{17}$ Reviews of the text tend to fall along lines that emphasize Native American tribalism and community in isolation, which also tends to emphasize ahistorical and fixed Native identities. Readings of the text lack nuanced analysis and instead accept in faith that Alexie is either writing to educate his audiences or just to tell a good story about Indians without any agenda. Reviews also applaud Diary's forwarding of a character who embraces white culture and by extension a transnational (Indian-US) identity.
} 
journey examines a "common teenage problem of discovering one's identity and making one's way in society" (32). Though Porizio's comments celebrate a mainstream connection, her work uses commonality to gloss over crucial cultural differences and elevate the importance of an illdefined relatability. Porizio shows little cultural sensitivity when she describes Junior as the "low man on the metaphorical totem pole" (32). Alexie asserts in interviews that his works should not be touted as universal because when people say universal "they mean white people get it" (Fraser). In spite of his rejection of universalism, Alexie has said that he wrote Diary for any teen that suffered. ${ }^{18}$

Alexie's own remarks about his work further complicate the tension between community and tribalism, specifically in terms of the visibility of indigenous peoples. Alexie argues that the lack of knowledge and recognition of the significance of Native Americans remains pervasive. In a 1998 PBS sponsored round-table discussion with President Clinton, Alexie repeatedly states that nobody "talks about Indians." "Nobody," Alexie says pointing out the Washington Redskin logo "cares about Indians" (“A Dialogue on Race"). He reiterates this point again in 2013 in an interview with Bill Moyers, arguing that other minorities have more economic power than Indians. "If you look at Chief Wahoo," on the Cleveland Indians hats, "and put Sambo next to him, it's the same thing" (Moyers). But, Alexie concludes, "you can never have Sambo anymore" (Moyers). In Diary, Arnold forces visibility by leaving the reservation to attend a high school with a bright, red Indian warrior mascot, but he also must face a community habituated to invisible (dead) Indians. Arnold's relationship to the tribe and both communities (on and off the reservation) remains tenuous. His peers cannot understand or relate to his world; his family and reservation community cannot understand his perceived betrayal.

\footnotetext{
${ }^{18}$ See "Why the Best Kids Books are Written in Blood."
} 
Throughout the text comics depict Arnold's discomfort in bridging the difference between his life on the reservation and his efforts to find belonging with the Reardan students, which suggest that his futurity might be linked to what Vizenor argues is an ongoing, active resistance to absence. Unable to afford a proper tux Arnold must wear his father's old suit to a school dance. The accompanying image titled "ME as unintentional DISCO FREAK" shows Arnold in a suit purchased by his dad in the 1970s mid-disco dance with a finger in the air and bell-bottoms "of course" (121). Ideally, joining the basketball team would mitigate Arnold's sense of belonging and alleviate his cognizance of difference by refocusing on team belonging; yet, in spite of the narrative suggestion that he fits in because of his skills, comics highlight

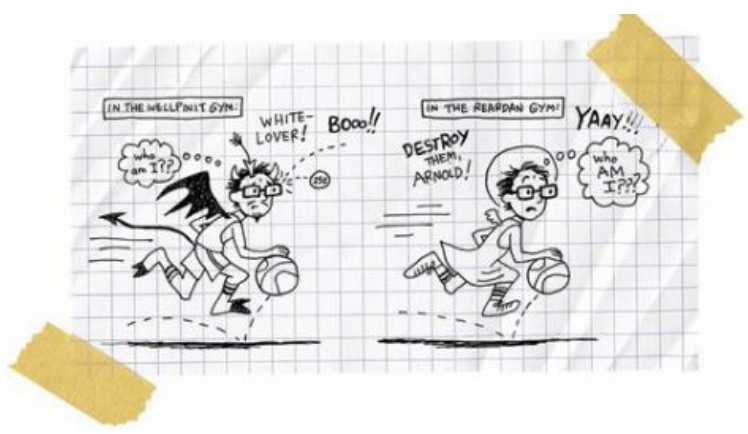

$$
\text { residual tension. In an image situated near }
$$
Arnold's story about trying out for the team, Arnold is dressed in a loin cloth, basketball socks and tennis shoes, and he is running and screaming "AAAUUAGH!" across the court (142). The surrounding text notes that he "knew" he was going to make the team because he had charged his bully Roger on the court. He "was a warrior" (141).

Ironically, Arnold's ability to join the Reardan team is related to his finding the warrior within himself - being Indian. Arnold continues to pair his sense of the warrior with the basketball court and later, playing again the Wellpinit team, he says that he was "some kind of crusading warrior" (182). Below this is an image of Arnold at two games, both against Wellpinit. Unable to reconcile the crowd's feelings - an Indian audience who hates him and a white audience who loves him—Arnold feels torn between opposing images of what it means to be 
white and what it means to be Indian, or more accurately, what it means to be Indian and be part of mainstream white culture.

As an Indian leaving the reservation, Arnold feels split between two worlds, neither of which offers Arnold a presence to which he feels connected. Throughout the text Arnold emphasizes that he feels invisible, unknown, and unfamiliar. Arnold frequently alludes to his isolation, both as a product of reservation life and his lack of connection to the Native community around him. The reservation, Arnold says, is perfect for the government to hide somebody because "no place is more isolated;" his reservation is "located approximately one million miles north of Important and two billion miles west of Happy" (30). In a similarly exaggerated tone, Arnold unhappily notes that on the reservation he is a "zero," and that even though he has contemplated suicide, he reasons that "if you subtract zero from zero, you still have zero" and concludes that there is no "point of subtracting when the answer is always zero" (16). But, "part-time" seems to refer less to his time on the reservation and more about his time off the reservation where his identity is filtered through race.

Much of the work in the comics lies in visualizing Arnold's witnessing and translating his experiences with racism. Early comics introduce familial expressions of Indianness, while later comics document Arnold's personal experiences on and off the reservation. Certain images reveal Arnold's struggle to understand himself through competing narratives about whiteness and Indianness. These illustrations reflect Arnold's inner thoughts rather than the written diary. For example, after hearing about Arnold's decision to attend Reardan, Rowdy reacts poorly and he punches Arnold in the face. A nearby image depicts Rowdy's angry face screaming "I HATE YOU!," "YOU SUCK!," and "YOU WHITE LOVER" (53). Rowdy never calls Arnold a "white 
lover" according to the diary's narrative, suggesting that the accusation speaks more to Arnold's guilt rather than Rowdy's anger.

Shortly after Arnold's comic projecting Rowdy's anger, readers see an illustration comparing a white and Indian Arnold. Rather than testifying to an absolute destiny, the text boxes within the comic reveal an internalized belief confirmed by individual experience. White families also deal with cancer and diabetes, and many experience bone-crushing realities. The

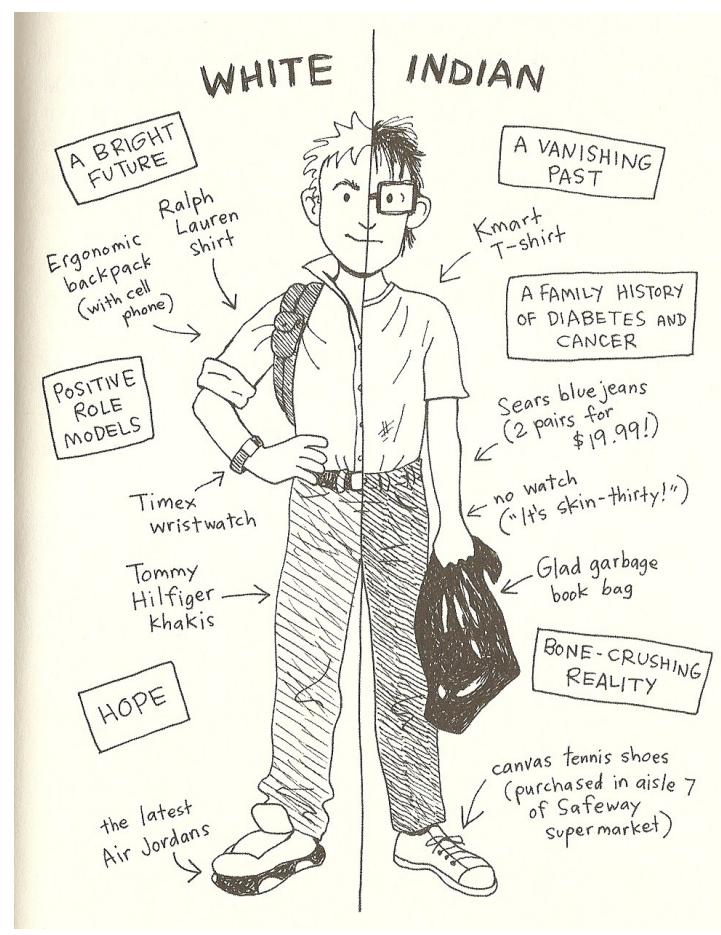
significance of these particular observations, however, is the way these realities have been mapped onto Arnold's story of his childhood and the way his childhood is tied to race. In other words, Arnold believes whiteness offers an inherent future of possibilities. The "Kmart Tshirt," "Sears blue jeans (2 pairs for \$19.99!), "canvas tennis shoes (purchased in aisle 7 of Safeway supermarket)," and "Glad garbage book bag," all spell out what Arnold already knows: he is poor and feels isolated.

In as much as Arnold tells a story about what it means to be Indian, he also uses comics to tell a story about what it means to perform whiteness through stereotyped images of white characters, a visualization that not only mocks white appropriation but also writes against history. An exaggerated caricature, his reservation math teacher, Mr. P, has an absurdly large, balding head with "dandruff (!)" and a similarly absurdly large nose with "nose hair" (29). The comic mocks Mr. P's effort to start a reservation Shakespeare Theatre Company, which "failed 
miserably," and his pathetic size (he weighs "maybe 50 pounds (but only when he's carrying his 15-pound briefcase)" (29). Arnold's first image of Penelope, his eventual girlfriend later drawn more carefully, depicts her simply with a speech bubble that says, "My name is Penelope" (a name Arnold sarcastically notes seems misplaced), and the note: "totally, absolutely gorgeous!" (59). Arnold's coach fits every stereotype as well, from the "SKINNY! 2\% body fat" to his use of "Skoal," his "voice like Thor," and "same shorts, regardless of the weather" (137).

In spite of the stereotypes, Arnold's descriptions of white characters provide no more animosity than his descriptions of his family, with the exception of oneTed. In the comic of Ted, a white man who has adopted Native identity, Arnold adopts a much more scathing commentary. Arnold mocks Ted by pointing to clothing he imagines Ted wears, like a "sacred leather scrotum sheath, purchased from Navajo shaman

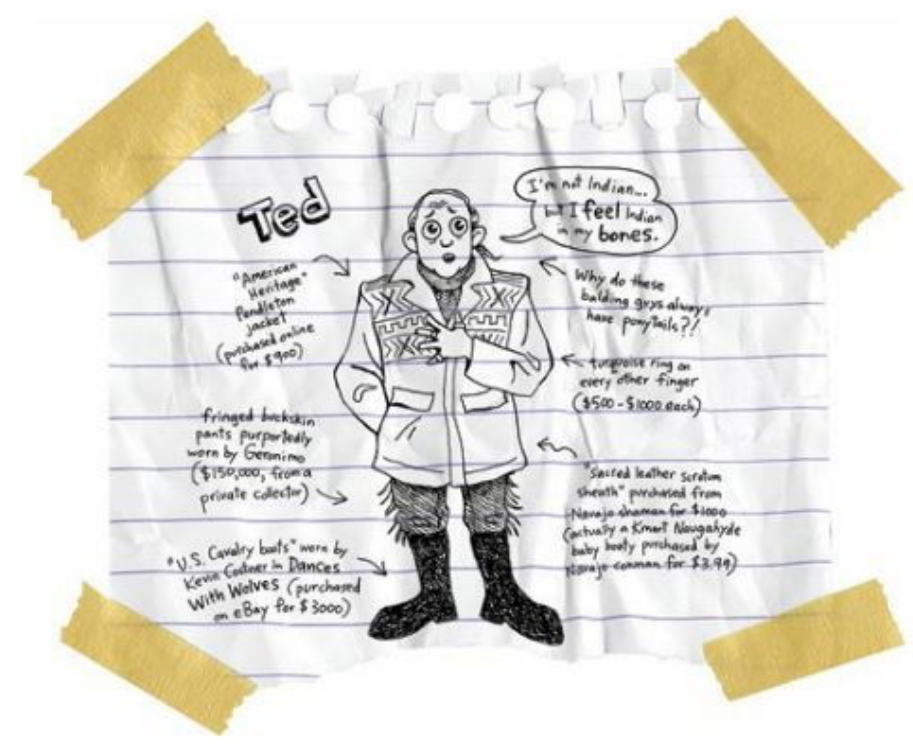
for $\$ 1000$ (actually a Kmart Naugahyde baby booty purchased by Navajo conman for $\$ 3.49$ ), and asks: "Why do these balding guys always have ponytails" (162)?!

The comics in Alexie frequently allude to the incongruity of racial images through illustrations that draw attention to Arnold's actual experience at odds with the historicized stereotypes used in racial slurs. Social fantasies about imaginary Indians play an important role in mediating citizens "born" under the laws of nations with a "structure of memory, a vocabulary, and a feeling of obligation to the state" (Vizenor Fugitive 98). Gerald Vizenor 
argues that under US social theory as constructed by Puritans, the "subjects' personal identifications — bonds of family, class, race, ethnicity, gender, or nation — are subsumed under the more pressing project of acting in the colony's providential, political interest" (98). Lauren Berlant's deconstruction of national fantasy also contends that national culture becomes authenticated through the stories we tell ourselves, in "images, narratives, monuments, and sites that circulate through personal and collection consciousness" (The Anatomy 5). "Playing" Indian is more than mimicking traits identified with indigenous cultures; it is legitimizing (or delegitimizing) claims for nationality through shifting terms used to define what Vizenor calls a "simulation"- the Indian (51). The term Indian, according to Vizenor, is a repository, an "archive," of "discoveries, treaties, documents of ancestry, traditions in translations, museum remains, and the aesthetics of victimry" (50). Diary, the title claims, provides readers a glimpse of a "true" Indian, an Indian not stranded in the past.

Like his readers, Alexie might be "playing Indian," his title ironically pointing out that his book is the "true diary" of a "part-time Indian". ${ }^{19}$ As a "part-time" Indian, time plays an important role in understanding how Arnold connects with his communities, but more importantly how time is filtered through terms for identity, marking Indian time as slow, unmoving, and dying, and white time as moving forward. Time also helps denote who is Indian and who is not. Social fantasies about Indians tend to look backwards, and even Arnold locates strength in the traditional image of a warrior. Nervous about his first day of school off the reservation Arnold's father reassures him telling him that he is "so brave" and he is a "warrior"

\footnotetext{
19 The either/or construction based on an imagined Native identity supplied an opportunity for Americans to define the terms for Native identity in various socio-political and legal institutional forms as well as a chance to "play" Indian when the need arose (see Philip Deloria's Playing Indian). Unable to define what it means to be American, yet imagining themselves as both saviors of civilized order and fierce advocates of freedom, America's practice of what Deloria calls "playing Indian" cluster around moments when Americans need to distinguish itself from its European background or verify a more "authentic" self (7). Deloria writes that throughout history Americans have adopted and coopted "Indian" identity because Americans, failing to produce a positive identity that stands on its own, have had an "awkward tendency to define themselves as what they were not" (3).
} 
(55). This reassurance offers a hopeful reclamation of what it means to be a warrior and gestures to Native futurity, if only in Native communities. Arnold thinks that it was the "best thing he could have said" (55). Despite his movement toward a different future, Arnold still finds strength in the past.

Arnold's part-time Indian status most strongly connects to his decision to leave the reservation in pursuit of an education at the more affluent Reardan High School, leaving behind an educational system leftover from colonialism. ${ }^{20}$ As a part-time Indian, he spends part of his time at the reservation and part of his time at Reardan, where in some ways he is more Indian than when he is an Indian on the reservation. Being Indian determines much about Arnold's education on and off the reservation. On his first day of school Arnold feels that students at Reardan looked at the "Indian boy with the black eye and swollen nose" and couldn't believe their eyes - they stared like he was "Bigfoot or a UFO" (56). Arnold notes that the only other Indian at the school was the mascot - a relic of the past, the fighting Indian. At Reardan Arnold's identity is filtered through racial terms and he is primarily recognized as a "potential killer," and no matter how "geeky or weak" he appeared to be, they called him names—“lots of names" (63).

20 As the United States continued to expand, the federal government continued to look for new ways to disappear Native peoples. Col. Pratt and the American project of assimilation in Native American boarding schools continued well into the early 1900s; education was a tool for undermining Native ways of life and extending federal control. Native families faced pressure to assimilate into U.S. social and cultural citizenry, and though some families sent children to Native boarding schools willingly, other children were kidnapped and forced to attend. Unlike Eastern boarding schools that increased prestige for the wealthy, white children, Native boarding schools operated more like prisons and became one of the most effective tools for assimilation (Szasz 210). Adopting militarized styles of structure and discipline, the schools maintained an atmosphere where "'lock-up' system[s] was common" and "other forms of punishment were applied according to the whim of each superintendent" (211). Chronically underfunded, Native boarding schools used student labor for almost every aspect of maintenance, from cleaning to food preparation to animal husbandry. These tasks were rationalized by a policy that linked education to urban industry employment, and failed to consider that students would be returning to reservations where life was primarily rural and lacked the employment opportunities. It's important to note, however, that experiences at Native boarding schools were not monolithic. Schools offered a mixture of opportunities, and for students from food insecure homes, boarding school offered more basic resources. Szasz notes that following the Meriam Report made during the late 1920s substantial changes were made to Native boarding schools, most notably in terms of funding for better living conditions. By the early 1940s enrollment dropped to 14,000, down from 21,000 and the number of boarding schools dropped from 77 to 49 (Szasz 213). 
While "Squaw Boy," "Tonto," and "Chief" were bad enough, bad enough that Arnold knows that eventually he would have to fight the white boys in order to stop the name calling, it's Roger the Giant who elevates the stakes by telling him a "joke:"

'Hey Chief,' Roger said. 'You want to hear a joke?' 'Sure,' I said.

'Did you know that Indians are living proof that niggers fuck buffalo?'

I felt like Roger had kicked me in the face. That was the most racist thing I'd ever heard in my life (64).

Arnold believes that by challenging Roger to a fight he was "defending Indians, black people and buffalo," and despite his fear, he punches Roger in face. Shocked, Roger can't believe that Arnold punched him in the face and challenges him to finish the fight after school. Arnold, too, is shocked and "absolutely confused" (65). "I had followed the rules of fighting," he reflects, "I had behaved exactly the way I was supposed to behave. But these white boys had ignored the rules" (65).

Students aren't the only people who cast Arnold in racist terms. In his geology class, Arnold attempts to clarify that petrified wood is not actually wood. His teacher, Mr. Dodge, sarcastically asks him, "If it's not wood, then why would they call it wood" (84). When Arnold says he doesn't know why because he didn't name it, the teacher's face becomes "hot red" (84). Arnold points out the irony that he had "never seen an Indian look that red," and wonders why they call Indians "redskins" (84). Mr. Dodge continues to try to humiliate Arnold, asking him to explain the process of creating petrified wood, and with each exchange Dodge becomes further incensed and demeaning. The exchange peaks with Dodge debasing Native culture as well as education. As the class snickers and points at Arnold giggling, Dodge says, "Where did you learn 
this fact? On the reservation? Yes, we all know there's so much amazing science on the reservation" (85). It isn't until one of Arnold's white classmates, Gordy, the "class genius," confirms Arnold's claim that Dodge believes him (85). This passage demonstrates collusion between race and history that produces not only an inequitable relationship, but also a profound absence; Mr. Dodge cannot see any value in Arnold's knowledge, in the reservation, or in Native culture.

Even isolated from Mr. Dodge and Reardan, Arnold struggles to know himself as a member of the Spokane tribe. He frequently looks back at cultural rituals with discomfort, a discomfort that interrogates the limits for "real." Arnold's description of the $127^{\text {th }}$ annual Spokane Tribe powwow celebration (a marker that speaks to both the tradition and relative recent documentation of the celebration) describes the event as a time of "singing, war dancing, gambling, storytelling, laughter, fry bread, hamburgers, hot dogs, arts and crafts, and plenty of alcoholic brawling" (17). Yet these rituals have no appeal for Arnold who wants "no part of it" (17). For Arnold the powwow is not just irrelevant because he does not participate in the rituals, it is also inaccessible because his experiences taught him that while the "dancing and singing are great," powwows also invite Indians who are "rhythmless, talentless, tuneless Indians" who "are most likely going to get drunk and beat the shit out of any available losers" (17). ${ }^{21}$ And Arnold is "always the most available loser" (17). Despite his friend Rowdy's promise of protection, Arnold ends up stumbling into the Andruss brother's camp and one of the thirty-year old triplets picks him up, dusts him off, and then knees him in the balls (21). In retaliation, Rowdy returns the favor and robs a cultural heritage from the brothers. He sneaks back into camp and shaves off

\footnotetext{
${ }^{21}$ Philip Heldrich argues that Alexie's work creates characters that exist within traditions and rituals that are: inaccessible, irrelevant, and eroded by a dominant culture that has stereotyped that Native body (28).
} 
the brothers' eyebrows and cuts off their braids, which is "about the worst thing you can do to an Indian guy" because it takes "years to grow their hair" (22).

Arnold's inability to participate in cultural rituals disconnects him from a notion of futurity based on his family's cultural history. Instead, Arnold has learned that he faces a choice between hope (and perhaps a different future) represented through opportunities off the reservation, and historical sadness of reservation life. One of the primary themes throughout Diary exemplifies the effort to find hope in a hopeless place, an effort often represented as a struggle between leaving and staying. Though Arnold's choice to transfer to Reardan is predicated on the debate between poverty and wealth (Reardan is described as a "rich, white farm town that sits in the wheat fields exactly twenty-two miles away from the rez"), the binary between rich and poor easily maps onto terms for white and Indian (45). The town is "filled with farmers and rednecks and racist cops who stop every Indian that drives through" (46). In one day, he tells readers, his father was stopped three times for a DWI, "Driving While Indian" (46).

The parallels between race and class extend to hope. Who has the most hope, Arnold asks his parents: "White people," they said at the same time (45). In their conversation about educational colonialism, Mr. P emphasizes that Arnold will have no hope as long as he stays on the reservation. "If you stay on this rez," Mr. P stresses "they're going to kill you. I am going to kill you. We're all going to kill you" (43). Mr. P suggests that there is no future on the reservation, and instead, Mr. P argues that Arnold needs to leave before Arnold cannot fight anymore. He insists that the "farther and farther" he walks from "this sad, sad, sad reservation" the more hope he will find (43). However, Mr. P fails to consider the importance of community as value for Arnold and the Spokane Indian tribe. 
In his attempts to persuade Arnold to leave the reservation forever, Mr. P emphasizes that people like Rowdy have already given up — though still a child, Rowdy has no future. Mr. P argues that Wellpinit is teaching kids how to give up — it's the "only thing you kids are being taught" (42). His admission underscores an institutional myth of the "vanishing Indian" that links hopelessness with a slow disappearance. Mr. P stresses: “All of these kids have given up. All your friends. All the bullies. And their mothers and fathers have given up, too. All their grandparents gave up and their grandparents before them. And me and every other teacher here. We're all defeated" (42). "You can't fight us forever," he cautions (42). Mr. P believes that Arnold's survival lies cultivating hope tied to leaving the reservation. He urges Arnold to imagine his survival as part of his lifelong trajectory; his success is imminent because he has already survived so much. Arnold's exceptionality is that he "won't give up" (42). Though Mr. P argues that Arnold has not given up, he encourages him to give up in another sense, trading hopelessness for hope by giving up his reservation community.

Mr. P's pleas inspire Arnold's departure, which creates a break between Rowdy and Arnold that moves their relationship into the more imagined world created in the comics of the diary. The relationship between Rowdy and Arnold provides a narrative of opposition that highlights Arnold's exceptionality and emphasizes the fluid boundaries between real and fantasized Indians. In some ways Rowdy and Arnold's lives parallel: both were "pushed into the world on November 5, 1992, at Sacred Heart Hospital in Spokane," both come from poor families on a poor reservation (17). But Arnold is born "all twisted broken and twisted," and Rowdy is born "mad" (17). Rowdy was "always crying and screaming and kicking and punching" (17). He "bit his mother's breast when she tried to nurse him," and he "kept biting her, so she gave up and fed him formula" (17). Arnold says he "really hasn't changed much since 
then" (17). In spite of his anger Rowdy is Arnold's protector, and Mr. P stresses that Arnold is the "only good thing in his [Rowdy's] life," the "only thing he hasn't given up" (42). Unlike Arnold, Rowdy better fulfills one type of caricaturized Indian; he is angry, he is hopeless, and he is going nowhere.

Unable to talk to Rowdy, Arnold writes back at him through comics and musings about the loss of his friend. Though the friends do have some contact (on the basketball court and through an email), Rowdy's anger defines their encounters. Previously his protector, Rowdy now targets Arnold on the basketball court. For Arnold's first game as a Reardan player, Arnold travels with his team to the reservation where he faces "Arnold sucks" cheers and snowballs filled with rocks (143). Arnold resents their motivation and says that "if those dang Indians had been this organized when I went to school here, maybe I would have had more reasons to stay" (144). No longer building relationships with his teammates, Arnold's understanding of their relationship can only exist in examples of the past. The narrative builds toward answering $\mathrm{Mr}$. P's call to break historical patterns and peaks with the second basketball game between Reardan and Wellpinit.

The basketball rivalry between Arnold and Rowdy represents Arnold's struggle to find balance between his Indian identity and the success he anticipates in leaving his community. Rowdy could just as easily be Arnold and vice versa; both live on the reservation, both live with violence and poverty, and both know their friendship helps them survive. What separates the two is the willingness and desire to leave. Players for rival basketball teams, their relationship on the court reflects the anger and resentment caused by Arnold's decision, a decision that is viewed as a betrayal. In their first game, Rowdy glares at Arnold from across the court and Arnold feels as though Rowdy wanted to "kill [him], face-to-face" (144). Arnold's coach encourages him to get 
mad and fight back, but just after he comes to the court someone throws a quarter at him from the stands and cuts his forehead open. Stitched up, Arnold returns to the court only to have Rowdy come from behind and smash his elbow into his head, knocking him unconscious. The same friend who had protected Arnold from hits to the head had now purposefully caused brain damage.

In spite of his injuries, Arnold rises to fame as a strong player for the Reardan team, which only increases the competition between him and Rowdy, who is also an impressive player. Before the game Arnold tells a journalist that he "never wanted anything more in [his] life" than to beat Wellpinit, a statement that reflects both his anger and his desire to establish success. On the court the two quickly begin to fight:

'Wow,' [Rowdy] said. 'You guys must be desperate if you're starting.' 'I'm guarding you,' [Arnold] said.

'You can't stop me. I've been kicking your ass for fourteen years.'

'Not tonight,' I said. 'Tonight's my night.'

Rowdy just laughed. (191)

Arnold steals the ball from Rowdy and makes a three point shot that establishes dominance; Rowdy and the Wellpinit team never recover. Proud, Arnold says that his team "killed the Redskins" and "humiliated them" (194). His statement fails to recognize the racist language he has acquired or the shift in identifying himself as part of the white community. Mid celebration he looks over and realizes that "two or three of those Indians might not have eaten breakfast that morning" and that "seven or eight of those Indians lives with drunken mothers and fathers" and that "One of the Indians had a father who dealt crack and meth" and "two of those Indians had fathers in prison" (195). He knew that "none of them was going to college" (195). Worse, he 
knew that Rowdy's father was "probably going to beat the crap out of him for losing this game" and suddenly he was "ashamed of [his] anger, [his] rage, and [his] pain" (196). Arnold runs out of the celebration and cries knowing that he had broken his best friend's heart. But I would argue Arnold also cries for himself, because he had irrevocably lost a connection to the tribe.

Despite the focus on Arnold, the narrative seems equally invested in saving the Indians left behind. Already in the process of vanishing, Rowdy and others like him appear to have no agency in determining their future except through repetitions of historical patterns. Moments such as Arnold's grandmother's unexpected death, his father's friend Eugene's drunken death, or his sister's tragic fatal accident, reiterate a Native story of death and dying that seems to suggest that nothing will change. As witness to this trauma, Arnold's diary speaks out in a testimonial that verifies presence—no matter how ugly or "stereotypical."

However, Arnold's relationship to the future is equally precarious as readers see in the final scene between Arnold and Rowdy playing one-on-one basketball. Rowdy tells Arnold that he has never beaten him in a game of one-on-one and Arnold says, "that's going to change" (228). But as the two begin to play they don't keep score. In delaying the change they know is coming the two also delay the future knowing that someday Arnold will leave. Rowdy tells Arnold that he "always knew" Arnold was going to leave, "always knew" he was going to "leave us behind and travel the world" (229). Arnold is an "old-time nomad" (230). Rowdy is the Indian that has been created by white colonialism, an imaginary Indian that cannot leave. Ultimately futurity is located not on or off the reservation, but in the effort to locate culture within oneself. The future suggested in this move allows the possibility for Native survival, but offers uncertain conclusions about who will be left behind and why. 
Arnold's narrative creates a paradox in which he verifies his authenticity as an Indian by witnessing and experiencing reservation trauma, but identifies exceptionality with his departure; he is the first in his family to leave the reservation. Yet, it's not his departure that is unique, but his ability to survive and succeed. Inspired by her brother, Arnold's sister also leaves, defying the expectations that she will disappear in her parents' basement. Her story ends in what might seem to be an all too familiar narrative about drunken Indians and death. In conflict with the relatively hopeful future Arnold secures with his departure are the stories of children who have no future, specifically his best friend Rowdy. Rowdy will never leave. Rowdy's story of anger, abuse, and alcoholism fulfills expectations about Native Americans and provide an allegory for Native peoples; Arnold's story writes back at Rowdy, telling him what he knows and does not know about what it means to be Indian and what it means to leave. Storytelling offers Arnold a way out of victimization by confronting the tragedies around him and showing that not all children survive.

Throughout the text Arnold is always headed away, toward hope, toward success, and Rowdy remains imprisoned in the present. Even Arnold, who wants nothing more than to find peace with his friend, must spend the year at Reardan imagining their friendship in memories of what they used to be: two superheroes, more powerful for their opposition and difference. Rowdy's most important role, however, is as secret-keeper for Arnold. Because the story is told from Arnold's point of view, and because it is structured as his diary, the narrative perspective is necessarily limited to what Arnold shares; it is his testimony to an unfamiliar life. However, Arnold often suggests that Rowdy is the person who knows him better than anyone, and as Arnold's secret-keeper Rowdy maintains Arnold's story, his silence memorializing the loss of childhood innocence experienced by him and his friend. 


\section{CONCLUSION}

Imbedded in the notion of futurity attached to the child is a larger claim for definitions of child and childhood. Critics of young adult literature argue that "teen fiction can be like a hall of fun-house mirrors, constantly reflecting back hideously distorted portrayals of what life is" (Gurdon). Megan Cox Gurdon argues that rather than validating "tortured” adolescent voices, texts like Diary "normalize pathologies" and "in the case of self-harm, may even spread their plausibility and likelihood to young people who might otherwise never have imagined such extreme measures" (Gurdon). In response to Gurdon, Alexie writes: "When I think of the poverty-stricken, sexually and physically abused, self-loathing Native American teen that I was, I can only wish I'd been given the opportunity to read The Absolutely True Diary of a Part-time Indian" ("Why the Best"). Their debate exposes a claim on childhood: what defines childhood, how we go about saving the child and childhood, and ultimately, which children are saved.

"They are trying to protect privileged children," Alexie argues, "Or the seemingly privileged" ("Why the Best"). Alexie promises the teens and preteens filling his mailbox with handwritten letters that he will write "more books about teenagers rescuing themselves from the adults who seek to control and diminish [them]" (Nygren 162; "Why the Best").

Gurdon's argument makes a claim for a normal child and childhood viewed through a lens of innocence, a paradigm that gained traction in Europe during the mid-1800s. Believed to be closer to nature because they lacked experiences with the corrupted adult world, the figure of the child became a focus for the modern family, particularly because the child's innocence promised possibilities for parental fantasies about the future. The presumed innocence failed to acknowledge diverse conditions shaping the child's life, the same conditions affecting adults and families. At the same time that Rousseau wants to naturalize childhood, cities were pushing 
children into factories and mines. As Alexie contends, Gurdon's child is much different from the Indian boy; Gurdon's innocent child is always already a white child. Furthermore, in establishing innocence as a condition of child Gurdon indirectly suggests that children exposed to adulthood are no longer children.

Diary confronts the figure of a child shaped by institutions interested in extending state claims for the "normal" child while simultaneously attempting to teach audiences what it means to be poor and to be Indian. Though childhood has always been complicated by diverse contexts (culture, environment, economic status, gender, to name just a few), public policies about the child have imagined and enforced a more monolithic child and childhood. For example, Eric Meiner highlights the role of the child in framing "transaction within the US carceral sphere" (121). He says that the flexible signifier "child" is "deployed in ways that elide" complexities, becoming both the reason for keeping and abolishing prisons (120). Historian Robin Bernstein describes the child as the "perfect alibi" because of its ability to "retain meanings but hide them under claims of holy obliviousness" (8). She emphasizes that the child alibi shields particular sociopolitical transactions, such as the racialized and hetero-gendered production of innocence, that creates the "ability to remember while appearing to forget" (8). The fluid and flexible sense of a child circles a nonexistent child, the normal child or childhood without trauma, pain, or adult contamination. Alexie confronts childhood innocence (or the lack of it) by teaching readers about the impacts of poverty.

Stressing his feeling of isolation and loneliness, Arnold tells readers that he feels invisible at Reardan high school: "I felt like an invisible mountain gorilla scientist" (156). On the same page, readers see a comic drawn on what looks like notebook paper of an invisible gorilla holding a test tube with a speech bubble that says, "So lonely..." (156). Underneath the image is 
the title: "Invisible Mountain Gorilla Scientist," a repetition of the surrounding text. Arnold calls attention to his loneliness more than once, a result of both his physical and emotional exceptionality. After throwing his text at Mr. P, Arnold thinks he will be in trouble when his teacher comes to visit. The nearby comic supplies an image to define what Arnold believes represents the world's smallest reservation, which gestures to both the text before the comic that claims his teacher Mr. P would not mind if Arnold was the only survivor of a plane crash in the Pacific Ocean and after when Arnold says that he thinks "at the very least" they would send him to jail (32). In the image Arnold is on an island with a single palm tree. He is figured from a distance with glasses and overly large feet sighing as an arrow points and explains that this is the “world's smallest reservation" (33). Arnold cleverly parallels jail and the reservation, suggesting that he is already imprisoned.

The suggestion of reservation as prison presents an important challenge to thinking about the impact of Native removal; in much the same way that prisons have disappeared black men, reservations have disappeared Indians. Arnold's isolation and feelings of imprisonment seem to parallel Rowdy's, but where Arnold fights with his mind, Rowdy fights with his fists. The dichotomy between the boys is less about difference and more about the paths toward survival and thinking about how might it be possible to escape. Though cultural narratives figure the child as the means of improving upon the past and link futurity to legacy survived through the child, on reservations (and in jails) childhood is always already missing. Diary's ongoing effort to reconcile Rowdy, who is set to vanish, with Arnold, who is poised to leave, wants to believe that hope lies in creating an active presence bound to both the reservation and what lies off the reservation. Storytelling provides the means of imagining that Rowdy (among others) remains a part of Arnold's life, which assures a tentative survival if only in narrative. Rowdy and Arnold's 
lives reinforce the stereotypes of Native lives, but their stories also write against the historical simulacra produced by constructed notions of the Indian. Ultimately, Rowdy and Arnold, in spite of being trapped within the fantasies of colonial imaginations, are both "real" Indians. 


\section{Chapter Two:}

\section{Lost Girls: Didactic Storytelling and Surviving the Legacy of Poverty}

"Two or three things I know for sure, two or three things I know for sure, and one of them is that to go on living I have to tell stories, that stories are the one way I know to touch the heart and change the world." Dorothy Allison, Two or Three Things I Know for Sure

“Just tell the truth,” Mom said. "That's simple enough.” Rose Mary Walls as written by Jeanette Walls, The Glass Castle

The year 2014 marked the 50 $0^{\text {th }}$ anniversary of Lyndon B. Johnson's "War on Poverty" and though Johnson's figurative notions of war imagined economic disparity as the enemy, his campaign depended on images gathered from one of the poorest regions of the U.S.: Appalachia. Widespread stereotypes about Appalachians assume poor hygiene, lack of education, and incest. Geographically isolated by the mountains and hollers, Appalachian culture and identity developed in response to financial hardship resulting from inadequate roads, sluggish industrial development, and most importantly, a version of colonialism that allowed large corporate interests to exploit mineral resources. ${ }^{22}$ Dorothy Allison's work (particularly her 1992 novel Bastard Out of Carolina) exemplifies the type of poverty Johnson hoped to combat with his welfare initiatives, but offers uncertain conclusions about successfully escaping poverty. ${ }^{23}$ Instead she argues that cultural entitlement masks the opportunities available to a select few. "The horror of class stratification, racism, and prejudice," she states, "is that some people begin

${ }^{22}$ See Lohmann's discussion of Appalachian poverty in context.

${ }^{23}$ Allison notes that she worked an afterschool job created by Johnson's War on Poverty in the introduction to Trash (1). 
to believe that the security of their families and communities depends on the oppression of others, that for some to have good lives there must be others whose lives are truncated and brutal; it is a belief that dominates this culture" (Skin 35).

The self-proclaimed "Roseanne" of literature, Allison explores the "inescapable impact of being born in a condition of poverty," a condition she says society finds "shameful, contemptible, and somehow deserved" (15). In interviews, Allison reiterates that her personal experiences and efforts to "survive" and escape her past have inspired characters that experience horrific forms of emotional, physical, and sexual abuse. Her novel, Bastard Out of Carolina, examines childhood memories of hunger and shame produced by life in 1950s rural South Carolina while cultivating links to social, political, and historical contexts that conditioned her family's experiences with poverty. Allison's fictional glimpse into Appalachian life and culture is followed by her 1995 memoir, Two or Three Things I know for Sure. As the title suggests, Allison's memoir - a metaphorical "second act" to the scene previously set in Bastard Out of Carolina - attempts to sift through the "two or three things" she believes she knows about her past to understand the impact of witnessing and experiencing trauma. The effects of chronic poverty cannot be separated from the complicated relationship with her "white trash" family, especially her mother who chose to remain married to the man who sexually and physically abused Allison and her sister. Though Allison professes a deep love for her mother, it was difficult for her to "reconcile her tangled feelings toward her" after her death (Jetter). Allison repeatedly states that storytelling provides a means of escape and the assurance of survival. While Allison offers uncertain conclusions about escape, Jeanette Walls, author of the 2005 memoir The Glass Castle, opens her book with every assurance of survival. Walls exemplifies the spirit of the 'admirable poor' having escaped childhood poverty by working her 
way through high school and college to build a Park Avenue career. She traces her journey from the deserts of the Southwest to the hollers of West Virginia, where her parents eventually settled in a vermin-infested shack without indoor plumbing or heat. In structuring her memoir around her family's movement, Walls provides environmental markers for the instability the children faced at home. Chronic homelessness (or what her father Rex called on the "skedaddle") fed Rex's obsession with building his family a glass castle, an impractical dream that juxtaposed his children's more pragmatic hopes for steady access to food and shelter. In a review of the book, Walls states: "You could look at the glass castle as another one of my father's drunken promises, or as hope for the future; it is whatever you choose to make of it" (Walls). In a separate interview Walls says that she can't be bitter or angry with her father because she "got the damn castle $[\ldots]$ and he and [her] mother gave [her] the tools to do it" (Witchel). Walls' choice to imagine her familial inheritance as a set of tools for future success obscures the impact of the trauma she experienced throughout her childhood. Her humble comments about her rise in fortune provide the perfect backdrop for a story about hope; however, she admits that she still fights a set of pathological impulses_-"bad habits"- that remind her of the past, such as nightmares about having to use a bucket for urination or repressing the urge to pocket room service leftovers.

Directly confronting the idea of "white trash," Allison and Walls account for material deprivation and regional stereotyping that constructed poor, Appalachian, white ethnicities. To survive adulthood these women wrote about their pasts using the memories filtered through the perspectives of a child figure. By recovering childhood memories to direct the story, these memoirs evoke a real child and childhood grounded in lived-experiences. However, in an effort to understand the impact of complex relationships with their parents and the institutional poverty 
that shadowed physical and social movement, child figures emerge to covey the relationship between the past and the adult perspective.

Though socially and culturally, the existence of the child and a period of development called childhood are regarded as fact, as both Allison and Walls show, there are no fixed definitions for the terms. Western society tends to define childhood as a biological phenomenon; however, as Susan Honeyman notes, the constructed image of the child and childhood serve more as a foil for projecting adult "nostalgia and desire" (2). Adult projections of childhood innocence not only reflect adult loss, but also rely on monolithic experiences of childhood and ignore the very important ways that class, ethnicity, geographic region, religion, race, and gender play in creating and defining space for childhood (Mintz 33). Not unlike other terms used to discuss identity, the child and childhood have been influenced and constructed by a set of ideals that fantasize about heteronormative, rich, white child. The ideal child construction buttresses patriarchy through a narrative of innocence crucial for continuing paternal control and law, particularly through the use of female bodies. This construction creates an inflexible bind in which women are both powerless and responsible, denied childhood and yet almost predestined to continue the cycle by becoming the parent to the child. Child figures provide commentary that juxtaposes the feeling of lost girlhoods while exposing cultural hypocrisy about privileged childhoods.

In addition to the social and financial limitations, there is an inherent melancholy in their memoirs drawn from interrupted girlhoods and the gendered conflicts they witness, especially the influence and impact of their mothers. Despite the contradictions, both Walls and Allison use storytelling as a source for healing and strength to talk about their families. In both memoirs, the narrative voice is fragmented by memory, story, and adult perspective. This adult perspective 
understands the precariousness of white privilege and of childhood itself. These writers use a relationship with the past and didactic performances to call attention to the act of storytelling as a necessary means for survival while depending on the child figure to assert new claims for the future.

\section{'WHITE' TRASH: REGIONAL HISTORIES \& THE SHADOW OF POVERTY}

Though contemporary audiences tend to use the term "autobiography" interchangeably with "memoir," historically memoirs have operated as a supplement to life-writing. A loose definition of memoir isolates the genre by emphasizing the narrator's role in offering perspective on the lives and actions of others within a social environment (Smith and Watson 274). In externalizing subjectivity, Lee Quinby argues that memoirs promote an ideographic self, a subjectivity that refuses particular forms of "selfhood, knowledge, and artistry that the systems of power of the modern era (including the discourses of autobiography) have made dominant" (298). Quinby highlights that scholarship tends to eschew memoir in favor of autobiography, targeting the autobiographical 'I' as "instrumental in establishing autobiography as a privileged aesthetic" and relegating memoirs to a "marginalized status" (299). Contrary to the lack of scholarly attention, markets have seen a sharp rise in memoir, particularly "misery memoirs," which focus on 'documenting the writer's 'inspirational' triumph over childhood abuse and trauma" and share with reality television the "construction of a reality which is both codified and commodified, both 'real and 'fantastic,' at the same time" (Anderson 115). Misery memoirs appeal to audience's desire to identify with hardship while at the same time maintaining the assurance of a safe ending — or as Tim Adams suggests — assurance of survival (Adams "Feel"). Further emphasizing the importance of survival, John Crace sardonically points out that the "art" of the form is to "portray yourself as a victim whilst selling yourself as a survivor" (Crace). 
While autobiography reveals the lives of the successful - the "great" men-memoirs unearth secrets.

Predestined by historical poverty endemic to the Appalachian region, the Walls and Boatwright families' opportunities for growth and self-determination are limited by the cultural stigmatism tied to the term 'white trash.' While the term 'white trash' is not limited to individuals from Appalachia, regional stereotypes about rural poor exemplify the pairing of race and class identity. Used to belittle and shame individuals for their poverty, the term 'white trash' provides an important recognition of an in-between status: white, but not good enough to be white and therefore trash. Allison notes in the introduction to her short story collection Trash, she continued to feel the effects of her "white trash" background even after she had moved out of the South to secure a college education and start a career. She writes,

By day I played at being what the people who were training me thought I was - a college graduate and a serious worker, a woman settling down to a practical career with the Social Security Administration. I imagined that if I played at it long enough, it might become true, but I felt like an actress in the role for which she was truly not suited. (xiii)

A refrain in Allison's work has been this tension between her past and present, where she came from and where she might go.

Long before Johnson's campaign, terms like "white trash” marked class difference. Though etymologically the term "white trash" began as a Black slave designation for White servants, late $19^{\text {th }}$-early $20^{\text {th }}$ century eugenics proponents adopted the term in their efforts to prove that rural poor whites were genetically defective. Nicole Hahn Rafter contends that the central image in their study was the "degenerate hillbilly family, swelling in filthy shacks and 
spawning endless generations of paupers, criminals, and imbeciles" (2). Despite the rejection of eugenics following WWI and WWII, stereotypes about rural poor Whites as "incestuous and sexually promiscuous, violent, alcoholic, lazy, and stupid" have remained (Newitz and Wray 2).

The designation "white trash" implies not only class connotations, but also geographical location as well. In revealing the poverty of the Appalachian Mountains, Johnson further bolstered the image (however false) of wealthy urban centers. These separate places produced different poverties and different types of poor people, but even locally, within Appalachian communities, terms like "white trash" helped designate areas where poor whites lived. For example, Allison notes a distancing between whiteness and poverty stating that she was "born trash in a land where the people all believe themselves natural aristocrats" (32). "Ask any white Southerner," she writes, "they'll take you back two generations, say, 'Yeah, we had a plantation"”(32).

What Allison describes abstractly, Walls represents concretely, particularly in terms of racial divisions. In Welch, West Virginia Walls knows that there are certain times when blacks use the pool (the free hours in the early morning), and certain times when whites use the pool (in the afternoon when they charge 50 cents per swimmer). However, Walls knows she can't afford to go to the pool in the afternoon and asks her friend if anyone would be mad if she went during free hours. Dinitia answers: "Your kind might, but we won't. And your own kind won't be there" (190). Segregation is not just for public spaces, but also divides community neighborhoods. When Walls attempts to fix up their house in Welch, WV, telling her mom that it would "help them fit in a little," her mother refuses: "I'd rather have a yard filled with genuine garbage than with trashy lawn ornaments" (157). Both Walls and her mother acknowledge that there are visual 
and spatial indicators for class, but they disagree about how to define what exactly makes their home "trashy."

Despite certain fixed geographical and regional indicators of poverty, both Allison and Walls' memoirs reveal a relationship between poverty and movement. The lack of placespecifically a permanent family home — contributed to familial discord and further cemented their lower-class status. In an essay in Skin, Allison writes that in spite of her stepfather's work as a route salesman and her mother's multiple jobs waitressing, laundering, cooking and fruit packing, they never have enough money. To escape debts and creditors the family frequently packed up and moved. One time her parents schemed to make it look as though her stepfather had abandoned their family but instead he "went down to Florida, got a new job, and rented us a house" ("A Question). He returned in the middle of the night with a moving van and packed the family up and left. In the Walls family this was known as the "skedaddle." Walls writes that her father would drive slowly in the middle of the night "so as not to alert anyone" and her father would grumble because he "couldn't understand why the hell it took so long to grab what we needed and haul our asses into the car" (17). However, neither family could ever move away from their poverty.

Both families brought the issues of poverty with them such that even if their home was in a nicer community or held the promise of a longer stay, the living situation quickly deteriorated. For Allison the near constant movement was not just related to her family's finances but also to her stepfather's volatile temper. Physically abused and molested from the age of five, she needed to leave the space of her home for safety. Sometimes her mother would move herself and her children out of the home and away from the abuse, but she always returned. Allison emphasizes that her family wasn't just economically poor, but socially poor; everyone in their community 
knew the Gibsons. Poverty came with the name. She remembers a new teacher, a substitute fresh out of college, who assigned a family tree project. When Allison asks about her family or the family Bible, her aunt's and mother recognize instantly recognize the social faux pas, and tell Allison, "this girl an't from around here. Is she" (10). They warn her that "parentage around here is even more dangerous than politics" and provide only cursory answers to her questions about the Gibson children (10). Family names alert the community about the Gibson men who went to jail and became "hard-faced men" (28). Allison explains in Skin that it wasn't until her family moved to Florida that she escaped the rigid class structure of South Carolina where "everyone knew [her] family, knew [they] were trash." (20). In Florida she found "normal" in an anonymity that allowed her to boosted to college-track courses and earn a grudging respect for "who [she] might become" (21).

White trash stereotypes serve as a "useful way of blaming the poor for being poor," according to Annlee Newitz and Matt Wray, emphasizing, like Allison, that "Americans love to hate the poor" (1). Writing about popular culture images of poverty, May Friedman admits that White trash culture can be difficult to define; however some of the "agreed upon characteristics involve poverty" and intrinsic character flaws, such as "laziness, offensiveness, poor choices" (85). Friedman draws attention to a pervasive cultural narrative that emphasizes the role choice plays in determining poverty, an indirect message claiming that those who make better choices must not be poor. Although Allison accepts her background, she rejects the term "white trash" because it has been used to differentiate white poor from poor. In the opening essay to her collection of short stories, Trash, Allison defines her own experiences growing up poor and white in South Carolina: 
My family's lives were not on television, not in books, not even comic books.

There was a myth of the poor in this country, but it did not include us, no matter how I tried to squeeze us in. (1)

She acknowledges the absent images of White poverty in the American class lexicon, which made it that much more difficult for her to understand her and her family's displacement.

However, Allison also knows that a term like "white trash" works to distance whites from poverty. Originally Allison chose to claim the label "trash" in self-defense, in reclamation of a word used to describe herself and her family in "crude and hateful ways" (xv). As an adult Allison noted the "look that would cross the face of any black woman in the room when that particular term [white trash] was spoken," and she knew that "some phrases cannot be reclaimed" (xv). Terms like "white trash," "redneck," and "hillbilly"—all of which signal white poverty—continue to circulate as titles that "inscribe" a "charged form of difference marked off from the privileges and powers of whiteness" (Hartigan 95).

Stories like Allison's and Walls' expose the conditions of white poverty and uncover the hypocrisy embedded in the United States "myth of classlessness" by sharing the powerful conflicts between individuals, families, and external institutions (Newitz and Wray 1). Understanding poverty begins with seeing the "precarious relationship to the routines and benefits that cement social order in the broader society" to "ensure that [the poor] do not become disruptive" (Fording et. Al. 1). The structural support provided by those who live and work in poverty helps masks systemic upper and middle class privilege. Working in tandem with the rise in neoliberalism organizing principles, the government, according to Fording et. Al., adopted increasingly more paternalistic patterns in "governing the poor" (2). Various social institutionsschools, prisons, child and adult protective services - manage and "transform [the poor] into 
cooperative subjects of the market and polity" (2). In her memoir Allison comments that her uncles and male cousins were frequently jailed. "My uncles," she says, "went to jail like other boys go to high school" (28).

Walls's memoir exposes additional institutional interventions, such as the child welfare system. Walls writes that she hated that "child-welfare" man more than everyone except her grandmother Erma. Already conditioned to fear government officials, the Walls children faced a visit from child welfare as a threat, telling the balding man that he needed to call the non-existent family attorney. The official explains that he is following up on an anonymous call about child neglect. Walls tells him, “no one's neglecting us,” and confirms that her parents work. Her father, she says is an entrepreneur developing a technology to "burn low-grade bituminous coal safely and efficiently" and her mother is an artist, writer, and teacher (193). The scene offers much to consider: the neighbors surveillance, the police-state used to discipline based on social and cultural values, the limits for private space as well as the limits for public interference, and failure of these systems for providing help to this family. Visits from child welfare left the family more vulnerable; Walls writes: "At least when Ernie and his gang came around yelling that we were trash, we could fight them off with rocks" (194).

Despite her clear distrust of child welfare, not all of her experiences with institution end poorly. Bright and capable, the Walls children thrived in public schools while they lived in the Southwest. Schools often supplied environmental protection from harsh weather, food, and occasional recognition for their talents rather than infamous social and familial histories. Sadly, returning to Welch, West Virginia meant returning to a region where the consequences for their family's difference were immediate. Walls remembers that the principal looked at she and her 
brother, with their "unwashed hair" and "thin desert clothes" and " his face took on a sour, skeptical expression" (136). He said:

"Wuts et tahm sebm?"

"Excuse me?" I said.

"Et tahm sebm!" he said louder.

I was completely bewildered. I looked at Mom.

“She doesn't understand your accent," Mom told the principal. He frowned. Mom turned to me. "He's asking you what's eight times seven."

“Oh!” I shouted. "Fiftysix! Eight times seven is fifty-six!" I started spouting out all sorts of mathematical equations. The principal looked at me blankly.

"He can't make out what you're saying," Mom told me. "Try to talk slowly."

Unable to understand one another, the principal assumes that the dirty children are "slow" and places them both in remedial classes. Throughout their first day of school Walls faces adult and peer bullying for being a stranger, which only increases when the town discovers the return of Rex Walls. Walls quickly discovers that she is neither welcome to befriend the Black girl (a bully who respects Walls willingness to fight), nor any of the white students who see her only as "white trash."

Identifying what it means to be "white trash" means acknowledging the ever-shifting terms for race. John Duvall locates this shift in what he calls the "whiteface minstrel," a literary figure who is Caucasian, but not white. Duvall's work examines characters who "lose their claim to Southern Whiteness in the very moment their race becomes visible," where whiteness becomes "colored" (xvii). Duvall's focus on fictional characters can easily extend to consider the 
way race conditions social privilege. Allison openly recognizes the marginal status of her people:

"Peasants, that's what we are and always have been. Call us the lower orders, the great unwashed, the working class, poor, proletariat, trash, lowlife and scum" (1). Allison's list highlights the association between "trash" and "work," suggesting that to be white means not "working." Yet women in Allison's family were predestined to be "solid, stolid, wide-hipped baby machines;" "workhorses with dull hair and tired eyes" and dumb wide faces (33). Her description couples work with beasts, which echoes language used to describe black slaves in the South. The term "white trash" purposefully distances whiteness from blackness by removing a claim for whiteness with the additional designation "trash." In other words, the term provides a colored identity to remove the chance of destabilizing the primary claim for whitenesssuperiority.

Allison's unease with the term "trash" is echoed in Walls" text, specifically in relationship to the way others look upon the Walls' clothes, cars, homes, and worst of all, her parents irresponsibility and neglect. Beyond the naming of 'trash,' Walls recognizes a state of being trash in West Virginia, which she associates with their open garbage pits, their missing school lunches, or their ill-fitting or ragged clothes. For example, Walls asks her parents what they are going to do about their nearly full garbage pit, and her mother responds: "Enlarge it" (157). Walls demands consideration of the neighborhood's opinions, but her mother dismisses her concern telling her that life is too short to care what others think. The margins between the two women's perspectives reveal an important difference in how each perceives the impact of the conditions of poverty based on the limits each has set for public versus private understandings of identity. For Walls the recognition of poverty and identification as "trash" fuels her desire to escape what others recognize as poor. However, escaping the impacts of 
poverty, she notes in the preface to her memoir, go beyond fiscal success. Pilisuk, acknowledging the paradox of poverty, states: "there is hope that certain poor people will escape their ghettos and move on the road to middle-class standards of living [but] there is less hope that our society will permit poverty to disappear" (11).

The word "trash" not only invites inquiry about "who the term glorifies as well as who it disdains," but also about the literal ways trash figures into their family's survival (xvi). In Walls' memoir the idea of trash is explored both metaphorically and literally. Walls provides multiple scenes in which trash provides resources: heat, food, furniture, and once, when the kids dig a diamond ring out of the trash hole, even wealth. She contrasts memories of warming herself by trash-can fires with descriptions of the creation of their home and family life. She recalls: "we couldn't afford to pay the town's trash-collection fee, our garbage was really piling up. One day dad told us to dump it in the hole" (155). The hole had been dug to lay the foundation for the dream house designed by her father — the glass castle — and though her father promised otherwise, Walls and her brother watched their hole slowly fill with garbage. Trash defined Walls' life. She and her siblings scavenged meals from industrial garbage cans and discarded school lunches. They used leftover cardboard and rope pieces to construct beds. They used trash to buy things; Walls writes, "The leak in the roof over Brian's bed had gotten so bad that when it rained he slept under an inflatable raft Mom had won in a sweepstakes by sending in Benson \& Hedges 100s packages we'd dug out of trash cans" (237). The physical remains of other people's lives provided the means of survival for the Walls children, furthering confirming their own social status as "trash." 
Allison's work exposes identities constructed by ideas about what it means to be "trash" and "poor," which parallel the terms "bastard," "daughter," and "white woman" and suggest that poverty isn't just a matter of economics. The organization and governance of family (and by extension the legitimization of children and childhood) developed in response to multiple factors - geographical location, religious upbringing, and economic conditions — as well as individual identities such as race and gender; but culturally, Southern Appalachian regions continued to rely on systemic paternalism to organize social, political and familial bodies. Without the security of a father and family name, Allison recognizes that the "central fact of her life" is that she was born "in Greenville, South Carolina, the bastard daughter of a white woman from a desperately poor family" (Trash 1$)$.

Allison turns to storytelling to better understand her history and family, which ultimately allows her to reconstruct a "loved version" of her life (Two or Three 3). The repetition of "two or three things I know for sure" (a phrase that acknowledges familial silences and loss) confronts her past while signaling that there are "things" she does not know. Rather than escaping poverty and the history of 'white trash,' Allison instead recovers stability in a repetitive motion of circling back into the past while asserting that she is the only one who can tell the story of her life (70).

Allison's direct confrontation with poverty contrasts the ways in which her narrative performance repeatedly defers what she suggests is the "real" story:

I'm only suppose to tell one story at a time, one story. I don't do that. I never do. Behind the story I tell is the one I don't.

Behind the story you hear is the one I wish I could make you hear. 
Behind my carefully buttoned collar is my nakedness, the struggle to find clean clothes, food, meaning, and money. Behind sex is rage, behind anger is love, behind this moment is silence, years of silence. (39)

Allison's memoir draws attention to narrative performances in which there is a doubled ' $\mathrm{I}$ ' - an 'I' related to the storyteller and an 'I' related to the act of storytelling. In the passage above, Allison makes clear that the story we see and hear is only one part of another story, or alternatively, one performance masks another. Allison expressly and self-consciously controls the prose narrative, a didactic performance that uses multiple stories to teach audiences about diverse childhoods.

Allison's efforts to control the narrative help determine how and when readers interact with the child and show the ways in which definitions for the child and childhood are conditioned upon gender and class. As the women in her family become more man-like, the men in her family become more child-like. Allison writes that men and boys are "all the same" (36). Lacking opportunities for education and gainful employment, the men seem to take advantage of a family structure that reverses constructed gender roles; women assume responsibility for their families, while men remain child-like, joining the ranks of the actual children. The burden renders women nearly unrecognizable, and certainly unrecognizable as children, instead they are "dogs," "bitches sprung full-grown on the world," who were "never girls, never little babies in [their] daddy's arms" (36). Sex and labor erode childhood; it "turns [women] into jokes 'cause we get worn down and ugly" (36). And men "never look at themselves," she concludes, "never think about what they're doing to girls they've loved, girls they wore out" (36).

The narrative 'I' frequently alludes to a relationship between the adult narrator and the child figure, a means for recalling painful contradictions for what it means to grow up to be 
Gibson man versus a Gibson woman. Though Allison concentrates on her own experiences and those of the women in her family, she also acknowledges that to be a Gibson man meant a different fate; the "tragedy of the men in [her] family was silence, a silence veiled by boasting and jokes" (28). Gibson men carried a "sharp glint of pain in their eyes," a "restless angry way they gave themselves up to fate" (28). In photos her uncles stare directly at the camera, arms crossed or braced on knees. Allison finds them "beautiful and frightening, as dangerous for those quick endearing grins as for those fast muscled arms;" the men were "too tall, too angry, and grown up way too soon" (28). Allison consistently pairs her uncle's and cousin's manhood with boyhood, suggesting that the men in her family never grew up but "seemed in a matter of weeks" to adopt sharp smiles, their hands "always open and ready to fight" (28). "Just boys," her aunt Mattie Lee said of them; and Allison concludes that they remained so all their lives (29). Trapped by economic limitations, the Gibson men never seem to settle into love, life, or themselves. Allison notes that of the two or three things she knows "one of them is that no one is as hard as my uncles had to pretend to be" (sic 32).

The hardness that Allison recognizes in the gendered performances of the men in her family juxtaposes her previous conclusions that her uncles and cousins would remain children all of their lives, indirectly interrogating cultural definitions for child (and by extension childhood). Contemporary mainstream definitions of childhood frequently emphasize innocence; however, Puritan legacies that fixated on original sin, childhood corruption, and the need for institutional correction remain undiminished (Mintz 10). Allison's descriptions of childhood shift between an imagined cultural understanding of childhood and experiences of childhood rendered almost unrecognizable by poverty, abuse, and trauma. 
Children haunt the text even when the narrative voice maintains an adult perspective. No scenes are more poignant than those where Allison attempts to reconcile the loss of innocence, a common marker for determining the shift from child to adult. Describing a picture of her mother at fifteen, Allison repeatedly returns to the image of a child, her mother's "white socks and an Aline skirt, hair in a Kitty Wells cloud, schoolgirl blouse, Peter Pan collar, and the most hesitant smile," all of which contrast with the revelation that in the photo she is also pregnant (20). Visually her mother's childhood could be confirmed with a gendered and child-like appearance, emphasized by perhaps one of the best allusions to perpetual childhood, Peter Pan; however, physically, the pregnancy, and in fact the sexual intercourse that preceded it and the menses that preceded the intercourse all provide physical indicators commonly associated with the end of childhood. For the women in Allison's family the end of childhood comes swiftly, arguably even before physical changes signal difference, and young girls become women before they are ready. Allison writes that "men wanted [her] mama, wanted her before she knew what that meant, when she was twelve, thirteen, still a child" (20).

Sexuality and sexual intercourse exposes the limits of social definitions for the child and childhood, particularly because heteronormative discourse depends on fantasies about childhood innocence (and conversely potential endangerment) to inform public regulatory policies. Interested in cultural fear in relation to public sex, Michael Warner and Lauren Berlant point out that the familial model of society "displaces" the recognition of inequity and masks the nostalgic mechanisms feeding a national fantasy dependent on the fetus and child "spectacularly elevated to the place of sanctified nationality" (550). Denied sexual agency, childhood has been coopted by a political agenda more interested in the "repression of queer youth," according to Pat Califia, than in examining the institution responsible for the majority of child abuse- "the heterosexual 
nuclear family" (57). Social investment in heteronormative familial structures helps preserve sameness, what Lee Edelman explains as an "erotically charged investment" in maintaining the "compulsory narrative of reproductive futurism," through monolithic constructions of childhood invested in false notions of innocence.

As Allison reveals, her childhood was always already in danger of corruption. She remembers the pretty high school girls wearing fashionable hairstyles and clothes with "with virgin pins on the right side," but notes that she and her cousins "were never virgins, even when [they] were" (36). Allison's indirect pairing of virginity with childhood innocence casts a shadow on separation between child and sex, if only to highlight the marginal space for the "sexed" child. And while her male cousins were allowed to remain boys forever, the women in her family seem to have had little to no childhood at all. Highlighting the gendered experiences of childhood poverty advances important concerns about the way sex and sexuality contribute to the trauma both Allison (and Walls) faced throughout their lives.

Allison struggles to come to terms with a childhood that did not fit the definition of childhood, in part, because her step-father starting molesting her at the age of five. The narrative moves between what sex means to a child and what it means to an adult. She emphasizes that "it was the rape of a child," but follows her direct statement by asking-"How could it have been different for a five-year-old and a grown man" (42-43)? Her struggle is further intensified by a culture that denies rape with an insistence that women invite abuse. Adopting the voice of a nameless football player, "boys who went on to marry and do well," Allison images the rape of a teen girl behind the high school bleachers: 
'Hell, it wasn't rape. She never said no. Maybe she said stop, but in that little bitty voice, so you know she wants you to love her, hell, love her for ten minutes or half an hour. Shit, who could love a girl like that? (36)

Allison adopts the voice of a boy who is convinced that rape is not rape and that abuse is wanted because the girl did not say no, or rather that she didn't say no forcefully enough, or loud enough, or with the right voice. The boy is able to infer her desire from her "bitty voice," equating emotional love with physical sex.

Tied into her reflections about sexual abuse are indirect statements about notions of beauty, femininity, and by extension, womanhood, which Allison uses to imagine the passing of childhood in her own family. Allison notes that "beauty is a hard thing" and a "mean story," foreshadowing the effects poverty will have on the women in her family (37). Admittedly jealous of her sister's appearance, Allison also recognizes her sister's beauty. She writes that beauty "divides she and her sister Anne" and that it took her "years to learn the truth behind that lie" (78). Though Allison believes her "ugliness" invited abuse, as an adult she and her sister talk about the ways that being beautiful was about hatred too, a hatred that "trailed over her skin like honey melting on warm bread" (78). Allison's descriptions remember childhood feelings of jealousy while maintaining adult reflections capable of recognizing the complex consequences for beauty.

Like Allison, her younger sister Anne experienced abuse, both from her father as well as from men eager to take advantage of her beauty, arguably enhanced by her youth. Allison imagines her sister's childhood was worn away by "boys sneaking over to pinch her breasts and whisper threats into her ears, of girls who warned her away from their brothers, of thin-lipped adults who lost no opportunity to tell her she really didn't know how to dress" (79). Anne's 
beauty did not save her from being labeled as "another piece of dirt masquerading as better" (79). To be poor and beautiful did not earn Anne any social credit, and instead, the worth of beauty was measured and doled out swiftly after she dropped out of high school and fell in love with a boy who "got a bunch of his friends to swear that the baby she was carrying could just as easily have been theirs as his" (79). By eighteen Anne was "no longer beautiful, she was ashamed: staying up nights with her bastard son, living in my stepfather's house, a dispatcher for a rug company, unable to afford her own place, desperate to give her life to the first man who would treat her gently" (79).

The faces of the women in Allison's family reflect their poverty and a labor of a life dedicated to caring for others. "We are the ones in the background with our mouths open," Allison writes, "in print dresses or drawstring pants and collarless smocks, ugly and old and exhausted" (33). Her descriptions confirm what social scientists recognize as one of the pervasive consequences of poverty—it ages you. In her survey Faces of Poverty, Jill Berrick explores the physical impacts of life on welfare ranging from poor housing to exposure to violence to early pregnancy; she concludes, "living in poverty is hard on children" (63). Scholarship reveals that poverty decreases life expectancy by as much as twenty years (Crimmins et. al. 290).

Allison sees aging in faces of the women in her family, a reflection of their impoverished lives. In contrast with the childhood beauty, the women in her family quickly age into adulthood; they were "measured, manlike, sexless, bearers of babies, burdens, and contempt," the type of women in photos taken at "mining disasters, floods, fires" (33). Allison argues that "beauty is slender girls who die young, fine-featured delicate creatures about whom men write poems;" she and the women in her family were not beautiful or living a life of leisure, they were "hard and 
ugly and trying to be proud of it" (37). Her images confront the effects of a traumatic life, a life of labor, of poverty, a life where you are limited by an oppressed identity, a life that extinguishes the opportunity for childhood innocence quickly.

Stressing loss and missing girls, Allison returns to the image of the girlchild and childhood in an attempt to recover from trauma. As an adult she shares that she "attracts" broken girls and that she herself has never grown up (50). "Somewhere inside me," she says, "there is a child always eleven years old, a girlchild who holds the world responsible for all the things that terrify and call to me" (71). This is one key to the child figure embedded within Allison's narrative voice. The adult narrator knows there is a child holding the world responsible. Allison also knows that there is also a teenager inside her who fought back.

Other moments offer conflicted understandings of childhood, moments when she talks to her sister Anne and tries to work through what it meant to have a beautiful sister, who she could not and who could not save her. Moments when her niece comes to ask if her mother is alright, and Allison feels as though she is once again in the kitchen of her childhood asking her own mother the same question - the cycle repeats; both say "Oh, girls, you know how your mama gets" (82). In a way that no other scene does, Allison's recognition of the cycle of poverty and the experiences related to the condition of poverty provides a definition for childhood unique to her situation and life.

For the women in Allison's life, childhood ends when the child becomes the mother, which too often ends childhood abruptly, before girlhood has ended. It also happens when mothers die and daughters assume the role of matriarch. Allison describes the way her sister Wanda takes over at their mother's funeral, they way she was "being Mama, doing what Mama would have done, comforting us the only way Mama had known to do" (16). And Allison knows 
that they had all "become Mama" (16). Despite this recognition, Allison ends her memoir with the remains of a painful past. In the final scene of the text she describes a dream and in the dream she is old and her injured eye has tears and she must face a brick wall. Each brick reiterates a trauma - bastard, her mother's pleas to treat her daughters kindly, photos from the past (94). Amidst the recycled traumas is the voice of a child, giving voice to a child figure that has all along haunted the text. Drawing her out of the past are her son's cries, his demand for his own mama.

\section{TRUTH-TELLING: WALLS \& ADULT CHILDREN}

Walls opens her memoir with the suggestion that she is struggling between two subjectivities: her adult identity, related to her successful journalism career, and the private, secret identity related to the vagrant mother she sees in the trash. In the prologue, she writes that in New York she was "overcome with panic" that her mother would see her and call out her name, and that "someone on the way to the same party would spot us together and Mom would introduce herself and my secret would be out" (3). At the end of the scene Walls confronts her mother about her unconventional lifestyle, wondering how to tell people about her past. Rose Mary insisted that her daughter is "too easily embarrassed," says that she should just tell the truth (5). Rose Mary's clear-cut notion of truth establishes an important contrast for Walls' story, immediately calling attention to the disparity between Rose Mary and her daughter's perspectives as well as challenging the relative narrative truth of the author.

Throughout the memoir, Rose Mary's understandings of truth, poverty, and safety normalize the dysfunction Walls witnesses. The prologue establishes Walls' conflicted sense of self related in part to the need to grant permission to write her version of her life's story; but, more importantly, sets up the memoir as an ongoing (albeit literary) conversation between Walls 
and her mother. Rather than asserting the presence of the child through child figures, Walls suggests that her mother and father's unorthodox life-style resulted in a role reversal that precluded childhood for the child and elongated childhood for the adults. Thus, child figures in her memoir are manifested not only in her efforts to reconcile what she witnessed throughout her childhood, but also through descriptions of her child-like parents.

Like Allison, Walls emphasizes the ways in which poverty shaped her childhood by increasing her responsibilities and forcing her to occupy a more mother-like role. In the opening scene of the memoir, Walls describes a fire that burned her arms and led to her hospitalization for several days. The fire was the result of her cooking hot dogs for dinner; she was three years old. Her descriptions of childhood often reflect the absence of a child while emphasizing her mother's child-like qualities, such as her "childish glee when she found something she liked" or child-like denial of responsibility in acts like keeping a diamond ring when her children starved, hiding half-eaten candy bars because she was a "sugar addict," or forcing her children to wake her in the morning for work as she whined "why can't I do what I want to do" $(3,174,74)$ ? Even Rose Mary herself imagines her children as the adult or "mothers." Begging for a change to their situation Walls complains that they had not eaten anything but popcorn for three days, to which Rose Mary replies, "You're always so negative; You remind me of my mother-criticize, criticize, criticize" (187).

With their refusal to accept the obligations of adulthood, Walls' parents shift the responsibilities of adulthood to their children. Walls reiterates the ways in which she and her siblings managed the health and welfare of the family: grading her mother's papers from her teaching job, caring for a new baby in the back of a moving van, planning a budget, foraging for food, and even applying for jobs for their mother. The reversal of responsibilities was due, in 
part, to her mother's philosophies about child rearing; she claimed, "people worried too much about their children" (28). Rose Mary argued that "suffering when you're young is good for you," it "immunized your body and soul," ignoring crying children was good for them because fussing over crying children only provided "positive reinforcement for negative behavior" (28). Denying any social or psychological need for childcare, Rose Mary in effect denies her children a childhood.

Rose Mary and her husband Rex don't just deny their children a period of emotional innocence, they also deny them physical innocence. Their lifestyle choices (commonly interpreted as child-like) are often impulsive and fail to consider consequences. Poverty frequently led the family into less safe spaces, places where the Walls' children worried about "perverts." In some neighborhoods this meant "shabby, hunched men with wheeling voices" following them to and from school, trying to give them boosts up fences or offering candy or loose change to go play with them (102). Though Walls feels empathy for the men and worries that her refusals might hurt their feelings, she also wakes up to "someone running his hands over [her] private parts" when she is ten years old because her parents don't lock any doors (103). The man groping her tells her he just wants to "play a game" with her and she recognizes the voice as a man who had given her brother a magazine called "Kids on a Farm, with pictures of boys and girls wearing only underpants" (103). After that the kids decide to go "Pervert Hunting," which she says replaced Demon Hunting, shifting the imagined enemy to a "real and dangerous" enemy no longer the "product of a kid's overactive imagination" (103). Both Rex and Rose Mary encourage their hunts; they are proud of their efforts to take charge. However, they fail to realize the dangerous atmosphere they had introduced. 
Sadly, moving in with Rex's parents did not reduce the danger; perverts were not just strangers. After moving to West Virginia, the Walls are forced to live temporarily with their father's mother, Erma and their uncle, Stanley. Walls catches Stanley masturbating in her presence and knows that she needs to give him wide birth. And it's not only Walls and her sisters who face perverts. After hearing her brother's cries from a bedroom Walls walks in to find her grandmother "kneeling on the floor in front of Brian, grabbing at the crotch of his pants, squeezing and kneading while mumbling to herself and telling Brian to hold still goddammit" (146). Seeing her brother's tears Walls screams at her grandmother to leave him alone, calling her a pervert. Her grandmother denies her abuse and tells her that she and her sister are "bitches" and "lying little whores" (146-7). When Rex hears about the situation he directs his anger at his children, and in a rare moment, disciplines them for disobeying their grandmother. However, he also stresses that the children are not children, telling Walls and her siblings that their brother Brian's "a man, he can take it" (148). Walls suspects that her grandmother may have abused her father as well, concluding that sexual abuse would provide a reason for his drinking and his ugly feeling about Welch. In scenes like this the child figure lingers unresolved, despite the presence of the child. Walls maintains an adult voice connected to scenes she witnessed as a child, a move that testifies for a unmitigated loss.

Walls not only accounts for personal loss, but the loss of children in her neighborhood, particularly her friend Dinitia. Friends in middle school, Walls notices that Dinitia changes when she starts Welch High. She says that the "spark had gone out of her" and that she "started drinking malt ale during school" (199). Though she tries to help, Walls is only able to find out that Dinitia's mother's boyfriend had moved in and the home was now a "little tight" (199). By Christmas Dinitia passes her note asking for baby names, and after Christmas break Dinitia 
doesn't return to school. Concerned Walls tries to talk to Dinitia at her house and is met with a man with "skin like an iron skillet" and "nicotine-yellow eyes" who tells her that her friend doesn't want to see her (199-200). Walls never speaks to Dinitia again, but learns that she had been arrested for stabbing her mother's boyfriend to death (200). Much like Allison, Walls notes that girlhood ends when her friend becomes a mother. Dinitia's childhood, already burdened by the effects of poverty and racial inequity, ends abruptly when her body is sexualized and raped.

Though the adult narrator is capable of recognizing Dinitia's sexual abuse, Walls commits to narrating the scene through the child figure's perspective, a construction of her child self as witness. Walls maintains a similar distance when she describes her father's attempt to pimp her. Realizing that his daughter's body is worth money, Rex takes her to a bar. Her father offers her to a couple of men who come close to raping her, but stop short when she insists that she is too skinny and scared (213). Counting his money, Rex tells her they make a good team, and even after she told her father that the guy was a creep, Rex pretends that he didn't understand exactly what he had arranged. He tells his daughter that he's sure "he just pawed you some" but he knew she could handle herself (213). Rex compares the bar situation to a scene Walls had described earlier, a time when her father had taught her to swim by throwing her into sulfur spring. He says, "you might have been convinced you were going to drown, but I knew you'd do just fine" (213). Like the scene with Brian, Rex imagines his children as capable as adults, despite maintaining a paternal right to determine the extent of their freedoms. Rather than judging her father directly, Walls sustains a narrative objectivity and shifts the voice to a child figure shaped by the memory of the event.

The narrative distance Walls uses (and the lack of direct engagement with her childhood traumas) allude to unresolved feelings projected through the child figures. Unprotected from life, 
the Walls children developed coping strategies for managing the losses and constant need; however, none escaped the trauma of life with Rose Mary and Rex. Lori, the oldest, leaves as soon as she graduates from high school, and moves to New York to attend art school. Walls quickly follows, as does their brother Brian. Left alone, their youngest sister Maureen begins to fail and the siblings move her to New York in the hopes of salvaging her lost childhood, but Maureen struggles.

While the three older children found strength in family, Maureen felt missing, more often than not adopted into her friends' families who felt sorry for the conditions of her home. After graduating from high school, Maureen fails to find stability, a reflection of an unstable past, and eventually she ends up squatting with her parents in an abandoned building. As an adult, however, Maureen no longer hides her contempt and she and her parents fight. Her dad calls her a "sick puppy, the runt of the litter, who should have been drowned at birth" and she calls her father a "drunk" (274). Failing to recognize Maureen's mental health needs, Rose Mary decides (after her daughter stabs her) that her daughter needs to "develop a little self-sufficiency" (275). Maureen is arrested, jailed, and eventually ends up in a mental health facility, all of which lead her to decide to return to California, where Maureen was born. However, Maureen only knows California through stories told to her by her siblings, stories about sun and warmth and a time when crisis in the Walls family seemed less imminent, and her success seems uncertain since it is based on the memories of a family plagued by unfulfilled hopes and unresolved loss.

Walls memoir shows that adult projections of childhood fail the child. Though cultural narratives maintain innocence as the primary characteristic of the child, this innocence not only reflects adult loss, but also relies on monolithic experiences of childhood and ignore the very important ways that class, ethnicity, geographic region, religion, race, and gender play in 
creating and defining space for childhood (Mintz 33). Not unlike other terms used to discuss identity, the child and childhood have been influenced and constructed by a set of ideals that fantasize about heteronormative, rich, white child. Even though the child is present in Walls text, and even though the child figure provides narration throughout the text, ultimately the memoir feels childless. Denied a "privileged" childhood, the Walls children are rendered unrecognizable such that they appear not to have existed as children at all.

\section{TWO OR THREE THINGS: DIDACTIC PERFORMANCE \& STORYTELLING}

Neither Allison nor Walls completely divorce themselves from a narrative 'I' connected to their childhood and relationship to their parents. For example, Rose Mary's voice often ends passages, particularly in moments when Walls attempts to reconcile the uniqueness of their family situation. Frequently Rose Mary's voice dominates the narration, creating a scene where the description of her history becomes less about her individual past and more about her mother as a character. In the following paragraph Walls moves from talking about her childhood freedom to quoting her mother's opinions about childrearing in the U.S. She writes:

Lori, Brian, and I, and even Maureen, could go pretty much anywhere and do just about anything we wanted. Mom believed that children shouldn't be burdened with a lot of rules and restrictions. Dad whipped us with his belt, but never out of anger, and only if we backtalked or disobeyed a direct order, which was rare. The only rule was that we had to come home when the streetlight went on. "And use common sense," Mom said. She felt it was good for kids to do what they wanted because they learned a lot from their mistakes. My mom was not one of those fussy mothers who got upset when you came home dirty or played in the mud or fell and cut yourself. She said people should get things like that out of their 
systems when they were young. Once an old nail ripped my thing while I was climbing over a fence at my friend Carla's house. Carla's mother thought I should go to the hospital for stiches and a tetanus shot. "Nothing but a minor flesh wound," my Mom declared after studying the deep gash. "People these days run to the hospital every time they skin their knees," she added. "We're becoming a nation of sissies" (59).

In this passage Rose Mary's voice plays a crucial role in narrating how her children should define freedom, play, and injury and contextualizes the conflict between what it meant to be a Walls child versus what it meant to be a child of a "fussy" mom.

Where Walls depends on her mother's voice to narrate opposition, Allison's work tends to exemplify and confront accepted political and social definitions for childhood and family. Allison offers various narrative voices, shifting from reflection to description to directly addressing the audience. One of the best illustrations of this narrative movement occurs when Allison discusses her relationship with her stepfather. She begins directly, "The man raped me," and moves quickly into description: "I was five, and he was eight months married to my mother" (39). The following pages weave together commentary, reflection, and description, but become politically charged when Allison writes about a conversation she has with a "therapist and a socialist" who told her that "people might get confused" by her rape and "imagine that sexual abuse makes lesbians" (45). Allison rejects this rhetoric and states: "Oh, I doubt it. If it did, there would be so many more" (45). Despite her frank acknowledgement, Allison returns to a haunting refrain that returns back to the central movement of the memoir- "Two or three things I know for sure, but none of them is why a man would rape a child, why a man would beat a child" (sic 43). Borrowed from her aunt, the refrain ("two or three things") demonstrates a doubled narrative 
"I," representing both the Gibson women's wisdom and Allison's individual interpretation of what her life "knows."

While the doubled 'I' in Allison and Walls' memoirs diversifies (and thereby potentially destabilizes) a singular narrative voice, the multiple narrative positions also recreate the conditions of their childhood. Both authors were subject not only to the influences of family, but also to institutional interventions - most often schools, prison, and child welfare— that demanded compliance with social and cultural performances. At school Walls pretended to eat lunch by eating an apple very slowly or chose to go to the bathroom to hide so that she could pretend that her family wasn't poor. Allison says that she told her sisters a story about the Greenville County General Hospital, about how they "take babies down there," about if you are poor "from the wrong family, the wrong color, the wrong side of town" that they "mess with you, alter your brain" (3).

Generally discussion of narrative voice in autobiography turns toward an examination and measure for truth and historical accuracy; however, critics such as Margo Perkins, looking at autobiographies by Assata Shakur and Angela Davis, argue that "political autobiographies" offer a chance for individuals to "reclaim and reconstruct their public images in a manner that is more consistent with their own perceptions of self" $(7,88)$. Political autobiographies, according to Perkins, sublimate the individual story to "document a history of struggle," provide "voice to voiceless" and expose the "repressive tactics of the state" (7). But above all, political autobiography is an intervention and a tool to "educate as broad an audience as possible to the situations and issues at stake" (7). In as much as the varied experiences of narrative 'I' in Allison and Walls memoirs speak to their fractured identity development, their perspectives also invoke a didactic storytelling performance relative to political autobiographies. Allison and Walls use 
storytelling to create a politicized performance of their life experiences and observations by exposing the act of storytelling.

Poverty created what Allison calls a "theatre of real life," demanding performances to help audiences feel comfortable ignoring the effects of economic disparity (26). She writes that her mother "intuitively" knew the "thing" that Allison would learn by watching her mother, that "the use of charm, the art of acting" was the "way to turn misery into something people find understandable or sympathetic" (27). As a waitress her mother "teased quarters out of truckers, and dimes out of hairdressers, pouring coffee for an extra nickel, or telling an almost true story for a half a dollar" (25-26). Despite her membership in the Gibson family (a family well known to local residents), Ruth Gibson used performance to tell a different story about herself to elicit tips from her customers.

Though Allison uses this story of her mother to talk about the effects of poverty, the story echoes throughout the memoir with each interruption and repetition of "two or three things I know," calling attention to Allison's own efforts to turn misery in her history into something with which her audience can identify. Conversely, Walls distances herself from her mother (and father's) non-conformist theories by highlighting dialogue exchanges that repeatedly expose Rose Mary's irresponsible attitude toward her children and their welfare. In both cases, the authors break a narrative 'wall,' introducing a separate voice to teach what authors know to be true about the conditions of poverty, neglect, and abuse.

As much as storytelling provides a means to teach audiences about poverty, storytelling also provides the means for surviving trauma. Allison often refers to the power of story: the stories in her body, "I am one woman but I carry in my body all the stories I have ever been told," the stories that might save her niece, the stories that saved her, and the stories she has yet 
to tell $(39,84)$. Two of the final three refrains of "two or three things" that end her memoir speak to story:

Two or three things I know, two or three things I know for sure, and one of them is that to go on living I have to tell stories, that stories are the one sure way I know to touch the heart and change the world (72).

Two or three things I know for sure and one of them is that telling the story all the way through is an act of love (90).

Allison imagines storytelling as life: story is history, cultural, our means of changing the world, an act of love, and above all, a means of achieving (with love) selfhood. Framed by the same phrase ("two or three things"), Allison's narrative interruptions about storytelling also provide reminders about the didactic purpose of her stories.

Her "two or three things" that she knows impart wisdom gained in experience, which she supports with evidence- - her stories. This is best exemplified in a scene describing a visit with her niece. Allison looks at her niece's "sunburned frightened face" and sees that "hungry desperate look that trusts nothing and wants everything," the same look as her mama, her grandma, and her aunts, and knows that she wants to "save her" (83-84). "Let me tell you a story," she whispers, "Let me tell you a story you haven't heard yet." (84). In this story she tells her she wants to "take her, steal her, run with her a thousand miles away from the daddy who barely noticed her, the men who had tried to do to her what [her] stepfather had done to me" (84). Though this passage expresses the desire to physically escape, it also shows that storytelling provides an available means to survive. And for "one moment, this moment leading to the next, the act of storytelling connecting to the life that might be possible" is enough of a promise (84). 
Though Walls' memoir lacks the direct discussion of storytelling found in Allison, stories play an important part in the way her family (and particularly her father) manages unconventional life. The title of the memoir refers to Rex Walls most important story, the story about how he and his family would escape poverty by living in the glass castle, a "great big house" that he would build in the desert bringing together all his "engineering skills and mathematical genius" (25). The house would have "solar cells on top that would catch the sun's rays and convert them into electricity for heating and cooling and running all the appliances; it would even have its own water purification system" and bedrooms for all the kids (25). Partdream, part-hope, the Walls family carried the promise of someday around like Rex carried blueprints.

In the early pages of the memoir Walls refers to family stories—birth stories, naming stories, stories about pets, stories about scorpions - many of which also provide reminders about surviving difficult situations, like the death of a child or the miracle recovery of another. Walls' brother Brian's story begins at birth, he couldn't breathe and "came into the world having a seizure" (27-28). When her mother told the story her arms would be "rigid" and she "clenched her teeth" and would go "bugeyed to show how Brian looked" (27). Though they thought he would be a "goner" he lived, despite seizures that continued through his first year of life. Rose Mary's active storytelling was nothing compared to Rex who was a "dramatic storyteller" (24). In his stories Rex always "fought harder, flew faster, and gambled smarter than everyone else" and "along the way, he rescued women and children and even men who weren't as strong or clever" (24). Walls notes that Rex's stories "taught the secrets of heroics," like how to straddle a wild dog or how to kill a man with one punch (24). Similar to Allison, stories provided the means of escape, or more precisely, the means for survival by imagining escape. 
Ultimately, Allison and Walls' didactic performance wants to teach audiences how to survive poverty. Neither Allison nor Walls concludes that poverty is escapable, and in fact, both stress the inescapability of their past. Escaping, however, is not the same as surviving. One of the most important distinctions between escape and survival in these memoirs relates to the relationship between the authors and their families. Despite moving out of their childhood homes, away from the Appalachian region, and despite having achieved relative financial success, both authors remained conflicted about their relationship to their family. For Walls, the relationship with her parents became more complicated; she could not refuse her mother a home and thus her mother moved in with her and her husband, and she is honest about her desire to remain childless. In the final pages of Allison's memoir, she describes a dream in which she is eight years old, surrounded by family, frightened and clinging to her mother's neck. As I will discuss in the next chapter, the description of dreams seems counter to the efforts of truth-telling, and yet both Allison and Gilmore use dreams to capture what appears to be indescribable turmoil. Though Allison's dream ends with her own son reaching for her, the anxiety about her past and family remains. 
Hammond 105

\section{Chapter Three:}

\section{Missing Children: Secrets Pasts, Haunted Silences, and Revising Family History}

But if I could choose the way people remember him [Gary Gilmore] — and I don't get to do that at all -I guess I'd want people to see him as a case study for the things you should not do to a child's heart. Mikal Gilmore

There are all kinds of ways to die in this world. Some die without taking others with them. It's a victory, no doubt, but that doesn't make it the same as redemption. Mikal Gilmore

Normal Mailer's mammoth text physically shadows Mikal Gilmore's Shot in the Heart (1994). After The Executioner's Song (1979), at well over a thousand pages, there doesn't seem to be much more that can be said about Gary Gilmore. A quick Internet search describes what most think they know about Gary—criminal, thief, murderer. In the mid-70s, the years leading up to Gary's early 1977 execution, everyone seemed to want to know why: why had he murdered the two young men, why did he want to die, why had years of reform school and jail time failed to save him? Lawrence Schiller and Norman Mailer might have been drawn to Gary Gilmore's story because he asked to die, begged to die, and Gilmore's story cannot be divorced from the United States' use of capital punishment. Mailer, in conjunction with Schiller, the American film director and writer who purchased the rights to Gary's story, taped hundreds of interviews with Gary, attempting to understand the enigmatic "killer" who was, according to his teachers, jailers, and family, gifted, a talented artist and unexpectedly kind. However, Gary seemed more 
comfortable when he was in trouble than when he was "free" and his continued defiance led to a relationship with the criminal justice system that contributed to an already deeply troubled family dynamic. Two years after Gilmore's death, Mailer produced a story based on personal interviews, legal documents, and news articles that tempted audiences to "see" through Gary Gilmore's eyes. ${ }^{24}$

Almost twenty years later, Mikal Gilmore published Shot In the Heart, the book he said he never wanted to write (Adler 25). A handful of reviews situate the book against Mailer, always beginning with the infamous "killer" and then turning to the brother left behind. The book accounts for the private life of the Gilmore family, a documentation of the history long before the eight months preceding Gary's execution. Beginning with his mother's Mormon roots and piecing together what little he can of his parent's early years, Gilmore attempts to draw together a family history based on the few stories he heard growing up woven into research drawn from interviews with extended family, teachers, and neighbors, documents from various institutions where Gary had been jailed, school records, and long overdue conversations with his brother, Frank.

Though a kind of second "act," Shot in the Heart is not just a continuation of or answer to Schiller and Mailer's work. At stake is both the cultural memory of his brother, already determined by a life of crime and public scrutiny, and Gilmore's personal legacy as the child left behind. Chronicling a life of sorrow and loss, Gilmore pieces together his personal recollections of the Gilmore family with the family history he didn't know existed. Gilmore opens his book with a dream that takes him back to the "good" times in his mother's dream home, but ends with his imagined suicide. The dream establishes important themes about family, isolation, and death,

\footnotetext{
${ }^{24}$ In 1977 the Adverts, UK punk-rock band, released a song called "Gary Gilmore's Eyes" based on the viewpoint of the patient who received Gilmore's donated corneas. The song reached eighteen on the UK billboard charts.
} 
which continue to inform both the private moments of his dreams and his recitation of family history. Gilmore then turns to the history more easily verified, his mother's family history and early Mormon settlement in Utah, and uses this history to provide explanation for his mother Bessie's partnership with a transient, surreptitious, and abusive man — his father, Frank Gilmore. The narrative moves through the birth of children and the development of the family as they attempt to cope with constant upheaval and pressure to escape Frank's illicit affairs. Despite the relatively linear progression, the story often lingers on the "tormented and hyperbolic family mythology that [Mikal] grew up with" (116). Documents, interviews, stories, and heresy help piece together a past that Gilmore worries is not even his own; he tells readers that this is a "story of murders: murders of the flesh, and of the spirit; murders born of heartbreak, of hatred, of retribution" (x) and the narrative of a man coming to terms with the details of a "terrible history and luckless past" (xii).

Part autobiography, part reflection, the book uses extensive interviews with the eldest Gilmore sibling, Frank, to provide a link to the history before Mikal's birth as well as insight into the abuse experienced by all but Mikal. However, the absence of physical abuse did not protect Mikal from the impact of spectacles of violence and cruelty experienced by his brothers, particularly Gary. While Gary seems to emote through anger and visible hostility, Mikal seems to internalize the family discord. He writes of haunted houses, nightmares, and the psychological impact of feeling “missing” from family photos. Family ghosts haunt Mikal's text, providing a historical intervention and means of negotiating with a traumatic past that did not physically impact him, yet scarred him so much that he seems to have wished for the physical abuse suffered by his brothers. The narratological rifts in his autobiographical performancespecifically the dream sequences_-reveal a conflicted sense of historical presence produced by 
Gilmore's struggle to understand the disparity between the loving relationship he shared with his father as a child and an inherited set of mythologies used to conceal a family legacy grounded in spectacles of violence and institutional cruelty.

Drawing from his work as a journalist, Gilmore pursues his "luckless" past and, like Mailer, often presents his history from a seemingly objective distance, a distance that heightens pressure on the autobiographical components of the work. Perhaps the strictest definition of autobiography_Philippe LeJeune's definition that limits autobiography to "retrospective prose narrative that someone writes concerning his own existence, where the focus is his individual life, in particular the story of his personality"-would exclude Gilmore's work from the genre of autobiography. Much of the text is not self-reflective. More recent scholarship has broadened terms for autobiographical studies, but one persistent thread has been the storytelling 'I' and its relationship to audience; autobiographical writers must be aware of audience in a way not required by novelists, specifically in terms of the audience's expectations for truth. ${ }^{25}$ Readers expect certain genre conventions that depend on an adherence to truth, which Mikal faithfully reproduces in the narrative through his understanding of the autobiographical ' $\mathrm{I}$ ' as related to his relationship to Gary (whose presence is too stated and comes to subsume the family), the separate and more affectionate relationship he had with his father (which was so unique as to seem unbelievable), and the history that seems to verify his position as an outsider in the family. In contrast to this truth telling, Mikal interrupts his autobiographical narrative with descriptions of his dreams. Though dreams are not inherently untruthful, they are not commonly the material evidence used to verify truth. Mikal's dreams unsettle his autobiographical performance by calling attention to the traces of his past that are not normal and continue to define his relationship to an uncertain, unverifiable past. The dreams attempt to bridge the impossible

\footnotetext{
${ }^{25}$ See Philip LeJeune's “autobiographical contract” and Nancy Miller 541.
} 
division between outsider and insider, a stark contrast to Gilmore's more objective writings of his family that reproduce what readers might have expected: Gary Gilmore_-violent killer—was a product of a violent home and institutionalization. ${ }^{26}$

But there is an equally important consequence revealed in Mikal's traumatic dreams that reminds audiences that Gary was not only a violent killer - he was also a brother and a son. Gilmore's work seems anxious about the process of truth-telling, an anxiety Leigh Gilmore identifies as an "anxiety about invention" that seems to view the autobiographical project through an almost "legalistic definition of truth telling" despite the ambivalent criteria used to evaluate literal or verifiable truth (3). The truth in Gilmore's autobiography lies somewhere between the shifting terms for what it means to a child split by a deep sense of loyalty and a need for a self-preservation.

Mikal's truth links to his unique narratological 'I,' which is necessarily distanced by his personal experience of the family events. Because he was not physically abused, Mikal seems to feel absent from the family narrative (and by extension family history) and disconnected from his brothers. In retelling his family's story, Mikal is not just sharing in the painful events of the past; he is searching for a connection between his childhood and that of his brothers. He relives the abuse so he can feel what it may have been like to be his brothers. In certain moments the narrative feels more like a biography, particularly in moments when Frank's voice takes over as the narrator. Mikal's conflicted sense of presence is impacted by relationships and events he was not able to contextualize. He depends on Frank to teach him about the father he did not know.

Mikal's sense of presence hinges on the loving relationship he shared with his father, an anomaly in a family plagued by abuse and neglect. Each familial loss, through death or removal,

\footnotetext{
${ }^{26}$ The purposeful shift from Mikal to Gilmore reflects my effort to accurately distinguish between the writer as artist and the writer as individual. Gilmore operates as the objective storyteller, while Mikal offers his private self.
} 
increases Mikal's loneliness and adds to his sense of feeling 'missing.' The dream passages return Mikal to physical spaces and emotional challenges he faced during his youth, in effect restaging the problematic anxieties produced by his traumatic childhood, which anticipate isolation and abandonment. Contrarily, the dream passages also interrupt the narrative, revising history by writing Mikal into the family history. In these moments Mikal writes his own story rather than writing the story of Mikal as read through Gary or the Gilmore family. Gilmore's loyalty to his father and the memory of the loving relationship they shared contradicts his family's understanding of Frank Gilmore, emphasizing the singularity of Mikal's experiences; however, despite the fact that he was the only child to have had a "real" father, Gilmore's relationship with the future was just as unstable as his brothers'- he too is grappling with what's missing. Mikal's narrative is in part a search for his presence in a family plagued by chronic absences.

The impact of sustained losses destabilized Gilmore's identity, leading him to craft a counter-narrative to the "most general form" of the American myth that describes human history as a "pilgrimage from imperfection to perfection" (Lundquist and Spengemann 503). In their discussion of myths and the American autobiographical tradition, Lundquist and Spengemann assert that autobiographers use metaphor in self-scrutiny to understand experiences that impacted their cultural status and self image; their writing assesses the "mythical significance of their new selves [and] re-establish[es] the cultural contact which the change interrupted" (508). Adaptations of Christian mythology, according to Lundquist and Spengemann, to the "particular problems of American life" continue to define the autobiographical genre. In the epilogue of the text, opposite the beginning of the final dream, Gilmore quotes a passage from the Book of Job. In the passage Job continues to deny sinfulness and finally gives in to hopelessness. The 
connection between Job and Gilmore suggests that he too feels sinless, and yet subject to God's wrath; having lost all of his family, Gilmore must continue to live a damaged and lonely existence. This sentiment is further emphasized in the final dream, which recreates his brother Gary's trial; however, this time the judges hear about the horrible violence in the Gilmore home. Gilmore expects that the memories of his childhood should represent a certain truth about his family, but as an adult, plagued by ghosts and haunted dreams, his incomplete understanding forces him to return to a savage past. Rather than moving toward perfection, Gilmore's pilgrimage deconstructs his father's memories and the inherited set of mythologies left by all but Frank Jr.

The narratological position of the autobiographer has retained the confessional aspects of the genre, which suggests that the genre is, as Mieke Bal writes: "one of an unstable identity in need of affirmation" (176). However, what is at stake is not just Gilmore's individual identity, but also the cultural memory of his brother Gary. Gilmore is not just searching for the truths of his own, but also deconstructing an image of his brother. In the final dream sequence these two images converge as an image of a child on trial, a child who can neither absolve the sins of the man, nor live without the father. The impact of the dream causes Gilmore to break-down; repeatedly he tells himself that it will "never be all right" until he finds comfort enough in the words to fall back to sleep (398). The few pages of the epilogue demonstrate a type of survival that embraces conflict and instability. To be "all right" he must accept that it will never be "all right."

Gilmore's confessions in the final dream sequence reveal his fears about saving "the child." Though life-writing provides a uniquely private translation of life events, in sharing his perspective Gilmore's work opens itself to public evaluation. Yet instead of using this public 
evaluation to interrogate the self, Gilmore directs attention to the institutions that impacted his family's development. These institutions are not limited to public institutions - specifically religion and prison - they include the family and family legends mythologizing that which they did not want to face. Gilmore begins the book with a discussion of his mother and the religious background that perhaps led to her partnership with Frank Sr. Religion plays a key role in dividing Gilmore between his mother and father; both envisioned their son Mikal as their legacy. In an interview with Laura Reynolds, Gilmore says that though he would "love to have children," he worries that "he might be no better parent than his father" and that "perhaps the Gilmore 'legacy' should not continue” (27). The name Gary Gilmore is too often tied with a notorious legacy, a legacy that continues to impact both Frank and Mikal. Lee Edelman suggests that children register as a transmission of legacy into the future - they are futurity - thus justifying political investment and intervention in childhood through various institutions. Gilmore's narrative tempts audiences to imagine his history through a series of institutional conflicts, all of which expose the violence inherent in institutionalization-familial institutionalization included. Though these institutions claim to protect the child from the possibility of real or perceived harm, the Gilmore family narrative demonstrates that not only do institutional interventions fail to protect childhood, they also fail to provide adequate substitution for family. Essential to the Gilmore family story are the violent effects of religion and the criminal justice system — all of which operate as the silent "father" throughout the text. Gary's final words: "there will always be a father" make surrogate forms of institutional power (in his case the criminal justice system) complicit in his damaged family legacy.

\section{LIFE WRITING \& TRUTH-TELLING}


Confessionals (and testimonies) participate in the secret, official discourses that merge with self-representation "such that any self-representational act is fully burdened by its public charge to disclose a private truth" (14). Leigh Gilmore is particularly interested in texts like Mikal's Shot in the Heart because its complicated relationship with genre allows the author to resist a "literal truth test" by turning toward the outer limits for self-representation (14). What Gilmore identifies as "outer limits," I would like to recast as rhetorical strategies invested in the didactic possibilities for autobiography, a particular function and performance of writing that places greater value on the purpose of the story than on a strict adherence to truth-telling. Gilmore's politically based understanding of autobiography prompts her to see Shot in the Heart as a story of family as well as a story of nation, an interweaving that "indicates the extent to which autobiography entails kinship narratives, personal histories entail collective histories, and self-representations of trauma are embedded in the long-standing patterns of other's violence" (72). Mikal Gilmore must continually face the demand to tell his story (auto) and the story of his family (biography) while confronting the haunted and persistent family secrets in speaking for the dead (72-73). The "auto" of biography happens almost exclusively in the dream sequences, passages that are arguably the most emotionally raw moments of Gilmore's self-reflection. Gilmore's dreams neither fit the style or the form of the surrounding text —even the font separate these moments from the rest of the work. Though the details change, each dream connects to a major life event, a death in the family, or a break-up, events that highlight Mikal's feelings about absence and isolation. Counter to the strict truth-telling found in the rest of the text, Mikal's dreams erode the objective tone, creating narratological ruptures that challenge autobiography as a truth-telling effort. 
Gilmore's truth-telling was no doubt linked to Mailer's work, even if Mailer's genre is relieved of some of truth-telling expectations because readers were not necessarily interrogating the "true-life story" for its adherence to fact. In the afterword Mailer acknowledges the limitations he faced: "This book does its best to be a factual account [but] this does not mean it has come a great deal closer to the truth than the recollections of witnesses" (1051). Throughout the text Mailer evokes the theatricality of Gary's "unreality" based, somewhat, on the observer position required of an outsider. Although Schiller hired Mailer because of his proximity to violent encounters, Mailer had not spent time in prison nor had he been raised in the Gilmore home. On the one hand Mailer felt obligated to fairly represent the "characters," and on the other hand he felt obligated to determine what story could be made out of all the versions (Aldridge 180). In spite of all the research as well as the admission that he knew Gary better than he knew his own relatives and friends, Mailer admits that his project left him unable to understand Gary; he was "terribly private, even secretive" (176). A limited number of pages explore Gary's history and relationship with his family. By the time Mailer begins the project, Gary's father and brother Gaylen have already passed. Mailer's best source for information was Bessie, Gary's mother. Bessie, however, was as secretive as her son, and Mailer complained that conversations with her were cryptic at best. Despite his "keen sense," as an outsider Mailer can only "see" what others allow him to see, particularly given that Mailer never interviewed Gary himself (Tonn 201). It's easy to forget that Mailer was as voyeuristic as any of the other journalists hungry for the story; his gaze set on Gary, Mailer tried to stage his version of the character Gary - the "masked actor" (Begiebing 187). This is not to suggest that either Mailer or Gilmore had an easier time negotiating between fact and fiction, but instead to draw attention to the role of audience as participating in the project of truth-telling. 
Gilmore also faced the challenge of thinking about how to invite audiences into the privacy of a family determined to keep others out. In a poignant moment Gilmore reveals that he felt an obligation to his father particularly:

My father feels so close, and yet so far. He's the biggest enigma in this history, and I'm worried that if I can't solve him -if I can't uncover his secrets and explain his fears-I have no right telling this story. Maybe to know my father, I'm going to have to examine my own heart and face up to the part of him that dwells there. At the same time, my greatest fear is that I am too much like the man, that I already own his sins. (93)

Gilmore is torn by the demands of history, the demands of his love for his father, and the demands to himself. Leigh Gilmore alludes to balance — between self and nation—as part of Gilmore's efforts to the tell truth. Layers of inside/outside dichotomies complicate Gilmore's autobiographical task, each requiring a different set of rules for truth-telling. Reflecting on the early years of his parent's marriage, Gilmore writes that he has "always felt left out because I was not a part of this time of wandering" (97). Though a member of the family —an insider in the world of the infamous Gary Gilmore- he says because he was "born apart from that time" he was an "outsider among my brothers" (97). Similarly, Gilmore experienced prison as an outsider, and yet also bore witness to the violence related to Frank Sr., Gary and Gaylen's fights with authority.

As the unofficial family historian Gilmore faced a daunting task; he had to sift through the family stories and attempt to verify their truth while filling in the missing history. Gilmore's truth-telling project is as much influenced by lies as it is by truth—-terms, which are not complimentary, or opposite. Adams points out that truth cannot be the opposite of lie because 
"we speak of truth in the singular and lies in the plural," as if to say that it is not possible to tell just one lie (15). Though Gilmore turned to Mailer and Schiller for help, his text primarily relies on over a hundred hours of interviews with his brother Frank, Jr. In spite of these resources Gilmore often acknowledges that there were secrets that died with his parents and brothers. Still other secrets turned out to be "lies," particularly stories Gary told about his experiences in various detention centers. In her search for her own absent parent and family legacy Carolyn Kraus turns her anxiety about truth into a mission, a journey that begins with the slow process of gathering documents that verify the few stories she has about her father. When her journey leads her to Maly Trostinets, a well-hidden concentration camp reported to have been the "dumping ground for the corpses of political dissidents long before the Nazi arrival," Kraus had to face two important "truths:" one, her grandmother's story was buried under a garbage dump and could never be retrieved; and two, that the fact-checkers would use Russian reports to verify one truth, even if local residents had lived a very different truth. Kraus' story provides an important metaphor about the limitations for substantiating history; documents can lie too.

Truth-telling seems to be one of the few consistent terms in autobiographical critical theory, particularly as it relates to the near contractual obligation readers demand for truth in life writing. Related to the religious turn to confession and testimony, social pressure for telling the truth has played an increasingly stronger role in in contemporary storytelling. Conversely, anxiety about lying has risen as well. Perhaps the best example is Oprah Winfrey's confrontation of James Frey in 2006. The Smoking Gun, a fact-checking website, alleged that Frey had fabricated a large portion of his Oprah-endorsed memoir A Million Little Pieces. Carolyn Kraus remarks that websites like The Smoking Gun have increased the pressure to prove truth; she simply states: "Does it matter if it's true? It certainly matters to readers" (246). Adams too 
confirms that authorship of autobiography is "tacitly plural, so that the truth of autobiography is to be found, not in the 'facts' of the story, but in the relational space between the story and its reader" (12). Unlike other genres, autobiography needs the audience. The reader, according to Nancy Miller, is the autobiographer's “most necessary other” (545). Miller stresses this partnership is the "burning core" of autobiography_- "you conjure the reader to prove that you are alive" (545). Gilmore's project is without a doubt coping with what it means to be alive, to be a survivor, and to be alone, or to think of it another way, without audience. Gilmore says he was “driven to explore his family's history when he 'came to real depressing halt' in his life," a turn that acknowledged the ways he felt that was "paying for [his] family" (Adler 25).

The quest for truth is equally troubled by potential conflicts between genealogy, family history, and the truth. Gilmore confronts this clash at the end of Shot in the Heart in his final conversation with his brother Frank during which he reveals that Frank, Sr. was not his father. Frank says that he'd heard his father insinuate that Bessie might have had an illicit relationship with Robert, but his mother and father had taken that secret to their grave. Because of the intense beatings Gary received, the family had assumed Gary to be the illegitimate child. Instead, Frank had to assimilate a new family truth, counter to his familial history, a new genealogy. Frank, in effect, must rewrite history and reason with his troubled past:

I guess that explains a few things. I guess it explains why I'm kind of fucked up emotionally. And I guess it explains why Mom was always so hard on me. I mean, after Dad died, Gary and Gaylen were in trouble constantly. They were ruining her. But she always had a lot of love for them. I was the one that had to bust my ass to try and keep her going as best I could and in turn I got nothing but just hatred, hatred, hatred (392). 
While Gary received the worst of his father's abuse, Frank was his mother's shame. Along with his father's arbitrary beatings, Frank was also beat by his mother - the only one to have received punishment from both parents. Bessie, Frank, Frank Jr. and Gary "paid a lot for that secret” (392). Miller writes that the challenge faced by autobiographers is to "invent themselves despite the weight of their family history," and adds: "autobiographical singularity emerges in negotiation with this legacy" (543). She posits that the "arc of becoming through self-knowledge is rooted in but never entirely bound to the stories of our familial past" (543). Though the family secret primarily impacts Frank Jr.'s identity, Mikal and Frank end their conversation affirming their continued relationship as brothers, despite genetics. This confirmation provides both Frank and Mikal a moment of solidarity in spite of a text that too frequently reflects Mikal's feelings of absence and isolation.

One of Gilmore's most daunting challenges was to live the lives of others - the lives of his brothers - to try to understand their experiences of life with Bessie and Frank Gilmore. The dream passages allow Gilmore to imagine his life as the life of his brothers, while maintaining his role as storyteller. For example, in the opening dream of the text—“The Dream"-Mikal's suicide is the result of using Gary's gun, an act that strongly reflects the part Gary played in his execution. Similarly, in “The House on the Hill,” Mikal and Gary's girlfriend, Nicole, pretend to be together in order to rent the family house. At the end of the dream Mikal is left alone in the house. All of Gilmore's dreams pivot around major life events that would commonly reaffirm one's place within a family, but instead of providing this much needed verification the dreams all end with a series of rejections, departures, and losses. Susan Bell suggests that for most readers the "appeal of life-writing is its evocation of a human, dead or alive, and the mythologizing (or demythologizing) power inherent in a written account of that life" (Bell 2). Bell suggests that 
biographers seize their own lives through accounting for those of others, and as biographers, both Mailer and Gilmore "live the life of others" in their accounts of history. However, while Mailer linked Gary's story to American mythologies, Gilmore was grappling with his place within his family's mythologies. To better understand and live the experiences of his brothers, Gilmore depends on Frank Jr. to operate as a medium. Frank Jr. shares his memories of the past, evoking and reliving his violent past such that Gilmore can be written into the family history. The life seized in the work is not exclusively Mikal's, and in fact, Frank Jr.'s presence haunts the text, an evocation determined by the memories of a family torn apart by secrets, lies and violence.

\section{'FEELING MISSING': ISOLATION \& ABSENCE}

Titled "The Dream," Gilmore immediate situates readers within the ephemeral world of the subconscious, providing a rare private moment during which he catalogues his losses. $\mathrm{He}$ begins simply: "I have dreamed a terrible dream" (ix). The dream is always set at night, in a house on the "far outskirts of a dead-end American town" (ix). The house is shabby, weather worn, and surrounded by industry—railroads, factories, and smoke. A train's howl precipitates its arrival out of the night's void. The train is both there and not there, an important connection to his mother's fantasy for a perfect family and a foreshadowing of the disappointment that follows. Like the illusive American dream, the train never arrives. In the dream the Gilmore family is temporarily back from the dead, each listed in terms of his or her passing, except Frank Jr., who, though still alive, is beyond reach:

There is my brother Frank, who turned increasingly quiet and distant with each new death, who was last seen walking down a road nearby the night-house of this dream, his hands rammed deep into his pockets, a look of uncomprehending pain seizing his face. (ix) 
The style of the passage is as important as the content of the dream, emphasizing the role of absence as it participates in shaping the presence. After Gary tells Mikal, "see you in the darkness beyond," Mikal grabs a gun and shoots himself. He describes the feel of the bullet damaging his brain and the death that follows:

There is darkness, but there is no beyond. There is never any beyond, only the sudden, certain rush of extinction. I know that it is death I am feeling - that is, I know this is how death must truly feel-and I know that this where beyond ceases to be a possibility. I always wake at this point, my heart hammering hard, hurting for being torn back from the void hat I know is the gateway to the refuge of my ruined family. Or is it the gateway to hell? Either way; I want back into the dream. (x)

This passage, by weaving fantasy and reality, becomes a place where Mikal can both commit suicide and survive to tell his readers about the experience. It uses Gary's final words before walking to his death sentence alongside a description of what Gilmore imagines to be hell. And it sets up an important pattern for what readers can expect to see in the dream passages-loss, guilt, silence, and a family endlessly preparing to die. In general, the dreams serve an important function in the text, providing an intimacy unmatched in Mailer's or any other work about the Gilmore family.

The dream passages compel audiences to examine Gilmore's position as family historian both in terms of his ability to represent the facts of the events and in terms of his manipulation of those events as he tries to understand his role in the family's history. Looking at the family pictures Gilmore says that the images "make plain a certain truth: My brothers and I did not inhabit the same time and space" (5). In his efforts to remember his relationship with his 
brothers, Gilmore recalls very little, toys that would not be shared or hurtful pranks in answer to careless accidents. The family photos, and more specifically the smiling faces of his brothers, further distance Gilmore from his brothers, his absence felt more acutely because "for all the hell [his] brothers may have gone through, they were, at least for a time, real brothers" (7). He does not feel as though he was a "real brother." Gilmore claims that he hates his brothers even though he doesn't want to; he hates them because he wasn't included in their picture, and he hates "them for not being a part of their family, no matter how horrible its costs" (7). As much as Gilmore did not want to be physically abused, his lack of abuse made him feel less connected to his family, especially his brothers.

Gilmore's dreams repeatedly return to descriptions of abandonment and death, demonstrating that despite his efforts to write himself into the family history he is always "missing." More often than not his absence originates from his emotional distress rather than a literal lack of presence. For example, Chapter Two Gilmore expresses a desire to walk through the "insides" of history while wandering in "House on the Hill" so that he can "find a way back into it" (215). He says that he feels like he "lost or left something there," and he thinks that if he could "just explore the rooms once more" he could "find what [he's] been missing" (215). However, like the rest of his dreams, Gilmore efforts lead only further mysteries: unfinished rooms, trap doors, and stories that go on forever. By the end of the dream Gilmore is trapped in the house alone, locked in with only the company of the "presence of evil" he felt upon entering the house (216). Another example follows later in the chapter, in what is one of the most disturbing historical revisions Gilmore provides. Just after discussing Gaylen's funeral Gilmore has a dream about one of his brother's executions; he "[has] these dreams often" (296). Though the details of the death sentence are similar to Gary's - they are waiting for a stay of execution, 
the means of execution is a gun shot to the heart - it is his brother Gaylen who awaits the death penalty for the menial crime of "being simply an irretrievable, small-time sinner" (296). Somehow it is decided that Gilmore would be the best choice to kill his brother because he would do it with expediency and the "most kindness" (296). At sunrise he is handed a rifle and he must look into his brother's eyes; eyes pleading for him to do the task cleanly and quickly. Despite his reluctance, Gilmore takes aim and watches his heart "burst out of him and fall to the dry dirt, pulsing blood onto the dust" (297). In this dream Gilmore's presence is confined to the role of executioner. As the killer Gilmore must face the guilt and responsibility, in effect, suggesting that he carries guilt for his brother Gary's death as well. In reality Gilmore did not attend his brother's execution, but the event remains part of the history he must negotiate in his work. His dream revises history to allow him to occupy an imagined presence at the event; even if that presence is contingent upon adopting the hangman's mask.

One of Gilmore's most daunting challenges was to live the lives of others - the lives of his brothers - to try to understand their experiences of life with Bessie and Frank Gilmore. To do this work Gilmore turned to his brother Frank Jr., whose memories bridge the distance between the documents and photographs that provide only traces of history. Gilmore as "caretaker of the pictures," studies the images, "trying to read them for clues to the riddles of our lives" (384). Frank sees the photos and comments that he has lost most of his pictures. The only remaining picture he has is a baby picture of Gilmore, in his playpen with a rubber toad (384). Together he and Gilmore sift through the photos, and as Frank looks at them Gilmore writes that he "knew a different story about every picture," while he looks at them as an "outsider" (384). The only color picture is of a Thanksgiving turkey, only the turkey, no people or smiling faces. Frank fills in the story telling Gilmore: 
I remember that turkey," Frank said. "I remember how good it looked sitting on the table while we waited for what seemed like hours to sit down and eat it. I remember Mom and Dad getting into a fight immediately. I remember Mom picking the turkey up and it hitting the floor-SPLAT! — and the dressing bouncing out all over the place. I remember that bird sitting there on the floor the rest of the day, because nobody would pick it up, because they were too busy calling each other filthy names. I remember never getting to taste it. [...] It looked like such a nice turkey. (384-385)

Frank's memories provide a crucial intervention in the family history because they verify the traumas that influenced Gilmore's childhood. In her discussion of "double-telling" Cathy Caruth states that trauma is both a crisis of death and the correlative crisis of life; it is both the unbearable nature of an event and the story of the unbearable nature of survival (7).

Though Caruth's theories help explain Frank's position as storyteller, they fail to include the position of the individual who is impacted by the traumas they did not witness. In her study of the role of witnessing, Marianne Hirsch defines "postmemory" as the "relationship that 'generation after' bears to the personal, collective, and cultural trauma of those who came before - to experiences they 'remember' only by means of the stories, images, and behaviors among which they grew up" (5). Hirsch emphasizes that postmemory is mediated by "imaginative investment, projection, and creation" (5). Hirsch's definition provides an important perspective for thinking about Gilmore's relationship to his family. Distanced from the events he can only see the past in the documents and photos; he cannot depend on experiential memory to verify the traumas that register in his dreams or in much of his book. Instead, the autobiographical act becomes a path for writing himself into the traumas, some of which depends 
on his bearing witness to Frank's retelling of family history. Their stories connect to the scattered photographs; photographs that Hirsch believes represent ghosts and the fractured disconnection between the past and present (35).

Like Gilmore's dreams, the text's photographs provide another layer to the text's negotiation with what is missing. Only one photo in the book shows the four brothers together; there are no photos of the whole family. The "holes" left by each familial loss, through death or removal, increases Gilmore's loneliness and adds to his sense of feeling 'missing.' Haunted by these losses, Gilmore tries to confront his family's ghosts. Dead and/or missing parents play an important role in both Nina Schwartz and Roger Porter's analysis of autobiography. Their works suggest that autobiographical writers are compelled by the desire to know the father whose identity may have been erased, lost, or so "baffling, problematic, or inauthentic" as to have been unknowable (Porter 2). ${ }^{27}$ Porter argues that autobiographical children are equally driven by the need to discover secrets. He writes that as findings become darker "we perceive how family memory has been directed, manipulated, and distorted to protect secrets" (2). As Gilmore and his brother study the family photos Frank reveals that Gary had a son and later Frank and Gilmore find proof that Frank, Jr. was not Frank's son. These secrets shift their understanding of their family history. For Frank Jr., the birth certificate explains why his mother only physically resembles him, not his brothers. For Gilmore, Frank's stories and the secrets they unveil threaten the already fragile presence he maintains with the past, specifically his memories of his father.

Gilmore's sense of historical presence hinges on the loving relationship he shared with his father, an anomaly in a family plagued by abuse and neglect. While the other brothers might have remembered their father as a violent abuser, Gilmore frequently highlights the disparity

\footnotetext{
${ }^{27}$ Porter notes that his study focuses on fathers because of they are figures of authority. He looks at how "such emotions as shame, blighted love, and the fury of disappointment figure in the competitive and collaborative dynamics of these paternal relations" (4).
} 
between his brother's experiences and his own. For example, Gilmore was only hit once, and after the spanking he told his dad "I hate you" (127). Gilmore notes that after that incident his father only touched him with love, and as an adult he realizes that he was the "only one in the family that he saved that touch for," and this knowledge leaves him with a guilt to this day for that "singularity" (127). Gilmore was the only son to travel with his father, and in fact, he spent a significant portion of his childhood living with his father in Seattle while his mother stayed in Oregon with his brothers. Frank, Jr. remembers a different father:

Sober Frank was worse, Jekyll and Hyde, but drunk Frank was nicer, “I don’t think we ever went two weeks during that time without some sort of wild, fistbanging fights. Many times I saw Mom with black eyes and a horribly swollen face. Man, she looked like she had been in a prize-fight sometimes, battered and bruised, her lips all swollen. I saw that so many times. He would just really pound on her. I remember once when I was about nine, stepping in and telling him to stop. $[\ldots]$ He just looked at me really funny that day. [...] And he actually stopped hitting her and turned around and went back to his desk. (106-107) Gilmore processes the disparity between these two versions of his father in his dreams.

Gilmore's dreams frequently reveal Gilmore's more intimate feelings and anxieties about the relationship he shared with his father. He reflects about this in chapter two, "New Families, Old Ghosts." In the dream Mikal is an adult, and his father comes to his house and tells him that he has found his mother. The two travel to Seattle as they had done many times in real life, but instead of a direct path the two become lost in the marshes because "someone has hidden the exit sign from him" (366). A cop pulls them over, but surprisingly helps guide them to Seattle. In their shared apartment Mikal encounters what he interprets as his live-in girlfriend as well as two 
"friends," one of whom he engages with sexually. He discovers that his sex partner is his father's girlfriend after the two move through a restaurant and find his frail mother sitting alone. His father, embarrassed by his old wife, instead sits with the young blonde and tells Mikal that this is his mother. Mikal reaches out to his actual mother, knowing she will crumble. From this passage it is easy to see how much he and his father shared, how close they were, and what their relationship demanded of Mikal. That the two men share a sexual relationship with one woman is on the one hand indicative of Oedipal desire, and on the other, suggesting that the two were so close as to have been equals.

The frequency of dream sequences increases as the book continues; the dreams become more sexual and draw more attention to the role of women. Though Bessie's history and place in the family occupies a substantial portion of the text, the dreams show Bessie's life as one framed by the consequences of Frank Sr. or Gary and Gaylen's decisions. However, she is also a secretkeeper. In one dream, just after his father's death, Gilmore says his mother comes to him and tells him that his father is not dead. She tells him that they "didn't know how to tell him" his father had run away and that he needs to "be kind" because he is very old and "truly sick" (238). In the dream it occurs to him that he can finally "learn the answers to so many bothersome questions about who his father was and what he did"- and more importantly — that his father would tell him (238). Before he finishes the thought his father collapses in his arms, and though in thirty years he has not been able to cry about his father's death, in the dream he begins to cry. One of the more disturbing dreams comes near the end of the text. Gilmore prefaces the dream by sharing that he had recently separated from his girlfriend. In the dream he sees a ghost that seems to be the same ghost that has haunted his family for his entire life; the ghost that both his father and Gary claimed to have encountered in their homes. The ghost has an "amber glow" and 
walks back and forth at the foot of the bed, dressed in white (376). The dream is sexual, more intimate than the others. Gilmore says she (the ghost) "straddled me, riding up to my chest" and "gripped me by the wrists and twisted the upper part of my body, until she had forced my hands and arms against the wall in a painful arrangement" (376). She then kisses his ear and tells him that he is the "last one," and that she has taken everything from all of them and that now she has come for him (376).

Gilmore's dreams expose the fragility and instability of the family — his father was always leaving, his mother alone and vulnerable — providing moments where he can reflect about life as a Gilmore. All of his dreams return to scenes of death and dying, repeating a traumatic story of loss. The repetition of loss sustains a past controlled not just by active memories, but also by that which cannot be remembered, what Domick LaCapra describes as "memory lapses of trauma:"

the memory lapses of trauma are conjoined with the tendency compulsively to repeat, relive, be possessed by, or act out traumatic scenes of the past, whether in more or less controlled artistic procedures or in uncontrolled existential experiences of hallucination, flashback, dream, and retraumatizing breakdown triggered by incidents that more or less obliquely recall the past. (10)

In providing access to the dreams and telling readers that these dreams happen again and again, Gilmore suggests that he is compelled to relive scenes of the past where his father crumbles and dies, his mother—old and frail—watches her husband cheat on her, his brother's heart is shot to ground, or he is tormented by the ghost who took his family. The characters in Gilmore's dreams are almost always fragile and in the process of dying, further emphasizing the connection between the dreams and Gilmore's understanding of his place in his family as one defined by 
loss and absence. In attending to absence and loss, Gilmore's stories reveal a counter-narrative that considers what happens to those left behind. He writes that the "misery of my brothers' childhood is so distinct from the misery of my own childhood, it's almost impossible for me to feel delivered from their hell, anymore than I feel saved from World War Two merely because I didn't have to live through it" (4-5). Traces of the past help Gilmore make sense of the deeply problematic presence, and more importantly, his guilt for having survived his family's trauma. Using his dreams to capture this history evokes the dead, but frees Gilmore from having to maintain narrative coherence, a compensation for the gaps in his history created by the secrets that will remain buried.

\section{FILLING IN THE BLANKS: LEGACY \& STORYTELLING}

As the surviving Gilmore, Mikal becomes the keeper of stories, photos, history-in short the family's legacy — a job that complicates his efforts to establish a thriving, stable adult identity. A Gilmore in name only, he feels his childhood was a world so different that he "may as well have grown up under another surname" (4). Having watched each of his family die (or "simply walk into a shadow world" where he could not be uncovered), Gilmore believes that he will finally be "free to pursue [his] own family dream" (3). However, he does not escape his family's "ruin" and he decides that the only way to stop the legacy is to "crack open its godawful secrets" and "go back into [the] family_-back into its stories, its myths, its memories, its inheritance" (4). The stories he inherits are the family's legends of mystery and death. He writes: I knew about the violence of Mormon history, and about the haunted death of Alta, because these were stories my mother told me, time and again. I knew also that my father had a shadowy past — that his own father had wronged him beyond 
repair, and he had fled some deadly secret for nearly half a century—because these stories, too, were part of our active mythology. (53)

Gilmore not only inherits a set of mythologies, but also a cultural memory of his brother's public persona. Gilmore does not simply ‘crack open’ his family's ruin for his own truths; he narrativizes his search for selfhood while simultaneously interrogating the American hero mythology used by Mailer (and others) to understand Gary Gilmore as a public metonym for killer. As the brother of the infamous killer, Gilmore must examine both the family (and other institutions) that created the man put to death as well as how these same institutional forces indirectly sabotaged his own efforts to realize an alternative future.

Gilmore provides an introspective examination of the 'inside' story and reveals the impact of the institutionalization, described in continuous cycles of violence. Gilmore initially locates this cycle early, beginning with $20^{\text {th }}$ century Mormon Utah, a "place that, in many respects, was dramatically different from the American that surrounded it" (10). The Mormons, writes Gilmore, possessed a strong and "spectacular sense of otherness and unity;" as a group they saw themselves "not only as God's modern chosen people, but also as a people whose faith and identity had been forged by a long and bloody history, and by outright banishment" (10). The migration of the Church of Latter-Day Saints, a crucial moment in Mormon history, was fraught with violence, from their forced exodus of England through to their banishment in the dry, Southern mountains of Salt Lake City. Mormon history has a direct impact on the Gilmore family, at time providing refuge and at other times increasing surveillance and tension. In an effort to pass the legacy of the Mormon faith to her son, Gilmore recounts that his mother nurtured him with the legends of her people: the haunting stories of exile and persecution of Joseph Smith, Jr., the battles of Mephites and the Lamanites, and the performance of blood 
atonement as contrition. He identifies a strong kinship with Smith, in particular the "damnation he feared" and the "long-coming doom that finally swallowed him" (14-15). He states: "I feel for him as a brother" (15). Gilmore's identification with Smith establishes a critical association between his individual self and the religious body as an external family.

Both physical and spiritual religious bodies influence Gilmore's mother Bessie, particularly her explanations of secret or mysterious happenings. In her childhood she and her sister Alta found an Ouija board for their Halloween party. Though her sister Mary believed it would bring the Devil into the home, Bessie, Alta and Patta looked for those who might be present but not seen; they found the dead Indian. Discovered by their mother the girls were forced to try again in the barn, this time reading "I-AM-A-DEAD-INDIAN. I-WAS-KILLEDBECAUSE-I-KILLED-A-MAN. HE-STOLE-FROM-ME. I-WANT-BACK...”(37). Again discovered by a parent, the Ouija board is chopped to pieces with an axe; however, Bessie retells this story to Gilmore as explanation for her sister Alta's death. Alta and Wanda were sledding, something spooked the horse, and the two were thrown into a utility pole. Bessie and her sisters continued to see ghosts, and Bessie knew that "what had spooked the horse in that winter dusk time" was the "demon of the dead man that she and Alta had conjured" and that "now he was the ghost that would haunt her family" (40). That Bessie believes to be haunted by the ghost of a wrongly executed Native spirit says much about her rationalization of injustice. The history of Western settlement is fraught with unequal exchanges of power, and as Gilmore acknowledges the brutal rapport between Natives and the Mormon settlers ended with "Indians" who "paid with their lives for these skirmishes" (23).

Bessie's stories adopt an increasingly darker view of the past as her conditions deteriorate. Gilmore notes that as his mother aged her memories of her father changed and with 
these changes came stories of abuse. Bessie recounts that her father's temper grew shorter and his primary targets were Bessie and her brother George. George was reportedly an odd individual, homely and gawky, a loner whose artistic skills were profound. Will Brown, Bessie's father, would occasionally explode in anger and tie a naked George to a tree and beat him so fiercely that his cries could be heard from the next farm over. George's description and humiliating abuse foreshadow Gary's experiences as an outcast, contributing to what Bessie calls the "milestones of our collective tragedy" (43). One of the key milestones in Bessie's memory is the day she came to hate her father. Bessie claims that her father forced her to watch a man condemned to hanging. She told Gilmore that she hated executions since they were the "only killings we might possibly prevent" (46). Bessie's stories about the abuse and loss she suffered as a child seem to provide a crucial connection to her children and possible explanation of her partnership with an abusive man. But, in researching his family history, Gilmore reads that the execution story could not have been true because there were not semi-public executions in Utah after the year 1919 (47). Gilmore is "struck by the impact that legends must have had on us" (47). The images, he believes, instilled a sense of otherness, a sense that the stories were not "just a story of a distant past in a cruel place," but also held within them "something about our own predestination" (47). Their family mythologies made outcasts of all of them, much of which was related to a fear of death. The noose was a talisman working not as a deterrent, but as a sign of destiny (48).

Bessie's memories of her childhood shift in relation to her adult experiences and challenge Gilmore to think about the purpose of storytelling in his family. He concludes that his mother's stories, though not necessarily truthful, help her convey the "harshness of growing up amid such an unforgiving land and its people" (48). As Bessie attempts to reconcile her adult 
life--"looking for the key to where everything had gone wrong"- she moves from speaking of her father as an "ideal" to a mythology that allows her to talk about the "other ways the her father may have visited ruin and violence upon her-ways that she might not have been able otherwise to talk about, or that perhaps she could no longer bring herself to remember" (44-48). Bessie's stories frequently return to loss and disappointment, a representation of families failing to thrive- her own family most of all.

Perhaps more than any other force, the Gilmore children faced prolonged institutional conflicts as a result of parents who were engaged in a longstanding battle for governance over the home, including control over of the prevailing metaphors that would guide their children. The presence of the Church body fed into the discord between Bessie and her husband and later between Bessie and the children. Religion divided their home, a source of ridicule and avenue for verbal abuse and control between Frank and his wife. Bessie wanted the children to be raised in the Mormon faith; Frank wanted the children to be raised Catholic. After loosing a baby, Bessie tells Frank that she is barren; but, as she watches each of her sons take the Catholic faith she finds herself making a deal with her husband: another baby and in exchange she could raise the baby in the Mormon faith. Mikal was the Gilmore promised to Bessie. Frank reneges on his promise after Bessie attempts to smother Mikal as she tells everyone that there is "something wrong with this baby" (111). Gilmore's near death as a baby launches a lifelong struggle between his parents, each using storytelling as a means of manipulation to win his loyalty and affection. Frank would tell him that his mother was crazy and had plans to kill him, which led to sleepless nights waiting for his mother's blade, while Bessie filled him full of tormented family legends and "ghost tales" (116). 
Gilmore's mother's stories act as a legacy and connection to the larger religious and biological family she left behind in Utah. Conversely, Gilmore inherits very few stories about his father or his father's family. A secretive man, Frank Sr. didn't share his past with anyone. Frank and Bessie left Utah and were married by Frank's mother Fay in an unlawful ceremony. Soon after, Frank leaves Bessie to travel for 'business.' In Sacramento, CA Bessie must face the fact that she doesn't know much about Frank. She meets his son Robert Ingram, a son she didn't know existed, and a product of a marriage she didn't know existed. Fay laughs and tells her: "he really hasn't told you much, has he" (63)? From Fay, Bessie learns that Frank has many alias, many wives, many pasts. She hints that his father might have been Harry Houdini, that Frank himself was a circus performer, and that by her count, Bessie might be wife six or seven (63-64). Fay also has a mysterious past; she claims to be a countess, the descendent of the French House of Bourbon, and that due to circumstance she and her sisters put together a dance performance and traveled the U.S. until she settled in California to work as a psychic. From Fay, Gilmore does not just inherit his father's stories, but also a lifetime of performances based on giving the audience what they need to see.

The Gilmore family used stories to conceal their secrets, specifically those secrets produced during periods of absence. Cycles of separation—Frank's departures for business or jail, Gary's arrests and sentences for juvenile hall or jail, Gaylen's arrests, Frank Jr.'s military service - fail to provide sustained relief from the tension in the home. Neither able escape the savagery nor create a civilized presence; the Gilmore home produced an inverse hero's journey, where those who left returned to inflict violence and harm. Gilmore frequently alludes to absence as the means through which he understands his individual history. He frequently highlights his brother's comings and goings, losses that add to Gilmore's feeling of abandonment and lack of 
kinship with his family. In fact, Gilmore's first memory of Gary is not having a memory of Gary. He explains that at four years old his brother was a stranger. Seeing the confused look on his face, his mother told him: "We've kept him buried out back next to the garage for a while [and] we finally got around to digging him up" (121). Though everyone laughed, the implied representation of buried secrets cannot be ignored anymore than the cruel undertone suggesting that his brother was always dead.

If Mikal Gilmore was the family's best hope for a promising legacy, Gary represented all their worst fears about the way their family would be remembered. Gilmore's "first glimpse of what life may have been like" for Gary was in 1979, when Executioner's Song was published. Gary isn't somebody who "comes back to me that much through my own memory;" he was only somebody who was "talked about" but whose activities outside the home had a "tremendous impact on our peace of mind, like a storm, always looming outside the door" (170). Gilmore describes two memories he does have of his brother: one, a time when he walked in on his brother having sex with two girls on his bed, and another, a conversation he had with Gary over a Christmas beer during which his brother told him about his time in juvenile detention. Gary makes his brother promise to allow others to beat him, repeating that he should never fight back - it is "the only way you will survive" (171). Gilmore realizes that Gary was telling him "how to survive in our family" (172). Gary's philosophies about survival cannot be detached from paternal abuses, either inside or outside the home. His experiences with institutionalization begin early with reform school stepping in for the discipline he appeared to be lacking at home. In reality, though, Gary bore incredibly hard abuses no matter where he lived. Frank Jr. reflects that Gary never learned how to endure pain: 
If you cried or screamed then Dad knew he was hurting you, and it only made him go harder. So I would just cover up and just hold it in. As a result, I got hit less than Gary, because Gary used to really jump and yell and scream. Dad would really go to town on him then. He would go completely off his rocker, and he just wouldn't stop. He's keep swinging and swinging and winging, and Gary kept yelling and crying and begging him to stop, which would only make Dad hit him harder and longer. (125)

While Frank was able to shut down emotionally as a way to cope with the abuse and psychic costs of witnessing his own and other's traumas, Gary was not. Gary never stopped fighting battles he knew he could not win (126).

Because Gary spent so much of his childhood and adult life in penal institutions, Gilmore must piece together a narrative about his brother's history. In documents gathered from prison officials and former inmates willing to talk, Gilmore tries to write the history that can never be verified. As an inmate his brother seemed to have been no less contrary than the child he was at home. He felt more comfortable in solitary confinement, and often committed acts of violence to continue his isolation. One of the most heart-wrenching stories of Gary's time at the MacLaren's Reform School for Boys comes from a letter he had written to his mother much later, while serving time at the Portland City Jail. The letter came in response to his mother's efforts to understand his most recent suicide attempt. Gary wrote that he was haunted by an incident at MacLaren's. He had befriended a young, orphan boy whose "pretty and fragile manner" made him more vulnerable inside a jail (158). Gary watched as ten boys held the orphan down, each taking their turns raping him; he refused his turn. The boy was a target for mistreatment and he spent more and more time in the infirmary. One cold night the boy asked to be taken away to 
infirmary and was refused; he then asked Gary if he could stay with him. The boy tells him that he just wants to disappear, to "disappear into the nothingness inside myself, where nobody can hurt me ever again" (159). Gary tells his mother that he is too healthy to die the way the orphan died, but he knows that this is what will happen to him if he doesn't get out jail, so he "tried to escape the only way he knew how" (159). Since no record of the death remains, Gilmore speculates that the story is "another one of the necessary lies that the members of my family learned to tell about themselves in order to tell far worse truths" (159). For better or worse, Gilmore writes, the "true story" of the past was "lost for good when my parents and brothers died" (55).

Despite their best efforts to conceal the missing 'parts,' traces of the inexplicable continue to impact the Gilmore home. Frank Jr. helps Gilmore fill in this part of his father's story, telling him about the absences that weren't for business, but because he had landed in jail for bad check charges or drunken abuses. Frank tells him about the time his father was missing for so long that he didn't think, "we remembered him" (95). Rather than distancing the children from the penal institution, Frank Sr.'s time in jail created a stronger link between the tension at home and the conflicts with social rule. Frank adopted stronger and more violent forms of discipline that he had both witnessed and experienced. According to Frank Jr. he was "like this new man in our lives," and "he was real mean" (95). Frank's "new" institutional identity shaped the home into a place of instability, uncertainty, and abuse. The boys were punished for the "slightest things," not eating fast enough, clumsiness, or crying; it wasn't difficult to discover a punishable offense. Frank Jr. says that "one time we were eating dinner and I dropped my cake and, man, he just went bananas. Made me get down and pick up every crumb and gave me a few good whacks along the way. He's screaming and yelling at me and hit me the whole time for 
dropping a piece of cake on the floor. Maybe he'd had a bad day, but was an immature way to treat a little kid" (96). Similarly, Gary’s frequent trips to juvenile detention centers and near constant interaction with police officers for crimes like petty theft and vandalism, bated Frank Sr. and increased his rage.

At the heart of the text lies a struggle between two representations, two stories, of the man and myth, Frank Sr. Unlike his brothers, Gilmore does not know a life without his father; he and his father were their "own family" (173). Gilmore writes that he watched a different type of fighting:

Whereas my brothers lived through vicious physical fights between my parentsall those occasions when my father battered my mother, and my brothers were made to watch-I remember a different experience of argument. I never once saw one of my parents strike the other-or if I saw it, I simply don't remember it. I don't doubt that it happened in the earlier years, but perhaps by the time I was born my father either had learned a certain belated restraint or was simply too old to whale the shit out of everybody all the time. Maybe beating my brothers was now enough to satisfy his rage. (174)

The isolation did not shield him from the abuses, but instead he learned to love "choosing between two loves that [he] could not live without and that [he] could never hope to reconcile" (177). For Frank Jr., Gary and Gaylen, Frank Sr. was a man crazed by a desire to inflict pain and discipline:

When Dad would grab the razor strap and go haywire on us [...] he wasn't talking to us about anything that we'd done wrong, nor was he telling us how we needed to improve our behavior [...] He wasn't doing it to teach us anything [...] he 
punished us: not to make us better but to make us sorry. But when you get punished like that how are you going to be sorry for what you did? [...] that's what he built up in us, resentment, because even as kids you know you are being overpunished for simple things. (125-26)

The three older boys suffer a lifetime of insufficient relationships, most of which substitute other forms of institutional discipline for their father's abuse. Frank Jr. was drafted into the military, but refused to kill. Unable to pay for a civilian lawyer he was sent to Fort Leavenworth to serve a jail term for disobeying an officer's orders. Gaylen's life got “strange and mysterious" (260). He too spent time in and out of jail, drank heavily, and disappeared for years at a time. All of the boys seemed to realize the assessment made by one of Gary's release counselors; Frank Sr. was unable to connect to his older boys with any sort of emotion:

Mr. Gilmore appears to be incapable of establishing even a marginal constructive emotional relationship with Gary. The only hope is that Gary can acquire the necessary maturity through his school relationships that will enable him to continue on parole in spite of these negative factors existing at home. (163)

Bessie, too, tries to point to Frank Sr. and ask that he look at himself the next time he comes after Gary for an offense. She sees too late that the sins of the father have been visited upon her sons.

Part of Gilmore's work lies in "demythologizing” spectacles of violence while simultaneously acknowledging the spectacular - a reality so far from reality as to seem "unreal"-which is, in part, achieved by maintaining images of children and childhood throughout the text. To understand his brothers, Gilmore turns back to his own childhood, but in doing so he realizes the he cannot identify with his brothers. As a child he lay in bed, contemplating the shadows, believing that he could hear moving the darkness that might be his 
"mother's madness," his "brother's pain," or the "spirit of a murder"-forces "ready to sweep down on us and stab out our lives" (179). At five-years-old the only way Gilmore remembers having made sense of his world was through dreams. The dreams took one of two forms: one set concerned thing dwelling in the darkness, spirits and demons that lie waiting to kill; and the other set were "more disturbing" (180). The most common scenario visualized Gilmore as a policeman or detective investigating a killing. He says he always had a partner, a little girl with blonde hair who he loved. In the dream Gilmore realizes that he is the killer and he must kill the girl to protect his secret; he would kiss her, then shoot her. All variants of the dream end with him killing a child. Despite his prayers, the dreams never stopped.

Though Gilmore claims that he has no idea what the dream might mean, the dream, like his brother's story about the orphan, utilizes the image a child to intensify the juxtaposition of lost innocence and violence. Children, according to Lee Edelman, have become an emblem of the family, aiding in a "fantasmic" vision of the future that provides the terms for imposing ideological discourse invested in preserving the "absolute privilege of heteronormativity" (2). This investment in the child and childhood, Edelman argues, justifies regular and consistent political intervention through various institutions — schools, jails, churches, or hospitals — which take over when the familial institution fails to provide culturally recognized forms of transmission. In theory the institutions step in a means of protecting children from the possibility of real or perceived harm, but as the Gilmore family narrative demonstrates, all institutions are capable of inflicting harm, including the family. In writing about the impulse to preserve family, Gilmore takes a similar stance to Edelman, arguing that when he hears "stay together for the sake of the family," what is really meant is: "the family—and the privacies of its authority—must be preserved" (243). Gilmore says he hates families. He writes: 
I see them walking in their clean clusters in a shopping mall, or I hear friends talking about family get-togethers and family problems, or I visit families in their homes, and I inevitably resent them. I resent them for whatever real happiness they may have achieved, and because I didn't have such a family in my life. And I despise them for the ways in which the notion of the family good is still used to shame or subjugate the children within the family, long past the time when they've become adults. (243-44)

He adds that his parents were "sad and wretched people;" it is "heartrending they ever had children at all" (244). Gilmore's work demythologizing his brother's violence depends on understanding the way his father was complicit in determining a futurity where his authority lingered.

\section{CONCLUSION}

The Gilmore family's sustains hope by mythologizing the past in an attempt to rescue failed attempts at normalcy. As the audience bears witness to the disclosure of his family's secrets, Gilmore takes advantage of the confessional aspects of the autobiographical genre, particularly in the epilogue where Gilmore closes the text with his final dream. Rather than saving the last moments of the text for self-interrogation, Gilmore focuses in on the institution as it impacted his family's development. The dream provides an endnote emphasizing the effects of prolonged childhood by repeating killing the child to save the man. Even in Frank's absence, paternal authority continues to stymie his children's growth; his children never grow up because a "father" continues to linger, or in the words of Gary Gilmore: "there will always be a father." The courts and lawyers and police did not protect the Gilmore children from abuse, and instead helped reinforce the fierce authority that left them hopeless and always in the process of dying. 
In the dream Gary is once again on trial and facing death, but this time the courts hear testimony from Gilmore about the lifetime of suffering, "how he was forced to watch his mother being beaten, how he was abandoned and abused a thousand times" (397). The courts deem the information unworthy: "what happens to the child doesn't absolve the man" (398). The courts then turn to a child, a dark-haired girl who is Gary's three-year-old daughter. They decide that she too must die, because she is "too contaminated by him to survive" (398). Gary accepts the decision, willing to sacrifice the child for his own reprieve from life. Gilmore fights for the child and breaks down in grief when he is told the child is dead. Her loss triggers inconsolable pain and the realization that to survive Gilmore must accept that "it will never be all right" (398).

Essential to the Gilmore family story are the violent effects of religion and the criminal justice system — all of which operate as the silent "father" throughout the text. Gary's final words stressing the extended presence of paternal authority make surrogate forms of institutional power (in his case the criminal justice system) complicit in his damaged family legacy. There will always be a father is most often connected to Gary's time in prison; however, as his brother Mikal demonstrates the role religion was equally complicit in the violence in their home-Will Brown (Bessie's father and a respected Mormon) is no less culpable for the damage inflicted on his daughter. The ghostly presence of a father whose impact long outlives his death haunts the text, inspiring the legends and histories Gilmore inherits. Though Gilmore's text somewhat answers Mailer's, filling in and supplementing Gary's familial history, Gilmore's narrative is still riddled with the unanswerable questions and unverified truths. In some ways the absent stories lend the narrative a familial authority, mirroring the family penchant for secrecy and illusion; but, unlike his family legends and mythologies (particularly those skirting indescribable violence and loss), Gilmore confronts the turmoil he feels in having survived his family by 
sharing his most intimate moments in the dream passages. The dream passages provide Gilmore with a strategy for historical intervention where he can be narrator to his family's past, interrogator of his family's secrets, and present in a way that he could not have been in the past. Gilmore's future depends on a continued negotiation between the father he knew and the father he didn't know. He must accept Frank Jr.'s conclusion that "everything in our family is hard to talk about" (392). 


\section{Chapter Four:}

\section{The Adult Child: Reviving the Father in Recycled Performances}

\section{[...] there's a lot of really serious stuff going on in The America Play, but I} swear, I can only think of the jokes. The jokes led me to write America. The relationship between "nigger" and "digger" was the whole play for me. When I could allow myself to have a little chuckle about "nigger" and "digger," I knew who those people were in the play. ${ }^{28}$-Suzan-Lori Parks

Dig. - Lucy

It's difficult to turn away from the Great Hole of history. Perhaps an allusion to a black hole_-an absence so powerful that even light, an absolute constant in our reality, cannot escape - the Great Hole of history pulls everything and everyone toward it. In the presence of a black hole light ceases to exist, the event horizon separating what we know from what we can never see, or to think of it another way, a black hole determines what we know in the present from what we cannot know of the past or in the future. But in Suzan-Lori Parks' The America Play this phenomenon doesn't separate audiences from the future and it isn't cosmic; the play is an "intensification of and an obsession with absence" 29 found just under our feet. Parks" play shifts the audience's gaze downward, toward the Earth, drawing attention to that which has been hidden and needs to be unearthed. This downward shift of the gaze is opposite our instinctual turn toward Heaven and, as Heidi Holder points out, also counter to the stage figures'

\footnotetext{
${ }^{28}$ See interview with Han Ong.

${ }^{29}$ See Heidi Holder for further discussion of staging history (18-21).
} 
"professional interests;" the Lesser Known, Lucy and Brazil should be putting things into the ground, but they are compelled to dig things up (21).

The play begins its excavation of history with the Lesser Known and the assassination of Abraham Lincoln. The assassination becomes the core around which the events of history and the story of "The Lesser Known" Lincoln revolve, a process that digs up the past in a Rep and $\operatorname{Rev}^{30}$ style (Parks' shorthand version of repetition and revision) reminiscent of jazz. Parks calls upon the Lesser Known to intervene and recycle Lincoln's famous words in penny-admission performances that allow passersby to assume the role of John Wilkes Booth and pretend to shoot a Black man dressed as Lincoln. The play offers scant details for plot summary; the first half of the play is focused on the Lesser Known and his monologues describing the trajectory of his career and life, specifically his desire to exploit what he imagines to be an unusually strong resemblance to Lincoln. The second half of the play reveals the family left behind when the Lesser Known takes his show out West. Left alone to manage the family's grieving business, Lucy, the Lesser Known's wife and a keeper of secrets, and their son Brazil must cope with the impact of the Lesser Known's loss. Just as the defining characteristic of a black hole is absence, so too is absence the shared state for the stage figures - everyone is searching to fill in the holes.

Ironically, the family's desire to fill in holes manifests by digging holes, and where better to dig holes than in 'open' space. The West is the place upon which the Lesser Known and his family project possibilities for the future while digging up the past. Though scholars have frequently noted Parks' timeline as non-linear, relocating the play's setting to the west invokes a trope about the West as before-history space. The West seems to open doors to the past.

\footnotetext{
${ }^{30}$ Parks defines Rep and Rev as the individual daily accommodation for the historical and familial absence, and more specifically, the secrets that are not witnessed except through gestures. See Harry Elam and Alice Rayner (181), Haike Frank (4), Heidi Holder (19) and interviews with Suzan-Lori Parks describing her style as "Rep \& Rev," (repetition and revision).
} 
Seeking to right and rewrite ${ }^{31}$ the loss of African American history, The Lesser Known recreates generational trauma through his penny-show performances. However, his search only accounts for the first half of the performance. Cast through the ever-shifting articulation of "forefather," the Lesser Known plays the father of America to the abandonment of his own son Brazil. And while in Act One the Lesser Known mourns the absences of Lincoln and potentially unwritten histories, in Act Two, Lucy and Brazil attempt to accommodate for the private loss of a father and husband. The absence forecasted by the Lesser Known in the first act is doubled for Lucy and Brazil; they are not only missing history, they are missing the Lesser Known. The term "missing" has more than one connotation: to miss or grieve absence and to be the absence itself, a lack of existence. Lucy and Brazil's search seems to be motivated by a desire for whole-ness, a reincorporation of that which has been absent, a search that parallels the Lesser Known's own desires for a "whole" history. Paradoxically the family digs holes to be whole. ${ }^{32}$

The desire for wholeness also surfaces in the relationship between Brazil and his parents, primarily in Lucy's coinciding orders to dig and to practice his father's Lincoln show. Brazil's revivals of his father's show trap Brazil in the past while ensuring the survival of his father's legacy, both of which offer uncertain conclusions about Brazil's ability to escape the hole of history. As a child figure, Brazil is held by parents who are looking backwards to fix a futurity determined by Brazil's ability to right the wrongs of the past. Although standard definitions of child do not necessarily consider figures like Brazil—he is not a child, he is a thirty-five year old man - as the son of the Lesser Known and Lucy he will remain the child though kinship relations as long as his parents survive. The Lesser Known's survival depends on Brazil and the continuation of his Lincoln performances, acts that demonstrate survival through the repetition

\footnotetext{
${ }^{31}$ The terms re-write and re-right are inspired by Harry Elam's introduction to The Past as Present in the Drama of August Wilson.

${ }^{32}$ For work about the stage and whole-ness see Harry Elam (180) and Katy Ryan (83).
} 
and revival ensured in the figure of the child. Brazil's Lincoln act offers survivalist presence in the absence created by history and his father.

The Lesser Known brings history to the West through his show, but also uses the West to bury his own past (to hide what he doesn't want his family to know), in effect trading fatherhood of a son for fatherhood of a nation. Lucy and Brazil's efforts to unearth family's secrets drive them to follow the Lesser Known out West where Lucy speculates that she will be able to discover the whole truth if only Brazil can only dig something up from the Great Hole of History. Though the West might be the frontier of individual discovery, the return to the self is contingent upon a bifurcation that provides permission to at once lay one history to rest and rewrite the next. Lucy fails to realize that while they are looking for the past they are participating in the present; their performances simultaneously re-vise and re-animate history and establish presence in the West. Their performance ignores the histories present before the Lesser Known's recreation of the Great Hole of History (such as Lincoln's order to execute three hundred Native Americans convicted of war crimes in the Dakota-Sioux Conflict) ${ }^{33}$ and crafts the West as a canvas for Disneyland-like fantasies of the Real history. ${ }^{34}$

That the family business is grieving is crucial for thinking about how Brazil negotiates his identity as a son and a citizen. Brazil mourns history through the reenactment of Lincoln, but this reenactment forces Brazil to lose his father over and over again. The act of public mourning is a testimony to presence in absence. The mourning itself substitutes for the individual's presence, or as Jennifer Griffiths states: “Testimony offers a public enactment of memory" (5). In the end, Brazil's means to self-actualization is paired with the act of grieving, an act tainted by the falseness of previous performances encouraged by his parents. Similarly, Lucy's repeated

\footnotetext{
${ }^{33}$ Also referred to as the Great Sioux Uprising (1862).

${ }^{34}$ For further discussion of Disneyland, history and simulacra see Elam and Rayner (178-179).
} 
command — dig — reverses her role as a professional confidence and instead of keeping secrets she asks her son to expose them. The presence of secrets, or rather the absence of knowledge, aggravates Lucy in a way that is counter to her job as secret keeper. Lucy may be used to keeping others' secrets, but she seems inconsolable about the secrets her husband might have kept from her. In possessing other's secrets, Lucy believes that she has the "whole" story and that she is capable of filling in the missing pieces of the story. What she cannot do is fill in her own story.

The copy of a copy, Brazil's efforts to mimic his father draws attention to the way we understand reproduction and artifice. Brazil is not simply a black man; he is a black man pretending to be his father who was pretending to be a white man. These layers of performativity are underscored by acts of speech—speech acts — that participate in the transmission of family secrets. Brazil's "foe-father" is his both his "faux-father" and his "forefather." Despite the wordplay, each reiteration of father retains roots in paternity, which stresses Brazil's role as a son. The son of the "forefather," Brazil is also the child of America, shaped by institutional racism as well as the institution of family. Brazil inherits his father's box of beards, his speech, and manners as well as the Hole of History (the cavity, the void, and the sum of it all). Brazil digs into the past to help his mother reconstruct their family (in effect ensuring survival) and by extension he works to recover a childhood lost when the Lesser Known left his five-year old son eating peas at the dinner table.

\section{THE WEST: HISTORY \& FATHERHOOD}

It's interesting that one Great Hole of History was not enough. Whether there was not enough space or not enough time, the Lesser Known had to go out West to make his own hole. Like the Lesser Known's version of Lincoln, the West is a space of 'not-but,' a place where the 
East journeyed and turned into the West, a version of the East, but not. According to Una Chaudhuri, the desire to replicate spaces comes from the "geopathology" of the play; the Great Hole produces the desire to move on, to move West and to reproduce similar images, a reproduction that suggests the frontier holds the "promise of countless replications of the original spectacle of greatness" (262). The text provides little indication or reason for the movement; the Lesser Known simply states in Act One: “The Lesser Known left his wife and child and went out West finally" (163). The word 'finally' implies inevitability; like Manifest Destiny, the move was always a foregone conclusion, which is foreshadowed by the Lesser Known's memories of the "Reconstructed Historicities."

On his way home from the theme park where he and Lucy spent their honeymoon, the Lesser Known cannot stop thinking about the histories paraded by him, not "on past but past. Behind him" (163). The Lesser Known imagines history as movement and in order to keep up he had to follow. He is fixated on this memory from his honeymoon, this staging of cultural memory, but ultimately, it's not that the Lesser Known needs to remember history, as much as he needs others to remember him in history. According to Dominic La Capra, history is often placed in opposition to memory; however, he emphasizes that memory is neither identical to nor the opposite of history (19). La Capra argues that a "critically informed" memory is "crucial in the attempt to determine what in history deserves preservation in living conditions;" it is the "feel of an experience, the joy or suffering, the quality of an experience" (20). The Lesser Known becomes obsessed with the past and particularly with the idea of becoming as memorable as figures of the past. To have made his mark in the West is to suggest that the only space available for this revision is the space where history has not yet been written - the West. 
The Lesser Known brings history to the West with his penny arcade show, burying his personal past, and hiding what he doesn't want his family or others to know. Much like the notion of the ahistorical West, the Lesser Known's use of the West as a space for secrets participates in a narrative of the West as a space for subversive behavior. The frontier frequently hosted those seeking a new identity. Richard Slotkin writes that American heroes had to cross boundaries — go beyond the pale_-and regress into a more "savage" state so that they could purge themselves of the "false" metropolitan ideals and survive a return to civilization. This regression equipped heroes to better mediate the "darker" side of their own human nature. Similarly, Phillip Deloria argues that the frontier represented the space where the modern, urban man could regain a more "authentic" male-hood outside of industrial anxiety, particularly through “playing Indian” (7). Both Frederick Douglas Turner and Theodore Roosevelt wrote compelling doctrines mythologizing the frontier as a space for developing masculinity, a space where Americans could "engage in collective fantasies about history and reality" and craft a master narrative for structuring a relationship between Whites and non-Whites (Johnson, M. 8). For Native Americans this relationship was based increasingly on removal, assimilation, and death - a steady march toward the vanishing point. For African Americans the West represented the promise of an alternative to Civil War politics and slavery. By traveling to the past and joining those who have passed, the Lesser Known attempts to acquire masculinity in two manners: by adopting a White identity through the disguise of Lincoln, and subsequently, by participating in the power of frontier regeneration.

The Lesser Known's migration to the West contributes to a mythos of the primitive West, a space where we can find evidence of the prehistoric or, worse still, the absence of history. Harry Elam and Alice Rayner appropriately highlight the script as a mediation of the absent 
history of the Black body, but more importantly they open a discussion about which body will provide presence for the absence. Elam and Rayner recognize the play's identity challenges as one of three paths that Parks uses to address African American exclusion and inclusion from history. Parks' exploitation of metaphors for theater, theme parks, and theatricality interrogate the myths of history and challenge the discrepancies between recorded history and lived experience, "challenging the fundamental myths and meanings of 'America' and foregrounding the role race has played in the construction of those myths" (Elam and Rayner 179). Beyond these metaphors, Parks' "resonance of the specific problem of historicity and meaning with a long dramatic tradition concerned with a dead or absent father figure," directly addresses Lucy and Brazil's search for the Lesser Known in the second act (Elam and Rayner 179). The play is as much about the missing Black father as it is the missing Black patriarch of American history.

The Lesser Known's acquisition of and intercession with history through the figure of Lincoln alludes not just to the predominantly White historical narratives, but also the heavily weighted rhetoric of fatherhood. Parks' acknowledges this tension by exchanging "Founding Father" with "Foundling Father;" one of course is the head of the nation, the other abandoned. Though the Lesser Known is referred to as the Foundling Father, in truth it is Brazil who should hold the title since he feels abandoned. Haike Frank points to Brazil's search for his absent father as a reconstruction of his father's work and highlights that the "forefather" (and faux-father) becomes a powerful linguistic pun that interrogates what neither Brazil nor Lucy stop to ask: can the father ever be "un-dug" (Frank 18). Frank argues that like his father, Brazil is "digging another Great Hole of History that resists the excavation of black history because there is none to be found" and instead (like the Lesser Known) Brazil is "merely preparing his own grave" (Frank 18). 
Death and the gravesite play a dual role in the play as both the equivocating role in humanity as well as the absence from which wholeness cannot be recovered - the ultimate absence. As a confidence ${ }^{35}$ Lucy listens to deathbed confessions, which reveal the commonness of secrets, lies, and performances. An obsession with history also emphasizes that eventually everyone dies. It seems appropriate that the Lesser Known reveals his own secrets at the gravesite; from the hole he tells Lucy that this is a "momentous occasion" and that he would like to say a "few words from the grave:" "Maybe a little conversation: Such a long story. Uhhem. I quit the business. And buried all my things. I dropped anchor: Bottomless. Your turn" (197). The big secret, that the Lesser Known failed, fails to impact Lucy and Brazil.

Lucy responds by asking mundane questions, would he prefer an open casket, would he do his Lincoln one last time for Brazil? These mundane exchanges are underscored by Brazil's comments telling his father that he is going to "gnash" for him, "teeth in thuh dirt, hands like this, then jump up rip my clothes up, you know, you know go all out” (196). Echoing previous conversations, Brazil promises his father a fake grief like any other. Laura Dawkins reads certain moments of the text, including this one, as expressions of genuine grief. She specifically draws attention to the "primal moans and gasps"- the release of "waaaaahhhhhHHHHH!" and "HUH HEE HUH HEE" after discovering the material history ("peace pacts, writs, bills of sale, treaties, notices")- as an act of "genuine mourning "and an "epiphanic moment in the play, shattering his performer's façade and revealing the raw agony of a bereft son" (87). Given that Brazil has spent much of text bragging about his expert ability to perform grief, I am not convinced that there is enough evidence in these lines to suggest any notion of genuineness. At several moments Lucy

\footnotetext{
${ }^{35}$ Verna Foster contends that Lucy's work as a confidence provides her the ability to know what is "real," and her insistence on digging for the truth is related to her ability to discern fake from real. Though my work in this essay aligns to this reading in some ways, there is no support for claiming that Lucy can indeed discern truth from lie. Lucy's focus on truth seems more likely to be an obsession with wholeness rather than truth, thus her ability to discern between real and false is less important than her personal desire for something more.
} 
tells Brazil to keep himself in check, suggesting that Brazil tends to exaggerate. It seems more likely that his moans are a moment of exaggerated grief, hyperbolized for the effect of emphasizing lack rather than genuine grief.

Lucy and Brazil use grief to create a type of presence, but ultimately what is missing has "a lot more to do with the search for an authentic father" (Richards 3). The Lesser Known looks to Lincoln to provide surrogate "father," but Brazil has difficulty following in his father's footsteps. Though Lucy coaches Brazil's Lincoln performances, she also seems to draw sadness and anger from the reminder that these performances issue. The performances emphasize the management of the past based on fatherhood, and more specifically, patriarchy. It's crucial to note that the search for the past and the absent father begins with the Lesser Known-we get to Lucy and Brazil's story through the Lesser Known and their story is mediated through his loss. The implications of Brazil's promise for public displays of grief may appear benign, but neither Lucy nor Brazil return the Lesser Known's request for genuine affection-a simple hug — a denial that reveals much about the emotional connections between the family members. In fact, more than once Brazil suggests an underlying anger. For example, though Brazil seems to brag that the hole is "our inheritance of sorts," after his mother tells him to dig, he replies: "I'd rather dust and polish" (185). Brazil doesn't seem as impressed by his inheritance nor is he interested in digging through the past. Like a petulant (or perhaps more self-aware) child, he asserts an independence counter to the performances he has given thus far in the play. A similar implication comes out a series of lines that begin with Brazil calling his father fake:

My faux-father. Thuh one who comed out here before us. Thuh one who left us behind. Tuh come out here all uhlone. Tuh do his bit. All them who comed before us - my Daddy. He's one of them. (184) 
As much as Lucy repeats that she cannot understand why, when she gave him everything, he left, Brazil cannot let go of the fact that the Lesser Known left him behind. Again, in a childlike manner Brazil says, "he's one of them," which could be a suggestion that the Lesser Known is one of the men of history, but could also be taken as Brazil's resentment that his father has become "one of them." Indistinguishable as "them," Brazil's performances of grief for his father's death will be like any of the funerals, a continuous echo of counterfeit grief.

The play's attempts to rescript the leftovers of history often elude to geological terms for historicizing: archeology, excavation, and echo, all of which are titles for the sections in Act Two. Linda Ben-Zvi, exploring Parks' connection between language and image, reports that as a child Parks wanted to be a geologist and that for Parks "writing is a form of digging: cracking open words to discover the secrets that lie hidden" (204). Ben-Zvi believes that the play itself is an "excavation" (204). As a field of study, archeology uses material history to reconstruct stories of the past; however, archeology as a practice is shadowed by less ethical practices. Calling Act Two the "Hall of Wonders" invokes history as it has been captured in museums, arcades, and theme parks, a commentary that problematizes the notion of authenticity. The Lesser Known, though not the authentic Lincoln, is still accepted as Lincoln because they look alike. Yet, the absurdity of this notion interrogates our understandings of who an authentic Lincoln might beis it the cardboard cutout? Or the bust of Lincoln crafted from stone? Sun Hee Lee notes this absurdity and argues that the Lesser Known's vaudeville-inspired performance was never trying to achieve verisimilitude. Each repetition, according to Lee carries a different signification and "history becomes cleaved from the real, crating and perpetuation its discursivity" (9).

Yet, what Lee fails to see is Parks's overt statement denying any possibility of an authentic or real history - history is faking it as much as the Lesser Known is. Faking is an 
integral part of the way the play demonstrates the critical limits of the historical and racial real. One of the "secrets" of the play is that only Lucy and Brazil recognize the Lesser Known for who he is: a father, a foe, a faker, a faux. Ironically, the Lesser Known abandons real fatherhood to play a father. Lucy proclaims at frequent intervals that she knows "uh faker" when she sees one and she tells Brazil that his father was "uh faker. Huh. One of thuh best. There wuduhnt nobody your fathuh coulnt do" (181). But Lucy makes a crucial distinction between the Lesser Known's "callin" and his livelihood_-"Fakin was your Daddys callin but digging was his livelihood" (181). That Lucy uses the term 'callin' is important to understanding her vision of his work; a calling is a religious vocation compelled by a Higher power. Though the Lesser Known might have been compelled to be a "faker," in reality, he and Brazil, according to Lucy, will always be a digger: "Youre uh Digger. Youre uh Digger. Your Daddy was uh Digger and so are you" (192).

Lucy may be suggesting that the Lesser Known is not just trying to be a part of history, but in fact he is trying to escape his history as a digger, or rather as Parks implies, as a nigger. Lucy tells Brazil that "back East he was always digging. Was uh natural. Could dig uh hole for uh body that passed like no one else. Digged em quick and they looked good too" (181). Again, Lucy points to the East as the space of authenticity, where the Lesser Known was his "real" self, perhaps in part because in doing so she legitimizes the history of their love and marriage. Lucy has to look East because her history with the Lesser Known does not exist in the West. Lucy consistently discerns the margins, between the faker and the digger, the official history and the fake. She tells Brazil:

At the Great hole where we honeymooned — son, at thuh Original Great Hole, you could see thuh whole world without goin too far. You could look intuh that Hole 
and see your entire life pass before you. Not your own life but someones life from history, you know someone who'd done something of note, got theirselves know somehow, uh President or somebody who killed somebody important, uh face on uh postal stamp, you know, someone from history. Like you, but not you. You know: Known" (196).

Lucy appears to acknowledge and even understand her husband's desire for notoriety, yet these lines also hint at the sadness she feels for a moment no longer available. On their honeymoon the whole world was before them, and now she faces a single, solitary hole that obscures her vision. Unlike the Lesser Known, Lucy sees the parade for what it is - a death march where you can see your "entire life pass before you" (196). Lucy is also able to recognize that the figures in the parade are not that different from her and the Lesser Known, and she edges out the margins between "like" and "but not," landing on "known" as the distinguishing characteristic.

\section{ECHOES \& ETCETERA}

If knowing is the defining characteristic of life in history, then it might also be important to understand who is doing the knowing. Brazil's history with his father always exists in a marginal state, balancing between the fragile memories he has of his father's absence and the present moments he shares with his mother as they attempt to write themselves into the chapters of the Lesser Known's life in the West. The archeological dig, like the penny arcade reproduction, is doomed from the start. As much as the Lesser Known fixates on the memory of the parade, Lucy fixates on the memory of her marriage, repeating often that she gave him everything. The fact that their work leads to nothing more than echoes further emphasizes that nothing remains except for the illusion of the original. The dig is not just an excavation of 
materials; it is also an excavation of memories, and much like the absence of silence and secrets, the memories guiding Lucy and Brazil's efforts are ultimately unreal.

Both Lucy and the Lesser Known privilege historical memory as belonging to dominant culture, forgetting that Brazil's memories provide as much or more possibility for a future legacy. Neither Lucy nor the Lesser Known consider how the history of their personal conflicts impacts Brazil's development, and instead with an eye on the past, both parents directly and indirectly establish paths for selfhood as a continued performance of the Lesser Known, and of course, Lincoln. Training Brazil to reenact his father's act not only restricts his self-realization, but also reduces the family history to nothing more than a performance. Performances defy their momentary presence only insofar as the performance becomes a part of someone's memory. Who remembers the Lesser Known upon his death? Lucy states that "there are hundreds upon thousands who knew of your Daddy, glorified his reputation, and would like to pay their respects," but only Lucy and Brazil stand before the grave (195).

Like his mother, Brazil notes that "Thuh original ssback East" (179), and in doing so, Brazil also locates some type of original familial history back East. For Brazil history begins and ends when he is five, and he repeats often that when his father left he was only five. The loss of his father arrests his development, and in some ways stops history. By this I mean not that time stops, but that for Brazil, the history he shares with his father from this moment forward is constructed based on memories and the repeated and revised statements made by his mother. Arguing for the power of the unseen, Peggy Phelan writes: "the distortions of forgetting [...] infect memories" (1). These misperceptions feed into a notion of self-identity that "needs to be continually reproduced and reassured precisely because it fails to secure belief. It fails because it 
cannot rely on a verifiably continuous history" (4). Brazil's selfhood absolutely hinges on an unreliable vision of the past.

Brazil remembers only a few lessons from his father, all of which construct a fake identity for Brazil. The Lesser Known teaches Brazil the family business—fake grieving — "'the Weep' 'the Sob' and 'the Moan'” (182). The day before he leaves the Lesser Known teaches him "'the Gnash" and then leaves. In a poignant moment Brazil recites all that he remembers about his father's departure: he left to "seek his fortune. In the middle of dinner-time. The Son was eating peas" (182). That the play continually returns to third-person only emphasizes the development of selfhood and identity; Brazil speaks of himself as a son, knows himself as a son, and as such matures under the illusion that to be a man he must also become like his father, he must also be a digger and an impersonator of Lincoln, all of which is located "out West."

In Act Two, Brazil echoes his father's lines about the journey West, telling audiences that his father "come out here all uhone" and he "cleared thuh path tamed thuh wilderness dug this whole Hole with his own 2 hands and et cetera" (178-79). Brazil's story is like his father's and yet, as previously discussed, crucial differences reveal and emphasize the possibility that Brazil is not as impressed as his words proclaim; he reverence is in fact empty. Brazil opens the story of his father's Westward migration with a string of identifications for his father: "My foe-father, her husband, my Daddy, her mate, her man, my Pa” (178). That Brazil opens by calling his father a "foe" father is indicative that his father is not necessarily his hero. Similarly, his reiteration of the tale of his father's travels ends with "et cetera" as if to imply a dismissal—and "the rest." Brazil seems aware that his father is a leftover of history in as much as he is the rest of what his father left behind; he is the "et cetera" of his father's life. 
Brazil's efforts to echo his father's sense of manhood play on the notion that the West fosters newness, especially given that Lucy and Brazil continually look to the East as the source for authenticity. Echoes produce a powerful metaphor for the play's work, particularly in terms of the relationship between Brazil and his father. The play doesn't just use repetition; certain lines are meant to reverberate, like "OHWAYOH..." and "Hell1111loooooo..." are written to suggest echoes. Though echoes are a form of repetition, an echo is by definition a sound that mimics an original sound. Most critics and scholars immediately highlight Parks' use of repetition; she herself discusses its use in the opening statements of her 1995 collection. What I want to add to this ongoing discussion is the way Brazil echoes his father, at once producing a similar sound and predicating impending silence-echoes eventually fade.

It is important to see echoes as a specific type of transmission because like black holes, they are in fact empty sounds, reflections of sounds, but not the sound or action itself. When the Lesser Known went out West, a "momentous journey," he endured all the elements "without a friend in the world" and "the beast of the forest took him in" (163). The story of his move to the West echoes the master narratives about the West as rugged, dangerous and wild and emphasizes his ability to master these unruly forces. Yet, while his move reflects the master narrative, eventually the Lesser Known reveals that he has failed to live the master narrative. In the end, only Lucy and Brazil remember him and search for clues to piece together the history he built for himself out West.

\section{A NOD, A SECRET, AND A DIG}

Though her plays engage with serious contemporary topics, in interviews Parks

frequently alludes to the humor in her work. Her use of language is meant to be taken literally and figuratively; she identifies her humor as "twisted" and "the kind of humor you can say in 
front of people, so [you] can get away with saying things like 'the great hole' [...] and stuff that's unseemly" (Drunkman 72). Within this context terms like digger easily evoke the rhyming nigger as a parallel between race and labor; the Lesser Known is both Black and a digger. What Parks' performance verbalizes — in speech acts and what I am calling speech acts (the gestures which accompany the act of speech) — plays an important role in determining the relationship between what is said and what is shown. That much of the play is based on the act of giving speeches is somewhat ironic; the play is telling audiences what they need to know. However, to simplify the Lesser Known's speeches as simply ironic is to ignore the idea that within the act of speech the Lesser Known narrates multiple stories and that the words themselves are showing audiences what isn't or cannot be told. Scholars frequently point to Parks' use of language to signal consciousness and being on the stage. Alisa Solomon quotes Parks' saying: “'Thuh,' [Parks] says, slumping, 'makes the body do something very different' — and here she straightens up- 'than The'" (76). Parks indicates that the words themselves connote gestures. What we hear is not simply a matter of what is said, but what is perceived about what is said, or what Solomon refers to as "signfiyin' on the signified." Solomon perceives the Great Hole of History as Parks' theatrical incarnation of "consciousness itself" where language is pulled apart, dissected and reconstructed (74).

Parks confronts missing history by using social expectations for what it means to be black, to be Lincoln, and ultimately to be a black family in America. The expectation that Lincoln could in fact look just like a black man disturbs our expectations for exterior identity. The Lesser Known's ability to mimic Lincoln provides confirmation of exterior signs, but also signals gestural expressions of a social relationship based on racial construction. Audiences know that the Lesser Known is not Lincoln, but are complicit in the play's suggestion that the 
Lesser Known can look and act just like Lincoln. In his theories about the alienation effect, Bertolt Brecht notes that the object of the alienation effect (the effort to make audiences more aware of themselves and social conditions) is to disappoint an expectation of an experience (144). Brecht argues that audiences should be "hindered from simply identifying itself with the characters in the play" (91). He relies heavily on gestures to produce the alienation effect, to take the ordinary and make it peculiar (143).

The play's language alongside its physical gestures reimagine the ordinary words in peculiar, or perhaps, less ordinary ways. For example, seeking evidence of the Lesser Known's existence, Brazil asks: "Zit him?” and Lucy answers: "Nope. Ssuhecho” (174). Reading the play becomes an effort in imagining the sounds of words, which ordinarily would not be pasted together nor written based on the way they sound. Analogous to the peculiar sounds are contradictory gestures that indicate continued absence. Act Two ties into Act One with the sound of gunshots, but the story itself switches from the singular perspective of the Lesser Known to the shared story of Lucy and Brazil. The two characters are said to be in the replica of the Great Hole of History where Lucy walks around with a horn to her ear and Brazil digs. A secret keeper, Lucy depends on the ability to listen, but is shown as hearing-impaired by carrying a hearing aid. Brazil used to mourn the dead, an act that puts the body to rest; however, he is actively digging in an attempt unearthing his father's body of secrets. Both characters are confined by and to patterns of speech that reveal their struggles with the absence of the Lesser Known.

The Lesser's Known's identity is a powerful presence despite his absence from the family, and it is because of this absence that the transmission of his speech in the first act becomes so important to Lucy and Brazil. Though audiences are privileged with the Lesser Known's speeches, Lucy and Brazil have only memories in the silence of his absence. While 
Parks certainly draws from the trope of the missing Black father to further complicate the play's already troubled relationship between race, history, and identity, in weaving Lucy and Brazil's reflections with scenes from Our American Cousin, Parks pairs a culturally popularized image with a less familiar, but still pop culture, performance of family. Adding to the layers of representation, Parks gathers these scenes under the umbrella of the comical title 'Hall of Wonders.' The title recalls the Lesser Known's earlier reflections about his honeymoon to the historical theme park; however, knowing Parks' affinity for double-entendre, the connotations of the word 'wonders' cannot be forgotten. The second act is structured under the mystery of musings, wonders, and curiosities—in short, the missing stories.

The missing history, the missing black body, becomes reincorporated into history through narrative re-tellings of history that depend on connections between the individual and the larger historical narratives. The act of speaking, of telling a story, introduces presence in absence; however, the Lesser Known indicates that the words are not enough. Though the Lesser Known has memorized the "Great Mans words" patrons won't pay to hear his speeches (Parks 164). The Lesser Known moves from speeches alone to inviting the audience to throw old food at him during speeches with moderate success, and "when someone remarked that he played Lincoln so well that he ought to be shot, it was if the Great Mans footsteps had been suddenly revealed" (164). It's important to note the missing apostrophe, an absence that indicates a different verbal delivery of the line and a gesture of language that implies that the words are men's words, but not necessarily Lincoln's words. Just as the Lesser Known stands in for the missing black body, Lincoln stands in for the Great Mans. The singularity of the Lesser Known and the Great Mans contrasts the play's frequent repetition of phrases, acts, and gestures. For the remainder of Act One, audiences witness the repetition of Lincoln's assassination. Though slightly revised, each 
assassination repeats the specific gestures_coming up from behind, shooting Lincoln, jumping away and yelling last words - that are associated with the assassination. The repetition both emphasizes and bolsters the physical movement of the characters, ritualizing the act, reviving the past, and ultimately, calling attention to the performance itself.

In Act One the Lesser Known attempts to establish the presence of African American history through a revised and repeated re-enactment of a historical narrative entwined with the narrative of an individual Black man. Nina Schwartz claims that repetition "occurs on the oedipal model in which those with less power, resisting authority, end up forming their own authority on the model of the simultaneously hated and loved parental precursor" (1). Schwartz emphasizes that despites their efforts to escape, the transformative power of "structures" lock individuals into self-destructive patterns where "they end up doing to themselves or soliciting others to do what, previously, others had done to them against their will” (2). Impacted by generational trauma and a missing history, the Lesser Known replicates structural paternalism by ignoring his personal history and the memory of his son. The Lesser Known provides only cursory details about the family he left behind. As the Lesser Known narrates history through bits and pieces of Lincoln's speech, he inserts his personal history and that of his family, and these "interruptions" function as moments when the more narrow institutional American historical narrative accommodates for the lesser known history of an African American man. In Act Two, Lucy and Brazil attempt to revive their family by searching for an absent husband and father, respectively. This revival is underscored by the repeated references to their work as public "weepers." Paid to attend funerals and grieve for the loss, the performance of grief provides for a relationship between the speech act of mourning and the effort to reanimate lost loved ones. In her work on trauma and memory, Jennifer Griffiths claims that because trauma moves beyond 
conscious understanding, memories become encoded on a body level. Griffiths cites testimony as the moment in which memory "emerges and reunites a body and voice severed" (2). The presence of witnesses provides a mirror that helps survivors recuperate their "fractured" selves (2). Yet audiences are doubly aware of the falseness of Lucy and Brazil's performances; not only do both characters directly acknowledge their theatrics, but they also commodify the act by accepting payment. Lucy and Brazil's testimonies simultaneously force mourners to witness the presence of the departed and make absent the labor of sadness. They are encoding both memories and secrets.

Admittedly there are a number of cultural tropes available for understanding African American texts; however, language plays a significant role "largely because of the historical necessity of verbal forms of cultural transmission," according to Lucille Fultz (77). Black vocal expressions_-dialect, folktales, signifying, testifying, work songs, spirituals, blues, and jazzhave been the "perennially reliable cultural resources" that fuel much of the work critics and artists have explored to establish critical paradigms for a Black literary canon (78). A less often examined aspect of speech is the act of silence. The power of speech is so deeply ingrained that it feels counter to the widespread assumption that to have speech is to be visible, or that those who lack speech are invisible. Like Peggy Phelan, I am arguing that there is value in what "really isn't there." Phelan interrogates the usefulness of the rhetoric of visibility, especially as it relies on self-referencing for extending political control. The Lesser Known's visibility and presence, his speech, his story, however troubled by race and othering, still establish his family's story, and do so with little to no suggestion that he has not communicated the "whole" story. Phelan's observations about invisibility and power can help decipher the Lesser Known's frequent nod to the cardboard cutout as an ironic gesture toward verification of the identity he has created in the 
likeness of Lincoln. Because the Lesser Known's words come first, his speech and visibility provide establish the map against which audiences read the second act.

From the beginning of the play (and his life) the Lesser Known's history is entwined with that of Lincoln; the story begins: "There was once a man who was told that he bore a strong resemblance to Abraham Lincoln. He was tall and thinly built just like the man" (Parks 159). The Lesser Known's monologue continues for the entire first act, punctuated by moments of silence, or Rest as they are indicated in the text. The silences mimic the Great Hole, a break in narrative, a moment of absence that parallels the Lesser Known's story about his likeness to Lincoln, which led to his employment in the penny arcade. As the Lesser Known narrates he nods and winks to the "pasteboard cutout" of Lincoln, a gesture written into the play's text. This gesture deliberately acknowledges the performance and draws attention to the exteriority of identity signs. The Lesser Known's acceptance of his likeness to Lincoln is at once humorous and discomforting, a suggestion that "our identities are invariably sanctioned and circumscribed through the eyes of others as well as through the repetition of performative acts" (Carpenter 188). Focusing on the connection between costumes and identity, Jennifer Larson argues that the Lincoln's exterior costume directs audiences' gazes from the "interiors of themselves or the other characters and take these gazes to the exterior, the superficial" (58). Elam and Rayner extend this concept further, suggesting that the cardboard cutout represents a simulacrum which removes the Real history and replaces it with an illusion that directs attention toward the absent elements of history: "one of which is the black body" (182).

Parks is directing our attention to the incomplete and missing transmissions and as such it is equally important to examine the acts of speech as well as the acts of silence, to compare what is present and what is absent. In "the Elements of Style," Parks asserts that her stage figures are 
not characters and that to call them so is an "injustice" (12). Instead Parks argues that her stage figures are "figments, ghosts, roles, lovers maybe, speakers maybe, shadows, slips, players maybe, maybe someone else's pulse" (12). Divorcing character and stage presence divides the performance from materiality and emphasizes the ethereal quality of the action as well as the importance of noting gestures. Much of what Parks lists—figments, ghosts, shadows, slips — are phenomena used to describe momentary notions of presence in absence. They are phenomena that leave inexplicable traces. Parks' definitions for stage presence align well with Esther Rashin's comparison of family secrets and the phantom. Secrets, according to Rashkin, are situations that are "transmitted without being stated and without the sender's or receiver's awareness of its transmission" (4). The secret, shameful, unspeakable, is "silently transmitted to someone else in whom it lodges [and] is called a phantom" and holds the individual within a group dynamic constituted by a specific topology that prevents the individual from "living a life as his or her own" (27). As Rashkin sees it, secrets are so strong that they come to define the individual without his or her knowledge of even having received the transmission. Both Parks and Rashkin emphasize phantoms, the invisible, unmarked forms of communication.

Secrecy is a specific form of communication linked to the distribution and privilege to information, a form of "metacommunication" so pervasive that the practice of secret keeping is "relevant to any type of social situation" (Bellman 1). The defining characteristic of secrets is the act we cannot necessarily see — the transmission — and yet secrets are always told either directly or through innuendo (Bellman 2). The telling and keeping of secrets is crucial to the play because it is through the act of secret keeping that Lucy both provides for her son as well as gains power. Though the Lesser Known may gain power through visibility and speeches, Lucy's survival depends on the silences. Narratologically speaking, Mieke Bal suggests that traditionally 
women have been placed in the role of secret keepers. By virtue of their ability to bear children, women maintain the secrets of life. Lucy's profession as secret keeper should intimate a degree of control, or at the very least trouble the patriarchal structures that moderate women's social power. In fact, the African-American woman as secret keeper has well established in the American literary canon. Leslie Lewis argues that the origin story for American consciousness relies on a "dialectical acknowledgment between master and female slave, where the Hegelian moment of self-consciousness is both raced and gendered" (1). Lewis sees two fundamental secrets in slavery, one of which concerns the "master's secret," that secret about the sexual behavior of White men kept by African American women. While Lucy does not appear to possess secrets about White men's sexuality, she continually returns to the "things she will never tell," the things that burned her eardrums. Though she reiterates that she will never tell, Lucy in fact does tell some of secrets: that Bram Price wore lifts, that Mrs. Brams went crazy and perhaps "sold herself," and that Bram Price Junior was as bad as his father (175). Lucy relies on echoes, whispers, and slips of conversation to gather up her stories about the past, stories that subvert the official, the documented, the approved versions of not only what was known, but also what we will come to remember about the people who have passed.

The transmission of secrets creates what Bal terms a fabula, a series of events that constructs a narrative based on actions. The term secret, according to Bal, implies action; a secret must be revealed and the process of discovery creates a story (35). While the presence of story in secrets may appear obvious, it is important to note that within the context of the play stories (and histories) are sites of contestation. Secrets form and inform the stories inherited by Brazil. The second act of the play is scripted around the repeated command to dig and the subsequent act of digging, an effort in excavating the (w)hole story-why the Lesser Known left them behind. 
Though what we usually see of secrets is limited to gestures (for example audiences bare witness to the burden of silence), in the play secrets manifest more materially through props (such as Lucy's ear horn), through geographical space (the Great Hole of History), or simply through action - quite simply, digging for the truth.

Secrets are thus indicative of a dual nature; they exist in both the past and the future, they are both present and absent, verbal (at least in one moment of time) and non-verbalized. Too often "secret tellings are misconstrued as silence," according to Lewis, who cites records from slavery that suggest that "quiet or coded talk among slaves being mistaken for no talk at all" (13). Parks' play is frequently interrupted with silence, or Rests as they are marked in the text. The rests "verbalize" the non-verbal, or in others words, the silences say as much as the words themselves. In Act One the Lesser Known is transmitting secrets in spaces of silence. For example, in the opening lines of the play the Lesser Known states:

To stop to fearful and too faint to go.

(Rest)

He digged the hole and the whole held him.

(Rest)

I cannot dig, to beg I am ashamed.

(Rest)

He went to the theatre but home went she.

(Rest)

Goatee. Goatee. What he sported when he dies. Its not my favorite. (Rest)

He digged the hole and the whole held him. 
(Rest) (159)

Without context and gestures, each of these lines is subject to interpretation-who is the subject of this story - the Lesser Known or Lincoln, the Founding Father or the Foundling Father? The pauses open up space for confusion, wonder, alternative stories, and begin the entwined histories of Lincoln and the Lesser Known. Shadowing the text is a subtext of secrets, or the transmission of what has not been explicated stated. In Act One the rests occur frequently, usually, but not always, marking the movement between the Lesser Known as himself and the Lesser Known in performance of Lincoln. In the second act, however, the pattern of rests frequently draws attention to lines about speech, speaking, or listening. During part A: Big Bang, Lucy, encouraging Brazil to dig, says "Now me I need tuh know thuh real thing from thuh echo. Thuh truth from thuh hearsay," (175) which is followed by a rest. The next rest is preceded by Lucy's discussion of the true secrets whispered before Bram Price died; the next rest comes after Lucy says "Thuh things he told me I will never tell" (175). Though not every rest references speaking or listening, the frequency of the pairings should encourage audiences to interrogate the intention of the lines that do not fit the pattern.

Parks' strategic use of silence contrasts the "sounds" of the play, specifically the sound of gunshots that reverberate in the first act and continue to echo throughout the second act. Like secrets, the echoes blur the difference between real/unreal, presence and absence. Lucy stresses that she needs to be able to distinguish between the truth and the hearsay, the echo and the sound, because "Itsalways been important in my line to distinguish" (175). For Lucy, secrets supply the means for filling absence and supplying the parts necessary for constructing the whole person. She taunts Brazil with the secrets of Bram Price, telling him that though Price's relatives claim to have been the keepers of his final word, Bram told her something "quite different;" he 
"whispered his true secrets" to her and her "uhlone" (175). With each of the Price family's passing Lucy adds to her store of secrets, repeating that she will never tell. While Lucy recounts her stories about secrets and secret keeping, Brazil relates by describing his weeping style. For Mrs. Price he "couldn't choose between wailin or gnashin. Weepin sobbin or moanin" but eventually, decided on "gnashin" because there was "more to it" and he "gnashed for her and hers like [he had] never gnashed" (176). While Lucy's work lies in the silences, Brazil's job is to make present the gestures and rituals of grief. Like the contrast of silence and sound, Lucy and Brazil's work compliment one another—one of them holds onto to the silence, the other erupts in grief.

Brazil's sounds — his grief, his speech, and his visibility—invite consideration of the margin between Lucy and the Lesser Known. In many ways Lucy's relationship with the Lesser Known is clear; she very directly addresses her reasons for digging:

I couldnt never deny him nothing.

I gived intuh him on everything.

Thuh moon. Thuh stars.

Thuh bees knees.

Thuh cats pyjamas.

Thuh best cuts of meat.

My baby teeth. (192-93)

Repeated throughout in the second act, these lines demonstrate aggravation, sadness, bewilderment, a gamut of messy emotions, but also a plain, uncomplicated inquiry: why did he leave when I gave him everything? Lucy's sadness haunts her relationship with her son as evidenced by Brazil's relentless inquiries about his father and more importantly his likeness to 
his father. Like the Lesser Known's nod to the cardboard cut-out, Brazil almost obsessively pushes his mother to verify his likeness to his father:

LUCY: I swannee you look more and more and more like him ever-y day.

BRAZIL: His chin?

LUCY: You got his chin.

BRAZIL: His lips?

LUCY: You got his lips.

BRAZIL: His teeths?

LUCY: Top and bottom. (190)

Brazil's inquiries emphasize the loss of his father and the absence created. Like most children, Brazil looks for evidence of his own identity by ascertaining the similarities between himself and his father; however, this effort is troubled by his father's absence and Brazil must instead rely on his mother to supply the memories, stories, and most importantly, the authority necessary to assure him of his connection to his father. As Brazil digs, he pauses asking: "Zit him?" He pauses telling his mother: "Mmlistenin." He pauses to ask questions, to tell stories, to brag about his grieving — all of which add up to Brazil's personal narrative. Acting in the present, yet actively seeking the past, anticipating a potential future with his father (what Brazil will become), yet attentive to what remains unfinished, the play's temporal beat swings back and forth; Parks' refutation of a singular, constructed historical narrative.

Brazil operates in the anticipation of a series of significations not yet realized: he is not yet his father, not yet a digger, not really a griever, and not really Lincoln. These anticipations are (at least in part) driven by his mother who tells him: "Cant stop diggin till you dig up somthin. Your daddy was uh digger" (174). Lucy coaches Brazil, reminding him when his 
Lincoln performances have become over-the-top or when his theories go too wide from the truth that he needs to "keep it tuh scale." These lessons culminate when Lucy confers upon Brazil his father's digging spade. By giving Brazil his father's spade, Lucy issues Brazil his patriarchal rights; he is now a digger, like his father. In the same act, however, Lucy also ties Brazil to his raced identity (he is a digger and a nigger), to his fake identity (“diggin was his livelihood but fakin was his callin"), and to his place in history as a man who looks like his father, who looks like Lincoln, but is a lesser known Black man, who fell into the hole and never came out.

\section{CONCLUSION}

Though the failure to find wholeness - in memory, in history, in identity — could cast a pall over my readings of the play, in the end I am much less interested in wholeness than I am in the provisions made for survival. Like Cornel West, I want to "ride the dissonance" and look at how ongoing negotiations with the broken, the absent--the "funk" of the past-can resist the language of disappointment. Brazil may well find a measure of wholeness in his accommodation of his father's identity and the whole of White history through his performance of Lincoln. The last lines of the play belong to Brazil, who tells audiences:

To my right: our newest Wonder: One of thuh greats Hisself! Note: thuh body sitting propped upright in our great Hole. Note the large mouth opened wide. Note the top hat and frock coat, just like the greats. Note the death wound: thuh great black hole - thuh great black hole in thuh great head.—And how this great head is bleeding.- Note: thuh last words.- And thuh last breaths. - And how thuh nation mourns-. (199)

Brazil begins by noting the significance of himself as an individual — the "newest" wonder, but still "one thuh greats Hisself." With this phrase Brazil establishes that he is both an individual 
and a member of a historical community based on greatness. In the following series of notes that conflate the Lesser Known, Lincoln, and the newly appointed Brazil, he emphasizes the absences: the wide-open mouth, the great black hole, and the head wound. Equally significant is that the whole is a "black" hole, a reiteration of the physical reality that holes usually are a place of darkness, but also a parallel between this darkness and race. Rather than seeing this darkness as an indication of Brazil imagining himself in the grave, as the death of America, or as Chaudhuri writes a "postapocalyptic no-place," I want to read these lines a moment of release (265). No longer beholden to the secrets, Brazil notes that the great hole finally bleeds. While there is certainly evidence that would support a reading such Jeanette Malkin's, who argues that the end of the play provides evidence that Brazil has acquired the skills to mourn his father, or that "through Brazil, Parks objectifies and makes discursive that which had comprised the haunting fabric of her previous plays: mourning for a missing past," there is something quite crucial about the last noun used in the play_-"nation" (178). Though the last lines of the play certainly suggest a different type of grief than we have seen before, I disagree that they indicate Brazil specifically grieving his father. Brazil references his father but ends the play with an inclusive pronoun; he states: "thuh nation mourns," not that he mourns or Brazil mourns or Lucy mourns, but that the nation mourns. In this moment Brazil shoulders an accumulation of histories and identities, and despite the opening indication of individuality, Brazil critically separates himself as an individual from himself as a member of a community of grievers. Taken in conjunction with the context of Brazil as the fake mourner, it is plausible that Brazil is acknowledging a nation of false mourners, a history of people who have looked to the cardboard cutouts or the Disneyland versions of history that pay tribute to the historical memory of the Great Mans. 
It is equally important to emphasize the way these final words echo earlier speeches, but in place of the Lesser Known's gestures to the cardboard cutout, Brazil nods to his father, noting that he must be propped up beside history, that holes remain, that the wound continues to bleed. The performance in this moment is self-referential, acknowledging the performativity of the performance. Despite this awareness of performance, Brazil uses this very moment to divorce himself from the political of nation, and more precisely the political of performance and memory that have provided the possibility for his father to be cast as Lincoln. Admittedly this reading seems to suggest that Brazil is not counting himself as a member of the nation, and indeed Parks' play, her interviews, and much scholarship has been spent confirming this very detail—-that Black America is different from nation-America. The shift in pronoun does not consume Brazil's identity because he does not allow for public grieving. In the end we really don't know how Brazil feels about his father, a lack that acknowledges the impossibility of wholeness.

Like his father though, Brazil begins to tell the story of himself, but unlike his father Brazil refuses the 'I.' Elizabeth Brown-Guillroy has suggested that Brazil's entire process of recognition "forces Brazil to turn his efforts to creating his own representations of self, to write his own history, to avoid following in his father's footsteps" (192). In the final moments of the play, Brazil certainly creates a representation of himself, but I would add that Brazil is not a product of either history or his father, either a son or a self, but both his father's son and an individual. By this I do not mean to suggest a wholeness, and in fact, I mean quite the opposite. To be a son, Brazil must accept loss and absence as part of his whole self — a "hole" whole self. Throughout the play Brazil has emphasized that he was only five when his father left, a fact that recognizes how little shared history exists between Brazil and father. Neither knew the other. In 
the last speech he delivers, the Lesser Known (by now the Foundling Father) finally acknowledges this loss:

LUCY: Do your Lincoln for im.

THE FOUNDLING FATHER: Yeah?

LUCY: He was only 5.

THE FOUNDLING FATHER: Only 5. Uh Hehm. So very loverly to be here so very very loverly to be here in the town of-Wonderville - has always been a special favorite of mine always has been a very very special favorite of mine. Now, I only do thuh greats. Uh huhm: I was born in a log cabin of humble parentage $[\ldots]$ You can fool some of thuh people some of thuh time! Of thuh people by thuh people an for thuh people! (197)

Lucy draws upon the only connection she has cultivated — the impersonation of Lincoln —and in doing allows the Lesser Known to demonstrate himself one of the greats. The speech is collusion of performances from the historical real ("I was born in a log cabin") to the traveling minstreltype audience hype (how "loverly to be here in the town of") to the family's history ("only 5), that I argue is equally a speech where the Lesser Known admits that the performance is at an end - he has fooled some people, for some time, but he cannot fool his wife. Yet the Lesser Known maintains the farce by continuing to say 'I' as though he is in fact Lincoln himself. Unlike his father, Brazil's last words remain in third person, one of many divisions between himself and history as it belongs to his father. Brazil refuses his mother's efforts to make him like his father, to extend his father's memory and legacy. Brazil survival depends on an ongoing negotiation between the inherited narratives that he has already begun to realize may not necessarily be part of his personal story. In the end the nation may mourn, but Brazil does not. 


\title{
Epilogue
}

Adrienne Rich, Diving into the Wreck (1973)

First having read the book of myths, and loaded the camera, and checked the edge of the knife-blade,

I put on

the body-armor of black rubber

the absurd flippers

the grave and awkward mask.

\begin{abstract}
$* * *$
I came to explore the wreck.

The words are purposes.

The words are maps.

I came to see the damage that was done

and the treasures that prevail.

the thing I came for:

the wreck and not the story of the wreck

the thing itself and not the myth
\end{abstract}

"My kind of blues begins with catastrophe, begins with the angel of history... it begins with piles of wreckage, of one pile on another." 
Hammond 176

Cornel West

In a 2008 interview, Louise Erdrich describes The Plague of Doves (2008), a Pulitzer Prize finalist, as a story that "revolves, or spins off of a lynching of Native American men, young men" ("Indian Writer"). Erdrich says that the incident, which occurred in North Dakota in 1897, haunted her, particularly because one of the young men was only thirteen years old. She notes that she "didn't know how [she] was going to get to it," so she "wrote around it for many years" ("Indian Writer"). In the story the lynching of an innocent child satisfies revenge for the murder of a white family that leaves a baby orphaned, crying in her cradle. One of the Indian men, Mooshum, too drunk to think about the consequences of a conversation, reveals what he and his friends had seen at the farmhouse, a report that saves him from death, but forces him to watch the youngest boy choke to death. The lynchers took little time to consider the facts or do any research; they immediately target the group of young men, drunk Indians, who stumbled upon the gruesome murder. The lynching of the child becomes an "act of vengeance that reverberates throughout the whole community for generations" ("Indian Writer"). The dead child shapes the childhoods of the town's families such that at the end of the novel the "dead of Pluto outnumber the living" (295). The novel offers hard lessons, ending with a reminder about community and shared lives. "Now that some of us have mixed in the spring of our existence both guilt and victim," Evelina (the granddaughter of Mooshum) reflects, "there is no unraveling the rope" (243).

The role of the child in contemporary American life-writing reflects a desire to, as Erdrich writes, "get at" a history or past that feels untellable. Though the selection of texts in my 
dissertation is diverse, and the histories they present are sometimes at odds with one another (Gilmore's stories of Mormon colonization seems an unlikely compliment to Alexie's part-time Indian), one condition unites all of the children in these texts: poverty. All of the children experience childhood shaped by the profound and (somewhat) permanent effects of poverty. And while poverty does not erase or reduce the relevance of race or gender, the individual experiences of race-based childhood or gender-driven childhood cannot be separated from issues of class. Brazil's gnashing and penny show performances have everything to do with limited opportunities, which result from historical racism as well as the limited resources available for education and social movement. Allison and Walls' designation as 'white' trash marks them as poor and white, neither of which is socially acceptable.

My dissertation imagines what it might mean to put a diverse set of stories together, as a single narrative, to ask: what can we learn about the child and survival? Each chapter examines different literary definitions for the child portrayed in stories in which adults attempt to capture feeling absent from the past while gesturing toward a more hopeful future. Vizenor's term survivance helps provide a way to define the simultaneous proximity of presence and survival, emphasizing that active resistance is crucial for rejecting a state of victimry. Beside the notion of survivance, however, is a subtle theme, a persistence in survivalist stories that gestures toward the sincere power of love. In defiance of the problems inherent in institution, the narrators and theatrical figures in my study show that family can provide both the source of and asylum from trauma.

Parents, even parents who participate in acts of violence, neglect, and irresponsibility, remain crucial in exploring childhood survival, often because the child is always a "child" in relation to the parent. In this way, the child and childhood can be reframed as a source of 
strength; the epic narratives can be mined for small acts of tenderness that succeed despite the odds. Arnold's strength to leave the reservation comes in part from his parents' support, however tentative and unreliable. His father, often absent, sits in the audience and watches his son play basketball for a team whose mascot denies Indians a living, dynamic culture. Gilmore's father was terribly violent towards his wife and family, and he was a complex source of love for Mikal. Though his parents frequently argued, they fought about how best to find hope in Mikal's future. Lucy loved her husband, mourned his loss, and found her way to him, despite his having left her to love her son all by herself. Again, I return to Piri Thomas' definition to help reiterate the power of love for determining survival. He writes that in prison he did his best to keep love alive by "tuning into the love that [his] mother" had "instilled in his heart" (334). It was the "barrio's greatest strength" and "proof" that against all the odds, children from the mean streets could "still smile with amazing grace as they struggle[d] to survive" (334).

While I chose to bring seemingly disparate voices together, in the end I have found merit in thinking about unresolved differences. For example, the boys and men in the texts appear stronger for the survival and suggest that escape is possible as long as they can, as Cornel West says, live in the "wreckage." Gilmore's repetition that it will never be okay appears to provide a measure of peace; he can survive because he knows it will not be okay. At the end of Diary the two friends chose not to keep score as they play basketball, extending the temporary truce between "old" and "new" ideas about Indian-ness. However, both know that Arnold will leave, even if he carries the reservation with him. Brazil too accepts his father's mantle, the Lincoln shows and the history they connote. He finds something in him to become like his father.

The women in the texts offer less comforting ends, and I argue that their survival is marred by continued entrapment. Walls has said that she will not have children of her own, an 
indictment of survival as defined through futurity and the legacy carried through children. As an adult she is the caregiver for her mother, a mother who could never take care of herself, and therefore could not take care of daughter (Witchel). Though Walls blames her "pathological" independence for her lack of children, none of the girls in her family had any children (Witchel). Allison and her partner have children later in life, a son named Wolf (86). At the end of her memoir, her sister flies into California to help her with the baby, and she tells Allison that "babies change things, open doors you thought were shut, close others; make you into something you never been" (88-89). "You the mama now," she says. Yet Allison too continues to feel unease. The memoir ends with dreams about a wall dismantled by her son; she stands in the "rubble of [her] life" (94). Allison carries the shame of 'white' trash with her and does not return to South Carolina often. Perhaps the most heart-breaking case is Lucy, who witnesses a deathbed confession and is forever the eight-year-old secret-keeper. Or Bessie Gilmore, who does everything in her power to maintain a family home, but is forced to die in a trailer after having watched two of her four boys die and the other two waste away in sadness.

In the same way that I could imagine my work isolating the stories of men and women, I could also imagine focusing on stories of imprisonment, particularly in terms of how the term "child" becomes even more difficult to align with common social definitions. As Arnold stresses, the reservation is already like a prison, and its effects render childhood absent; children on the reservation are born in a prison-type environment. Gilmore's story, a response to Mailer's work highlighting the eight months prior to his brother Gary's execution, reveals Gary's childhood as a series of institutionalizations. Gary moved between juvenile detention, asylums, and prisons with little time in civilian life. The victim of a criminal justice system that determines the end of childhood through criminal conviction, Gary shows that the child is child only insofar as the 
child stays "innocent." I could imagine extending this study to look at other life-writing pieces, such as James Baldwin's “Sonny’s Blues," or Ann-Marie Macdonald's The Way the Crow Flies, or Malika Oufkir's Stolen Lives, to explore the shifting terms for child based on the degree to which criminality has been levied.

As much as my dissertation has centered on how social narratives fail to include diverse childhoods and children, instead I would like to return to the texts to think about how the child's perspective aids in redefining the term "child." Much like Thomas' definition for the child of earth - the poetic child — child figures in life-writing demonstrate the impossibility of limitations; children are knowing and unknowing, capable of seeing what may not otherwise be visible. I believe that the effort to recapture the child's perspective and the motivation to use the child's voice speaks to a desire to shift the world such that readers can view the familiar in unfamiliar ways. The abuse and violence in these works is, sadly, all too common; it is far too familiar to read stories about childhood trauma. What I would like to emphasize is that performative storytelling through life-writing reveals the ways in which our daily lives mask efforts to survive.

I argue that we need stories to show how survival is possible and to show why survival is necessary. The stories themselves are incredible testaments of and sources for hope. We need stories to uncover the child within, the ghosts and slips of the past that haunt as well as hide. Though childhood can be defined as a period lacking experience (and that can be viewed negatively), I want to contend that it is productive to consider how this lack of experience also inspires not only hope, but also ambition. It is the lack of experience that lets Arnold and Rowdy jump hand in hand into the lake. It is ambition that allows Walls and her siblings to forage in the trash to send their oldest sister to New York so that they might follow in her footsteps one day. It is the memory of the child that drives Allison to return to her family, to try again and again. It is 
the desire to be brothers until and after the end. And it is the strength of the child that adopts his father's (and father) voice to tell America that despite the "great black hole in thuh great head," despite the heart left bleeding, and the last breaths; Brazil will get up again (199). 


\section{Bibliography}

A Dialogue on Race with President Clinton. Panel dir. Jim Lehrer. PBS. 9 July 1998. YouTube.

Web. 20 July 2016.

Adams, Tim. "Feel the Pain.” The Guardian, 28 January 2006. Web. 5 February 2015.

Adams, Timothy Dow. Telling Lies in Modern American Autobiography. Chapel Hill: The University of North Carolina Press, 1990. Print.

---. “Telling Stories in Dorothy Allison's Two or Three Things I Know For Sure.” Southern Literary Journal 36.2 (Spring 2004): 82-99. Project Muse. Web. 5 November 2015.

Adler, Laura Reynolds. “The Dark Heart of a Dream: A Profile of Mikal Gilmore.” The San Francisco Review of Books October/November 1994: 25-27. Web. 23 October 2014.

Alcoff, Linda and Laura Gray. “Survivor Discourse: Transgression or Recuperation?” Signs 18.2 (Winter 1993): 260-290. JSTOR. Web. 5 November 2015.

Aldridge, John. “An Interview with Norman Mailer.” Partisan Review 47.2 (Spring 1980): 174182. Web. 1 Feb. 2015.

Alexander, Pamela and James Edwards. "The Contribution of Family Background to the Long -Term Adjustment of Women Sexually Abused as Children.” Journal of Interpersonal Violence 7.3 (1992): 306-320. Sage Publications. Web. 18 November 2015.

Alexie, Sherman. Flight. New York: Black Cat, 2007. Print.

---. "Why the Best Kids Books Are Written in Blood." The Wall Street Journal, 9 June 2011. Web. 15 August 2016.

Algeo, Ann M. The Courtroom as Forum: Homicide Trials by Dreiser, Wright, Capote, and Mailer. New York: Peter Lang, 1996. Print. 
Allison, Dorothy. Two or Three Things I Know for Sure. New York: Plume, 1996. Print.

---. Bastard out of Carolina. New York: Plume, 1993. Print.

---. Trash. New York: Firebrand Books, 1988. Print.

---. "A Question of Class." History is a Weapon. History is a Weapon. Web. 26 February 2017.

Allison, Sue. “All Stories Are True." Fourth Genre: Explorations of Nonfiction 6.2 (Fall 2004): 119-120. Project Muse. 19 January 2016.

Anderson, Aly. "The 1977 Execution of Gary Gilmore.” Utah Communication History Encyclopedia. Utah Community History, May 4, 2010. Web. 28 January 2015.

Anderson, Linda. Autobiography. ${ }^{\text {nd }}$ Ed. New York: Routledge, 2010. Print.

Arellano, Lisa. Vigilantes and Lynch Mobs: Narratives of Community and Nation. Philadelphia: Temple University Press, 2012. Print.

Ariès, Philippe. Centuries of Childhood: A Social History of Family Life. Translated by Robert Baldick. New York: Vintage Books, 1962. Print.

Arlett, Robert M. “The Veiled Fist of a Master Executioner.” Criticism 29.2 (Spring 1987): 215232. JSTOR. 13 October 2014.

Avilez, GerShun. "Housing the Black Body: Value, Domestic Space, and Segregation Narratives." Representing Segregation: Toward an Aesthetics of Living Jim Crow, and Other Forms of Racial Division. Norman, Brian and Piper Kendrix Williams, eds. New York: State of New York University Press, 2010, 131-148. Print.

Bailey, Peggy Dunn. "Female Gothic Fiction, Grotesque Realities, and Bastard Out of Carolina: Dorothy Allison Revises the Southern Gothic." Mississippi Quarterly 63.1-2 (WinterSpring 2010): 269-290. MLA International Bibliography. Web. 5 November 2015.

Bakhtin, M. M. The Dialogic Imagination: Four Essays. Trans. Michael Holquist. Austin: 
University of Texas Press, 1981. Print.

Bal, Mieke. Narratology: An Introduction to the Theory of Narrative. $2^{\text {nd }}$ ed. Toronto: University of Toronto Press, 2009. Print.

Bal, Mieke, Crew, Johnathan, and Leo Spitzer, eds. Acts of Memory: Cultural Recall in the Present. Hanover, NH: University Press of New England, 1999. Print.

Barcott, Bruce. "Off the Rez.” The New York Times. The New York Times, 11 November 2007. Web. 20 July 2016.

Barthes, Roland. "The Reality Effect." The Novel: An Anthology of Criticism and Theory. Ed. Dorothy Hale. Malden, Mass.: Blackwell Publishing, 2006, 229-234. Print.

Baym, Nina. "Melodramas of Beset Manhood: How Theories of American Fiction Exclude Women Authors." American Quarterly 33.2 (Summer 1982): 123-139. JSTOR. Web. 11 May 2015.

Bechtel, Roger. Past Performance: American Theatre and the Historical Imagination. Lewisburg: Bucknell University Press, 2007. Print.

Begiebing, Robert. Acts of Regeneration: Allegory and Archetype in the Works of Norman Mailer. Columbia: University of Missouri Press, 1980. Print.

Bell, Susan Groag and Lillian Robinson. Revealing Lives: Autobiography, Biography, and Gender. New York: State University of New York Press, 1991. Print.

Bellman, Beryl. "The Paradox of Secrecy.” Human Studies 4 (1981): 1-24. JSTOR. Web. 22 Sept. 2014.

Benjamin, Walter. "The Storyteller: Reflections of the Works of Nikolai Leskov.” The Novel: An Anthology of Criticism and Theory. Ed. Dorothy Hale. Malden, Mass.: Blackwell Publishing, 2006, 361-378. Print. 
Ben-Zvi, Linda. “'Aroun the Worl': The Signifyin(g) Theater of Suzan-Lori Parks.” The Theatrical Gamut: Notes for a Post-Beckttian Stage. Ed. Enoch Brater. Ann Arbor: University of Michigan Press, 1995, 189-208. Print.

Berglund, Jeff and Jan Roush, eds. Sherman Alexie: A Collection of Critical Essays. Salt Lake City: Univerity of Utah Press, 2010. Print.

Berlant, Lauren. "The Queen of America Goes to Washington D.C.: Harriet Jacobs, Frances Harper, Anita Hill." Subjects and Citizens: Nation, Race, and Gender from Oroonoko to Anita Hill. Ed. Michael Moon and Cathy Davidson. Durham: Duke University Press, 1995, 455-480. Print.

Berlant, Lauren and Michael Warner. "Sex in Public." Critical Inquiry 24.2 (Winter 1998): 547566. JSTOR. 17 March 2015.

Berlatsky, Eric. "Memory as Forgetting: The Problem of the Postmodern in Kundera's 'The Book of Laughter and Forgetting' and Spiegelman's 'Maus."” Cultural Critique 55 (Augtumn 2003): 101-151. JSTOR. 16 September 2014.

Bernardin, Susan. "Alexie-Vision: Getting the Picture.” World Literature Today 84.4 (July/August 2010): 52-55. JSTOR. 6 July 2016.

Bernstein, Robin. Racial Innocence: Performing American Childhood from Slavery to Civil Rights. New York: New York University Press, 2011. Print.

Berrick, Jill. Faces of Poverty: Portraits of Women and Children on Welfare. New York: Oxford University Press, 1995. Print.

Bhabha, Homi. "Of Mimicry and Man: The Ambivalence of Colonial Discourse." October 28 (Spring 1984): 125-133. JSTOR. Web. 27 July 2016.

Bindas, Kenneth. "Re-Remembering a Segregated Past: Race in American Memory." History and 
Memory 22.1 (Spring/Summer 2010): 113-134. JSTOR. Web. 27 September 2015.

Björling, Fiona. "Child Narrator and Adult Author: The Narrative Dichotomy in Karel Poláček’s Bylo nás pět." Scando-Slavica 29 (1983): 5-19. Taylor \& Francis. Web. 5 April 2016.

Blatanis, Konstantinos. "Enacting History, Defining Wholeness: Suzan-Lori Parks's The America Play and Topdog/Underdog." The Search for Wholeness and Diaspora Literacy in Contemporary African American Literature. Ed. Silvia Pilar Castor-Borrego. Newcastle upon Tyne: Cambridge Scholars Press, 2011, 171-187. Print.

Blouch, Christine and Vickroy Laurie, eds. Critical Essays on the Works of American Author Dorothy Allison. Lewiston, NY: Mellen, 2004. Print.

Blume, Thomas W. "Social Perspectives on Violence." Michigan Family Review 2.1 (Spring 1996): 9-23. Web. 24 January 2015.

Bonilla-Silva, Eduardo and Ashley “Woody” Doane, eds. White Out: The Continuing Significance of Racism. New York: Routledge, 2003. Print.

Booth, Wayne C. The Rhetoric of Fiction. $2^{\text {nd }}$ ed. Chicago: The University of Chicago Press, 1983. Print.

Bouson, J. Brooks. “'You Nothing But Trash': White Trash Shame in Dorothy Allison's Bastard Out of Carolina." Southern Literary Journal 34.1 (Fall 2001): 101-123. Web. 18 November 2015.

Boyd, Melanie. "Of Shards, Subjectivities, and the Refusal to Heal: Refiguring the Damage of Incest." Theorizing Sexual Violence. Ed. Victoria Grace and Heberle Renee. New York: Routledge, 2009, 72-96. Print.

Bradford, Clare and Kerry Mallan, ed. Contemporary Children's Literature and Film: Engaging with Theory. New York: Palgrave Macmillan, 2011. Print. 
Bragg, Melvyn. “A Murder’s Tale: Norman Mailer Talking to Melvyn Bragg.” Conversations with Norman Mailer. Ed. J. Michael Lennon. Jackson: University of Mississippi Press, 1988, 252-261. Print.

Braxton, Joanne M. Black Women Writing Autobiography: A Tradition within a Tradition. Philadelphia: Temple University Press, 1989. Print.

Brecht, Bertolt. Brecht On Theatre: the Development of an Aesthetic. Trans. John Willett. New York: Hill and Wang, 1964. Print.

Bridges, William E. "Family Patterns and Social Values in America, 1825-1875." American Quarterly 17.1 (Spring 1965): 3-11. JSTOR. Web. 23 January 2015.

Brockmeier, Jens. “Autobiographical Time.” Narrative Inquiry 10.1 (2000): 51-73. Web. 14 April 2015.

Broderick, Dorothy M. Image of the Black in Children's Fiction. London: R.R. Bowker \& Co., 1973. Print.

Bronfenbrenner, Urie. "What do families do?” Family Affairs 4.1-2 (1991): 1-6. Print.

Brooks, Daphne. Bodies in Dissent: Spectacular Performances of Race and Freedom, 1850 -1910. Durham: Duke University Press, 2006.

Brooks, Peter. Troubling Confessions: Speaking Guilt in Law and Literature. Chicago: University of Chicago Press, 2000. Print.

Brown, Micheal, et. al., eds. Whitewashing Race: The Myth of a Color-Blind Society. Berkley, CA: University of California Press, 2003. Print.

Brown, Stephanie and Keith Clark. "Melodrama of Beset Black Manhood?: Meditations on African-American Masculinity as Scholarly Topos and Social Menace.” Callaloo 26.3 (Summer 2003): 732-737. JSTOR. Web. 11 May 2016. 
Brown-Guillory, Elizabeth. "Reconfiguring History: Migration, Memory, and (Re)Membering in Suzan-Lori Parks's Plays." Southern Women Playwrights: New Essays in Literary History and Criticism. Ed. Robert McDonald and Linda Rohrer Paige. Tuscaloosa: University of Alabama Press, 2002, 183-198. Print.

Bruhm, Steven and Natasha Hurley, eds. Curiouser: on the Queerness of Children. Minneapolis: University of Minnesota Press, 2004. Print.

Buckley, William F. and Jeff Greenfield. "Crime and Punishment: Gary Gilmore." Conversations with Norman Mailer. Ed. J. Michael Lennon. Jackson: University of Mississippi Press, 1988, 228-251. Print.

Bullock, Kurt. "Famous Last Words: The Disruptive Rhetoric of Historico-Narrative 'Finality' in Suzan-Lori Parks's The America Play.” American Drama 10.2 (2001): 6987.

Burn, Gordon. "Dead Calm." The Guardian, The Guardian News and Media Limited, June $4^{\text {th }}$, 2004. Web. 7 March 2015.

Bush, Melanie E. L. Everyday Forms of Whiteness: Understanding Race in a 'Post Racial' World. $2^{\text {nd }}$ Ed. Lanham, MD: Rown \& Littlefield Publishers, Inc., 2011. Print.

Butler, Judith. Bodies that Matter: On the Discursive Limits of "Sex." New York: Routledge, 2011. Print.

Butler, Octavia. Kindred. Boston: Beacon Press, 1979. Print.

Califia, Pat. Public Sex: The Culture of Radical Sex. San Francisco, CA: Cleis Press, 1994. Print. Campbell, Jennifer. "Teaching Class: A Pedagogy and Politics for Working-Class Writing." College Literature 23.2 (June 1996): 116-130. JSTOR. Web. 18 November 2015. Carpenter, Faedra Chatard. "Spectacles of Whiteness from Adrienne Kennedy to Suzan- 
Lori Parks." The Cambridge Companion to African American Theatre. Ed. Harvey Young. Cambridge: Cambridge University Press, 174-195. Print.

Carr, Helen. Inventing the American Primitive: Politics, Gender and the Representation of American Literary Traditions, 1789-1936. New York: New York University Press, 1996. Print.

Carter, Natalie. “'A Southern Expendable': Cultural Patriarchy, Maternal Abandonment, and Narrativation in Dorothy Allison's Bastard Out of Carolina." Women's Studies 42 (2013): 886-903. Taylor and Francis. Web. 18 November 2015.

Caruth, Cathy. Unclaimed Experience: Trauma, Narrative, and History. Baltimore: John Hopkins University Press, 1996. Print.

Castañeda, Claudia. Figurations: Child, Bodies, Worlds. Durham: Duke University Press, 2002. Print.

Chaudhuri, Una. Staging Place: The Geography of Modern Drama. Ann Arbor: University of Michigan Press, 1995. Print.

Chevigny, Bell Gale. "Twice-told Tales and the Meaning of History: Testimonial Novels by Miguel Barnet and Norman Mailer.” The Centennial Review 30.2 (Spring 1986): 181195. Web. 12 October 2014.

Clark, Beverly Lyon. “Kiddie Lit in Academe.” Profession (1996): 149-157. JSTOR. Web. 11 May 2016.

Clawson, Rosalee and Trice Rakuya. "Poverty As We Know It: Media Portrayals of the Poor." The Public Opinion Quarterly 64.1 (Spring 2000): 53-64). JSTOR. Web. 31 March 2016. Claycomb, Ryan. Lives in Play: Autobiography and Biography on the Feminist Stage. Ann Arbor: University of Michigan Press, 2012. Print. 
Crace, John. "How to write a misery memoir." The Guardian, 5 March 2008. Web. 5 February 2015.

Coates, Ta-Nehisi. Between the World and Me. New York: Spiegel \& Grau, 2015. Web.

Coates, Karen. “Keepin' It Plural: Children's Studies in the Academy.” Children's Literature Association Quarterly 26.3 (Fall 2001): 140-150. Web. Project Muse. 3 April 2016.

Coe, Richard N. When the Grass Was Taller: Autobiography and the Experience of Childhood. New Haven, Conn.: Yale University Press, 1984. Print.

Cohen, Dov. "Culture, Social Organization, and Patterns of Violence." Journal of Personality and Social Psychology 75.2 (1998): 408-419. MEDLINE. Web. 24 January 2015.

Costello, Lisa A. “Performative Auto/Biography in Ruth Klüger's Still Alive: A Holocaust Girlhood Remembered." a/b: Autobiography Studies 26.2 (Winter 2011): 238-264. Project Muse. 7 January 2016. Web.

Crandall, Bryan Ripley. “Adding a Disability Perspective When Reading Adolescent Literature: Sherman Alexie's Absolutely True Diary of a Part-time Indian.” The Alan Review 36.2 (Winter 2009). Web. 11 July 2016.

Crimmins, Eileen, Jung K. Kim, and Teresa E. Seeman. "Poverty and the Biological Risk: The Earlier 'Aging' of the Poor." The Journal of Gerontology Series A: Biological Sciences and Medical Sciences 64A.2 (2009): 286-292. Web. 9 December 2015.

Culbertson, Roberta. "Embodied Memory, Transcendence, and Telling: Recounting Trauma, Re -Establishing the Self.” New Literary History 26.1 (Winter 1995): 169-195. JSTOR. Web. 5 November 2015.

Cvetkovich, Ann. An Archive of Feelings: Trauma, Sexuality, and Lesbian Public Cultures. 
Durham: Duke University Press, 2003. Print.

Davis, Robert Con and Patrick O’Donnell, ed. Intertextuality and Contemporary American Fiction. Baltimore: John Hopkins University Press, 1989. Print.

Dawkins, Laura. "Family Acts: History, Memory, and Performance in Suzan-Lori Parks's The America Play and Topdog/Underdog." South Atlantic Review 74.3 (Summer 2009): 82-98. JSTOR. Web. 13 October 2014.

"Death and Confusion at the Court." Time 108.24 (1976): 87. Academic Search Complete. Web. 5 November 2014.

Deloria, Phillip Joseph. Playing Indian. New Haven: Yale University Press, 1998. Print.

De Man, Paul. “Autobiography as De-facement.” MLN 94.5 (December 1979): 919-930. JSTOR. Web. 13 October 2014.

de Mause, Lloyd, ed. The History of Childhood. New York: The Psychohistory Press, 1974. Print.

Denard, Carolyn. "'Some to hold, some to tell': Secrets and the Trope of Silence in Love." Toni Morrison: Paradise, Love, A Mercy. Ed. Lucille Fultz. New York: Bloomsbury Academic, 2012. Print.

DeYoung, Allan, Thomas Shaw, and Eric Rademacher. "Educational Attachment in Appalachia: Growing with the Nation, But Challenge Remain.” Journal of Appalachian Studies 10.3 (2004): 207-329. JSTOR. Web. 16 November 2015.

Diamond, Elin. Unmaking Mimesis: Essays on Feminism and Theatre. New York: Routledge, 1997. Print.

Donahue, Deirdre. "The Violence that Begot Gary Gilmore." Review of Shot in the Heart. USA Today June 7, 1994: 1D, final edition. Lexis Nexis. Web. 23 October 2014. 
Donlon, Jocelyn Hazelwood. “'Born on the Wrong Side of the Porch': Violating Traditions in Bastard Out of Carolina." Southern Folklore 55.2 (1998): 133-144. MLA International Bibliography. Web. 5 November 2015.

Drukman, Steven. "Suzan-Lori Parks and Liz Diamond: Doo-a-Diddly-Dit: An Interview.” TDR (1988-). 39.3 (Autumn 1995): 56-75. JSTOR. Web. 12 Sept. 2014.

Dunbar, Eve. "Black Is a Region: Segregation and American Literary Regionalism in Richard Wright's The Color Curtain." Representing Segregation: Toward an Aesthetics of Living Jim Crow, and Other Forms of Racial Division. Norman, Brian and Piper Kendrix Williams, eds. New York: State of New York University Press, 2010, 185-200. Print.

Duvall, John. Race and White Identity in Southern American Fiction: from Faulkner to Morrison. New York: Palgrave McMillan, 2008. Print.

Eakin, Paul John. Touching the World: Reference in Autobiography. Princeton: Princeton University Press, 1992. ProQuest Ebrary. Web. 1 March 2015.

Edelman, Lee. No Future: Queer Theory and the Death Drive. Durham: Duke University Press, 2004. Print.

Edmundson, Mark. "Romantic Self-Creations: Mailer and Gilmore in The Executioner's Song." Contemporary Literature 31.4 (Winter 1990): 434-447. JSOR. 13 October 2014.

Elam, Harry Jr. The Past as Present in the Drama of August Wilson. Ann Arbor: University of Michigan Press, 2006. Print.

---. "The Device of Race.” African American Performance and Theater History: A Critical Reader. Ed. Harry Elam Jr. and David Drasner. New York: Oxford University Press, 2001, 3-16. Print.

Elam, Harry Jr. and Alice Rayner. "Unfinished Business: Reconfiguring History in Suzan 
-Lori Parks's The Death of the Last Black Man in the Whole Entire World." Theatre Journal 46.4 (Dec. 1994): 447-461. Literature Resource Center. Web. 21 Sep. 2014. ---. "Echoes form the Black (W)hole: An Examination of The America Play by Suzan-Lori Parks." Performing America: Cultural Nationalism in American Theater. Ed. Jeffrey Mason and J. Ellen Gainor. Ann Arbor: University of Michigan Press, 1999. Print.

Ellwood, David T. Poor Support: Poverty in the American Family. New York: Basic Books, Inc., Publishers, 1988. Print.

"Episode 6: Ellen Forney." A Tiny Sense of Accomplishment. Host Sherman Alexie. American Public Media, 15 October 2014. iTunes. Web. 31 August 2016.

Erdrich, Louise. Plague of Doves. New York: Harper Collins, 2008.

Ernest, John. Chaotic Justice: Rethinking African American Literary History. Chapel Hill: University of North Carolina Press, 2009. Print.

Evans, Stephen. “'Open Containers': Sherman Alexie's Drunken Indians.” American Indian Quarterly 25.1 (Winter 2001): 46-72. JSTOR. Web. 16 September 2016.

Felty, Darren. “Media Representations of Gary Gilmore in Norman Mailer's The Executioner's Song." Ed. Robert Con Davis and Patrick O'Donnell. Intertextuality and Contemporary American Fiction. Baltimore: John Hopkins University Press, 1989, 141-45.

Ferrence, Matthew. "You Are and You Ain't: Story and Literature as Redneck Resistance." Journal of Appalachian Studies 18.1/2 (Spring/Fall 2012): 113-130. JSTOR. Web. 16 November 2015.

Fessler, Pam. "Poverty, A Frustrating Mix of Bad Choices and Bad Luck." War on 
Poverty, 50 Years Later. NPR. Washington, D.C. 18 May 2014. Web. November 16, 2015.

---. "One Family's Story Shows How The Cycle Of Poverty Is Hard To Break." War on Poverty, 50 Years Later. NPR. Washington, D.C. 7 May 2014. Web. November 16, 2015.

--- "The Changing Picture Of Poverty: Hard Work Is 'Just Not Enough'." War on Poverty, 50 Years Later. NPR. Washington, D.C. 7 May 2014. Web. November 16, 2015.

---. "In Appalachia, Poverty Is In The Eye Of The Beholder." War on Poverty, 50 Years Later. NPR. Washington, D.C. 18 January 2014. Web. November 16, 2015.

The First 1,000 Days: Investing in WV Children When It Counts. Produced by West Virginia Public Broadcasting. 2 February 2015. YouTube. Web. 2 February 2016.

Footlick, Jerrold and Elizabeth Leonard. "What Happened to the Family?" Newsweek. Newsweek, 1991. Web. Lexis Nexis. 31 March 2015.

Fording, Richard C., Sanford F. Schram, and Joe Soss, eds. Disciplining the Poor: Neoliberal Paternalism and the Persistent Power of Race. Chicago: The University of Chicago Press, 2011. Print.

Forney, Ellen. Home page. ellenforney.com. Ellen Forney, 2006. Web. 15 August 2016.

Foster, Verna. "Suzan-Lori Parks's Staging of the Lincoln Myth in The America Play and Topdog/Underdog." Journal of American Drama and Theatre 17.3 (Fall 2005): 24-77.

Web. 22 October 2014.

Frank, Haike. "The Instability of Meaning in Suzan-Lori Parks's The America Play." American Drama 11.2 (2002): 4-20. Web. 12 Sept. 2014.

Fraser, Joelle. Interview with Sherman Alexie. "Sherman Alexie's Iowa Review Interview." Modern American Poetry, 2001. Web. 25 February 2017. 
Friedman, May. "Here Comes a Lot of Judgment: Honey Boo Boo as a Site for Reclamation and Resistance.” Journal of Popular Television 2.1 (2014): 77-95. Gale Group. Web. 18 November 2015.

Fritzsche, Peter. Stranded in the Present: Modern Time and the Melancholy of History. Cambridge, Mass.: Harvard University Press, 2004. Print.

Frye, Northop. Anatomy of Criticism, four essays. Princeton: Princeton University Press, 1957. Print.

“Gary Gilmore: A Fight to Die.” Host Jack Perkins. A \& E Biography, 1996. YouTube. 1 February 2015.

Garvey, John. “The Executioner's Song: Mailer's Best in Years." Review of The Executioner's Song. Commonweal 107. 5 (March 1980): 1342-135. Web. 12 October 2014.

Gilen, Martin. "How the Poor Became Black: The Racialization of American Poverty in Mass Media." Race and the Politics of Welfare Reform. Ed. Richard Fording, Sanford Schram, and Joe Soss. Ann Arbor, MI: The University of Michigan Press, 2003, 101-130. Print.

Gilmore, Leigh. The Limits of Autobiography: Trauma and Testimony. Ithaca: Cornell University Press, 2001. Print.

---. "Last words: Transference and the Auto/Biographical Demand in Mikal Gilmore's Shot in the Heart." American Imago: Psychoanalysis and the Human Sciences 55.2 (1998): 277298. Web. 12 October 2014.

Gilmore, Mikal. Shot Through the Heart. New York: Anchor Books, 1994. Print.

Goodenough, Elizabeth, Mark A. Heberle, and Naomi Sokoloff, eds. Infant Tongues: The Voice of the Child in Literature. Detroit: Wayne State University Press, 1994. Print.

Griffin, Susan. A Chorus of Stones: The Private Life of War. New York: Anchor Books, 1993. 
Print.

Griffiths, Jennifer. Traumatic Possessions: The Body and Memory in African American Women's Writing and Performance. Charlottesville: University of Virginia Press, 2009. Print.

Grunewald, Amina. "Ethnic Labeling and Imaging: Stereotyping by Branding vs. Native Counter-Narratives." Transnational American Studies. Ed. Udo J. Hebel. Heidelberg: Universitätsverlag /West German University Press, 2012, 323-340. Print.

Guise, Megan, DeAnn Long Sloan, and Amanda Haertling Thein. "Exploring the Significance of Social Class Identity Performance in the English Classroom: A Case Study of Analysis of a Literature Circle Discussion.” English Education 44.3 (April 2012): 215-253. Web.

Gurdon, Meghan Cox. "Darkness Too Visible.” The Wall Street Journal. The Wall Street Journal, 4 June 2011. Web. 15 August 2016.

Gwin, Minrose. "Introduction: Reading History, Memory, and Forgetting." The Southern Literary Journal 40.2 (Spring 2008): 1-10. JSTOR. Web. 31 March 2016.

Haaken, Janice. "The Recovery of Memory, Fantasy, and Desire: Feminist Approaches to Sexual Abuse and Psychic Trauma." Signs 21.4 (Summer 1996): 1069-1094. JSTOR. 11 March 2015.

Halberstam, Judith. Female Masculinity. Durham: Duke University Press, 1998. Print. Handley, William. Marriage, Violence \& the Nation in the American Literary West. New York: Cambridge University Press, 2002. Print.

Harkins, Gillian. "Surviving the Family Romance? Southern Realism and the Labor of Incest." The Southern Literary Journal 40.1 (Fall 2007): 114-139. JSTOR. Web. 31 March 2016. Harmes-Garcia, Michael Roy. Fugitive Thought: Prison Movements, Race, and the Meaning of 
Justice. Minneapolis: University of Minnesota Press, 2004. Print.

Harrison, Kathryn. "In His Brother's Shadow." Review of Shot in the Heart. New York Times May 29, 1994: BR3. ProQuest Historical Newspapers. Web. 23 Oct. 2014.

Hartigan, John Jr. 'Who Are These White People?: 'Rednecks,' 'Hillbillies,' and 'White Trash' as Marked Racial Subjects." White Out: The Continuing Significance of Racism. Eduardo Bonilla-Silva and Ashley “Woody” Doane, eds.New York: Routledge, 2003, 95-111. Print.

Hathaway, Rosemary. “The Unbearable Weight of Authenticity: Zora Neale Hurston's Their Eyes Were Watching God and a Theory of 'Touristic Reading."' Journal of American Folklore 117.464 (2004): 168-90. Web. 15 October 2016.

Hartman, Saidiya. Scenes of Subjection: Terror, Slavery, and Self-Making in Nineteenth Century America. New York: Oxford University Press, 1997.

Hawes, Joseph M. and N. Ray Hiner, eds. Growing Up in America: Children in Historical Perspective. Urbana, IL: University of Illinois Press, 1985, Print.

Hazirjian, Lisa Gayle and Annelise Orleck. The War on Poverty. Athens: University of Georgia Press, 2011. Print.

Heldrich, Philip. “Survival=Anger X Imagination: Sherman Alexie's Dark Humor.” Jeff Berglund and Jan Roush, eds. Sherman Alexie: A Collection of Critical Essays. Salt Lake City: Univerity of Utah Press, 2010, 25-43. Print.

Hellman, John. "Postmodern Journalism." Postmodern Fiction: A Bio-Bibliographical Guide. Ed. Larry McCarrery. Westport, Conn.: Greenwood Press, 1986, 51-61. Print. Helmbrecht, Breinig. "Native Survivance in the Americas: Resistance and Remembrance in 
Narratives by Asturias, Tapahonso, and Vizenor.” Gerald Vizenor, ed. Survivance:

Narratives of Presence. Lincoln, Nebraska: University of Nebraska Press, 2008, 39-59.

Print.

Heywood, Colin. "Centuries of Childhood: An Anniversary — and an Epitaph?” The Journal of the History of Childhood and Youth 3.3 (Fall 2010): 341-365. Project Muse. Web. 11 May 2016.

Hirsch, Marianne. Family Frames: Photography, Narrative, and Postmemory. Cambridge, MA: Harvard University Press, 1997. Print.

---. "Surviving Images: Holocaust Photographs and the Work of Postmemory." The Yale Journalism of Criticism 14.1 (Spring 2001): 5-37. Project Muse. Web. 30 May 2016.

Hirsch, Marianne and Valerie Smith. "Feminism and Cultural Memory: An Introduction." Signs 28.1 (August 2002): 1-19. JSTOR. Web. 11 May 2015.

Holder, Heidi. "Strange Legacy: The History Plays of Suzan-Lori Parks.” A Casebook: Suzan-Lori Parks. Ed. Kevin J. Wetmore Jr. and Alycia Smith-Howard. New York: Routledge, 2007, 18-28. Print.

Holloway, Karla. "The Body Politic." Subjects and Citizens: Nation, Race, and Gender from Oroonoko to Anita Hill. Ed. Michael Moon and Cathy Davidson. Durham: Duke University Press, 1995, 481-495. Print.

Honeyman, Susan. Elusive Childhood: Impossible Representations in Modern Fiction. Columbus: The Ohio State University Press, 2005. Print. Horeck, Tanya. "'Let Me Tell You a Story': Writing the Fiction of Childhood in Dorothy Allison's Bastard Out of Carolina." 42 (2000): 47-56. Web. 9 November 2015. 
Horvitz, Deborah M. Literary Trauma: Sadism, Memory, and Sexual Violence in American Women's Fiction. New York: SUNY Press, 2000. Print.

---. “'Sadism Demands a Story': Oedipus, Feminism, and Sexuality in Gayle Jone's Corregidora and Dorothy Allison's Bastard Out of Carolina. Contemporary Literature 39.2 (Summer 1998): 238-261. MLA International Bibliography. Web. 5 November 2015.

Howe, LeAnne. Indian Radio Days. Seventh Generation: An Anthology of Native American Plays. Ed. Mimi Gisolfi D’Aponte. New York: Theatre Communications Group, Inc. 1999.

Hutcheon, Linda. The Politics of Postmodernism. New York: Routledge, 1989. Print.

Illick, Joseph E. American Childhoods. Philadelphia: University of Pennsylvania Press, 2002. Print.

Interview with Lawrence Schiller. The Believer, The Believer, May 2010. Web. 7 March 2015. Interview with Louise Erdrich. "Indian Writer and Independent Bookseller Louise Erdrich." Democracy Now, 9 June 2008. Web. 15 February 2017.

Jackson, Shannon. Lines of Activity: Performance, Historiography, Hull-House Domesticity. Ann Arbor, Mich.: University of Michigan Press, 2000. Print.

Jaggi, Maya. “All Rage and Heart.” The Guardian. The Guardian, 2 May 2008. Web. 15 July 2016.

Jetter, Alexis. "The Roseanne of Literature.” The New York Times Magazine, The New York Times Company, 17 December 1995. Web. 30 November 2015.

Johnson, Jan. "Healing the Soul Wound in Flight and the ATD of APTI." Jeff Berglund and Jan 
Roush, eds. Sherman Alexie: A Collection of Critical Essays. Salt Lake City: University of Utah Press, 2010, 224-240. Print.

Johnson, Michael K. Black Masculinities and the Frontier Myth in American Literature. Norman: University of Oklahoma Press, 2002. Print.

Johnson, Miriam M. Strong Mothers, Weak Wives. Berkeley: University of California Press, 1988. Print.

Jones, Gavin. "Poverty and the Limits of Literary Criticism." American Literary History 15.4 (Winter 2003): 765-792. JSTOR. Web. 18 November 2015.

Kakutani, Michiko. "Portrait of a Killer in a Violent Family's Embrace." Review of Shot in the Heart. New York Times May 27, 1994: C25. ProQuest Historical Newspapers. Web. 23 October 2014.

Karsten, Fitz. "Initiation and Cultural Identity in Sherman Alexie's Young Adult Fiction.” The 'Journey of Life' in American Life and Literature. Ed. Peter Freese. Heidelberg: Universitätsverlag /West German University Press, 2015, 205-218. Print.

Katrina, Iring. “'Writing It Down So That It Would Be Real': Narrative Strategies in Dorothy Allison's Bastard Out of Carolina." College Literature 25.2 (Spring 1998): 94-107. MLA International Bibliography. Web. 5 November 2015.

Kelly, Kevin. "Diamond Sparkles in the Director's Chair." Rev. of The America Play, Suzan-Lori Parks. The Boston Globe 28 January 1994: 45.

Kennedy, Rosanne. "Vulnerable Children, Disposable Mothers.” Life Writing 5.2 (October 2008): 161-184. Web. 14 April 2014.

Kertzer, Adrienne. "Not Exactly: Intertextual Identities and Risky Laughter in Sherman Alexie's 
The Absolutely True Diary of a Part-time Indian." Children's Literature 40 (2012): 49-

77. Project Muse. Web. 6 July 2016.

Kincaid, James R. Erotic Innocence: The Culture of Child Molesting. Durham, NC: Duke University Press, 1998. Print.

King, Vincent. "Hopeful Grief: The Prospect of a Postmodernist Feminism in Allison's Bastard Out of Carolina." Southern Literary Journal 33.1 (Fall 2000): 122-140. Project Muse. Web. 5 November 2015.

Klein, Kerwin Lee. Frontiers of Historical Imagination: Narrating the European Conquest of Native America, 1890-1990. Berkeley: University of California Press, 1997.

Kodó, Kristina. "The Creation of the Stereotypical Indian Within Native Canadian Culture." Indigenous Perspectives of North America. Judit Nagy, János Kenyeres, Enikő Sepsi, and Miklós Vassányi, eds. Newcatle Upon Tyne, UK: Cambridge Scholars Publishing, 2014, 280-287. Print.

Kolodny, Annette. "Dancing through the Minefield: Some Observations on Theory, Practice and Politics of Feminist Literary Criticism." Feminist Studies 6.1 (1980): 1-25. JSTOR. Web. 5 Feb. 2013.

----. "Letting go our Grand Obsessions: Notes Toward a New Literary History of American Frontiers." Subjects and Citizens: Nation, Race, and Gender from Oroonoko to Anita Hill. Ed. Michael Moon and Cathy Davidson. Durham: Duke University Press, 1995, 9-26. Print.

Konkle, Maureen. Writing Indian Nations: Native Intellectuals and the Politics of Historiography, 1827-1863. Chapel Hill: The University of North Carolina Press, 2006. Print. 
Konigsberg, Eric. "In His Own Literary World, a Native Son Without Borders." The New York Times, The New York Times, October 20, 2009, “Books.” Web. 13 August 2016.

Kraus, Carolyn. "Bastard Logic and the Epics of Female Illegitimacy." Auto/Biography Studies 18.2 (2003): 196-218. Taylor and Francis. Web. 18 November 2015.

---. "Proof of Life: Memoir, Truth, and Documentary Evidence." Biography 31.2 (Spring 2008): 245-268. JSTOR. Web. 26 February 2015.

--- "The Road from Illegitimacy to Art: Dorothy Allison's Bastard out of Carolina." The North Dakota Quarterly 71.3 (2004): 127-143. Print.

Krips, Valerie. "Imaginary Childhoods: Memory and Children's Literature." Critical Quarterly 39.3 (October 1997): 42-50. Project Muse. Web. 4 May 2015.

Krupat, Arnold. Red Matters: Native American Studies. Philadelphia: University of Pennsylvania Press, 2002. Print.

---. "The Dialogic of Silko's Storyteller." Narrative Chance: Postmodern Discourse on Native American Indian Literatures. Vizenor, Gerald, ed. Albuquerque: University of New Mexico Press, 1989, 55-68. Print.

Kubiak, Anthony. “America/Amnesis.” Performance Research 5.3 (2000): 30-36. Routledge. Web. 15 October 2014.

LaCapra, Dominick. History and Memory after Auschwitz. New York: Cornell University Press, 1998. Print.

Lacy, Meagan. "Portraits of Children of Alcoholics: Stories that Add Hope to Hope." Children's Literature in Education 46 (2015): 343-358. Springer. Web. 15 August 2016.

Larson, Jennifer. Understanding Contemporary American Literature: Understanding Suzan-Lori Parks. Columbia: University of South Carolina Press, 2012. Print. 
Lee, Sun Hee. "Unnatural Conception: (Per)forming History and Historical Subjectivity in Suzan-Lori Parks's The America Play and Venus." Journal of American Drama and Theatre 19.1 (Winter 2007): 5-31. Web. 22 October 2014.

Leitch, Vincent B. American Literary Criticism Since 1930. New York: Routledge, 2009. Print. LeJeune, Philippe. On Autobiography. Trans. Katherine Leary. Minneapolis: University of Minnesota Press, 1989. Print.

Lesnik-Oberstein, Karin, ed. Children in Culture, Revisted: Further Approaches to Childhood. New York: Palgrave Macmillan, 2011. Print.

Lesnik-Oberstein, Karin and Stephen Thompson. "What is Queer Theory Doing with the Child?" Parallax 8.1 (2002): 35-46. Web. 23 March 2016.

Levin, Amy. "Familiar Terrain: Domestic Ideology and Farm Policy in Three Women's Novels about the 1980s.” NWSA Journal 11.1 (Spring 1999): 21-43. JSTOR. 29 March 2016. Web.

Lewis, Leslie W. Telling Narratives: Secrets in African-American Literature. Urbana: University of Illinois Press, 2007. Print.

Lhamon Jr., W.T. Raising Cain: Blackface Performance from Jim Crow to Hip Hop. Cambridge, Mass.: Harvard University Press, 1998. Print.

Lockard, Joe. "Facing the Wiindigoo: Gerald Vizenor and Primo Levi." Gerald Vizenor, ed. Survivance: Narratives of Presence. Lincoln, Nebraska: University of Nebraska Press, 2008, 209-219. Print.

Lohmann, Roger A. "Four Perspectives on Appalachian Culture and Poverty." Journal of the Appalachian Studies Association 2 (1990): 76-91. JSTOR. 16 November 2015. Web.

Lott, Eric. Love and Theft: Blackface Minstrelsy and The American Working Class. New York: 
Oxford University Press, 1993. Print.

Lowry, Annie. "50 Years Later, War on Poverty is a Mixed Bag." The New York Times, The New York Times Company, 4 January 2014. Web. 30 November 2015.

Lundquist, L. R. and William Spengemann. "Autobiography and the American Myth." American Quarterly 17.3 (1965): 501-519. Web. JSTOR. 11 Sept. 2015.

Lynch, Claire. “'Unlike Actors, Politicians, or Eminent Military Men': The Meaning of Hard Work in Working Class Autobiography." a/b: Autobiography Studies 25.2 (Winter 2010): 186-202. Project Muse. 7 January 2016. Web.

Macdonald, Ann-Marie. The Way the Crow Flies. New York: Harper Collins, 2003. Print.

Macdonald, Robert and Tracy Shildrick. "Poverty talk: how people experiencing poverty deny their poverty and why they blame 'the poor."' The Sociological Review 61 (2013): 285303. Wiley \& Sons. Web. 30 November 2016.

Mailer, Norman. The Executioner's Song. New York: Vintage International, 1979. Print. Malkin, Jeanette. Memory, Theatre, and Post-Modern Drama. Ann Arbor: University of Michigan Press, 1999.

Martin, Carol, ed. Dramaturgy of the Real on the World Stage. New York: Palgrave Macmillan, 2010. Print.

---. “Bodies of Evidence.” TDR (1988--) 50.3 (2006): 8-15. Web. JSTOR. 25 September 2011.

Marx, Leo. The Machine in the Garden: Technology and the Pastoral Ideal in America. New York: Oxford University Press, 2000. Print.

May, Elaine. "Myths and Realities of American Family." A History of Private Life: Riddles of Identity in Modern Times. Ed. Antoine Prost and Gérard Vincent. Trans. Arthur Goldhammer. Cambridge, Mass.: The Belknap Press of Harvard University, 1991. Print. 
McCord, Phyllis F. "The Ideology of Form: The Nonfiction Novel." Genres: Forms of Discourse and Culture 19.1 (Spring 1986): 59-76. Web. 12 October 2014.

McHale, Brian. Postmodernist Fictions. New York: Methuen, 1987. Print.

McLaughlin, Robert L. "History vs. Fiction: The Self Destruction of The Executioner's Song." CLIO: A Journal of Literature, History, and the Philosophy of History 17.3 (Spring 1988): 225-238. Latindex. Web. 12 October 2014.

McWilliams, John. The American Epic: Transforming A Genre 1770-1860. Cambridge: Cambridge University Press, 1989. Print.

Meiners Erica. "Trouble with the Child in the Carceral State." Social Justice 41.3 (2014): 120 -144. JSTOR. Web. 30 March 2016.

Merrill, Robert. “Mailer's Sad Comedy: The Executioner's Song." Texas Studies in Literature and Language 34.1 (Spring 1992): 129-148. JSTOR. 13 October 2014.

Meyer, Sabine N. "From Nationalism to Cosmopolitanism? Contemporary Native American Literature and the Transnational Turn.” Transnational American Studies. Ed. Udo J. Hebel. (2012): 283-303. Print.

Miller, D. Quentin. “'On the Outside Looking In': White Readers of Nonwhite Prison Narratives." Prose and Cons: Essays on Prison Literature in the United States. Ed. D. Quentin Miller. Jefferson, NC: McFarland \& Company, 2005, 15-32. Print.

Miller, Mae, ed. Conversations with Dorothy Allison. Jackson, MS: University Press of Mississippi, 2012. Print.

Miller, Nancy K. "'But enough about me, what do you think of my memoir?"” The Yale Journal of Criticism 13.2 (Fall 2000): 421-436. Project Muse. Web. 19 January 2016.

---. "Introduction: Extremities; or, Memoirs at the Fin de Siècle." a/b Auto/Biography Studies 
14.1 (1999): 1-4. Taylor \& Francis. Web. 29 March 2016.

---. "The Entangled Self: Genre Bondage in the Age of Memoir." PMLA 122.2

(March 2007): 537-548. JSTOR. Web. 26 February 2015.

Minrose, Gwin. "Nonfelicitous Space and Survivor Discourse: Reading the Incest Story in Southern Women's Fiction." Haunted Bodies: Gender and Southern Texts. Ed. Anne

Goodwyn Jones and Susan V. Donaldson. Charlottesville, AV: University Press of Virginia, 1997, 416-440. Print.

Mintz, Steven. Huck's Raft: A History of American Childhood. Cambridge, MA: Belknap Press of Harvard University Press, 2004. ACLS Humanities e-book. Web. 22 March 2016.

Moyers, Bill. "I know a lot more about being white, than you know about being Indian." Interview with Sherman Alexie. Huffington Post. Huffington Post, 10 April 2013. Web. 25 February 2017.

Mũnoz, José Esteban. Cruising Utopia: The Then and There of Queer Futurity. New York: New York University Press, 2009. Print.

Nadel, Alan. Containment Culture: American Narratives, Postmodernism, and the Atomic Age. Durham: Duke University Press, 1995. Print.

Nelson, Joshua. "Fight as Flight: The Traditional Reclamation of Exploration." World Literature Today 84.4 (July/August 2010): 44-47. JSTOR. Web. 6 July 2016.

---. "Humor is my Green Card: A Conversation with Sherman Alexie." Interview. World Literature Today, July 2010, np. Web. 15 August 2016.

Newitz, Annalee and Matt Wray, eds. White Trash: Race and Class in America. New York: Routledge, 1997. Print.

Norman, Brian and Piper Kendrix Williams. "To Lie, Steal and Dissemble: The Cultural 
Work of the Literature of Segregation." Representing Segregation: Toward an Aesthetics of Living Jim Crow, and Other Forms of Racial Division. Norman, Brian and Piper Kendrix Williams, eds. New York: State of New York University Press, 2010, 1-10. Print.

Nygren, Ase. “ A World of Story-Smoke: A Conversation with Sherman Alexie.” MELUS 30.4 (2005): 149-169. Gale-Centage. Web. 13 August 2016.

Olander, Renee. "A Conversation with Dorothy Allison." Association of Writers \& Writing Programs. AWP, October/November 2002. Web. 9 December 2015.

Walls, Jeanette. “The Glass Castle—Book Video.” CBS BookVideos.tv. Youtube. Youtube, June 14, 2007. Web. 9 December 2015.

Olney, James, Ed. Autobiography: Essays Theoretical and Critical. Princeton: Princeton University Press, 1980. Print.

---. "Psychology, Memory, and Autobiography: William and Henry James." The Henry James Review 6.1 (Fall 1984): 46-51. Project Muse. Web. 2 February 2015.

Ong, Han. “Suzan-Lori Parks.” BOMB-Artists in Conversation. BOMB, Spring 1994. Web. 15 July 2014.

Ortiz, Simon. "Excerpt from 'Children of Fire, Children of Water: Memory and Trauma."” Studies in American Indian Literatures, Series 216.4 (Winter 2004): 9-11. JSTOR. Web. 31 March 2016.

Owen, Gabrielle. "Queer Theory Wrestles with the 'Real' Child: Impossibility, Identity, and Language in Jacqueline Rose's The Case of Peter Pan." Children's Literature Association Quarterly 35.3 (Fall 2010): 255-273. Project Muse. 22 March 2016. Web. Owens, Louis. Mixed Blood Messages: Literature, Film, Family, Place. Norman, OK: University 
of Oklahoma Press, 1998. Print.

Park, Soyoung. “'Survival is the Least of My Desires': Testimony, Shame, and Desire in Dorothy Allison's Bastard Out of Carolina." Feminist Studies in English Literature 18.2 (2010): 57-85. Web. 5 November 2015.

Parks, Suzan-Lori. The America Play and Other Works. New York: Theatre Communications Group, 1995. Print.

Pearce, Michele. "Alien Nation: An Interview with the Playwright." American Theatre. 11.3 (Mar. 1994): 26. Literature Resource Center. Web. 12 Sept. 2014.

Pember, Mary Annette. “Intergenerational Trauma: Understand Natives' Inherited Pain.” Indian Country Today, Indian Country Today Media Network LLC, 2016. Web. 1 January 2017.

Perkins, Margo V. Autobiography as Activism: Three Black Women of the Sixties. Jackson: University Press of Mississippi, 2000. Print.

Petch, Simon. "Norman Mailer, Gary Gilmore, and the Untold Stories of the Law." HEAT (Heat) (1997): 142-160. Web. 12 October 2014.

Peter Goldman, et. Al. "Death Wish.” Newsweek 29 November 1976. Lexis Nexis. Web. 5 November 2014.

Phelan, Peggy. Unmarked: The Politics of Performance. New York: Routledge, 1993. Print.

Pilisuk, Marc and Phyllis Pilisuk, eds. Poor Americans: How the White Poor Live. Piscataway, NJ: Transaction Publishers, 1971. Print.

Porter, Roger J. Bureau of Missing Persons: Writing the Secret Lives of Fathers. Ithaca: Cornell University Press, 2011. Print.

Porzio, Allison. “Absolute Critical Literacy for Part-Time Critical Readers: Sherman Alexie’s 
The Absolutely True Diary of a Part-Time Indian and Cultural Studies." The English Record 58.1 (2008): 31-38. Print.

Preston, Rohan. "Watching from the Outside; Pulitzer Prize-winning playwright SuzanLori Parks Believes the Writer has a Role as Part of and Apart from the World." Interview with Suzan-Lori Parks. Star Tribune 24 March 2008 metro ed.: 1. Print. Purdy, John and Sherman Alexie. "A Conversation with Sherman Alexie.” Studies in American Indian Literatures, Series 29.4 (Winter 1997): 1-18. JSTOR. Web. 18 August 2016.

Rafter, Nicole Hahn, ed. White Trash: The Eugenic Family Studies 1877-1919. Boston: Northeastern University Press, 1988. Print.

Railton, Ben. Redefining American Identity: From Cabezade Vaca to Barack Obama. New York: Palgrave Macmillan, 2001. Print.

Rak, Julie. "Are Memoirs Autobiography? A Consideration of Genre and Public Identity." Genre 37 (Fall/Winter 2004): 483-504. Duke University Press. Web. 3 January 2016.

Rashkin, Esther. Family Secrets and the Psychoanalysis of Narrative. Princeton: Princeton University Press, 1992. Print.

Rawson, Christopher. "Parks Offers a Unique View of American History, Race.” Rev. of The America Play, Suzan-Lori Parks. Pittsburgh Post Gazette 24 October 2007: C4. Print.

Rector, Robert and Rachel Sheffield. "The War on Poverty After 50 Years." Backgrounder, The Heritage Foundation, 15 September 2014. Web. 30 November 2015.

Review of Flight. "Native Teen Time Travels in Alexie's Flight." Los Angeles Times. Los Angeles Times, 8 April 2008. Web. 20 July 2016.

Review of The Absolutely True Diary of a Part-Time Indian. "Alexie's 'Absolutely True 
Diary." Alan Cheuse. NPR. NPR.com, 1 October 2007. Web. 20 July 2016.

Review of Shot in the Heart (HBO). "Brotherly Love, and Disdain: Acting as His Keeper, Years After His Execution.” The New York Times, March 27, 2002. Web. 23 Oct. 2014.

Review of Shot in the Heart. "Shot in the Heart." The Economist, July 9, 1994: 90. ABI/INFORM Complete. Web. 23 October 2014.

Reynolds, David. "White Trash in Your Face: The Literary Descent of Dorothy Allison." Appalachian Journal 20.4 (Summer 1993): 356-366. JSTOR. Web. 5 November 2015.

Richards, David. "Seeking Bits of Identity in History's Vast Abyss." Rev. of The America Play, Suzan-Lori Parks. New York Times 11 March 1994 late ed.: C3. Print.

Roberts, Rebecca. Interview. Sherman Alexie. NPR, 11 April 2007. Web. 15 August 2016.

Ronda, Bruce. "Lost in Space: The Child in the American Landscape." Proceedings of the 1991 International conference of The Children's Literature Association, University of Southern Mississippi, Hattiesburg, Mississippi, 30 May-2 June 1991. Ed. Syvia Patterson Iskander. Battle Creek, Michigan, 257-262. Print.

Roscher, Jennifer. “The Ambivalence of The Executioner's Song: Postmodern Captivity from Death Row." Prose and Cons: Essays on Prison Literature in the United States. Ed. D. Quentin Miller. Jefferson, NC: McFarland \& Company, 2005, 217-232. Print.

Rose, Jacqueline. The Case of Peter Pan; or the Impossibility of Children's Fiction. London: MacMillan Press Ltd., 1984. Print.

Rosenfield, Israel. “Memory and Identity.” New Literary History 26.1 (Winter 1995): 197-203. JSTOR. Web. 18 November 2015.

Ryan, Katy. "No Less Human: Making History in Suzan-Lori Parks's The America 
Play." Journal of Dramatic Theory and Criticism. 13.2 (Spring 1999): 81-94. Google. Web. 1 May 2014.

Rich, Adrienne. "Women and Honor: Some Notes on Lying." Heresies 1.1 (Jan. 1977): 23-26. The Heretics. Web. 12 Sept. 2014.

Rule, Ann. "A Murderer in the Making." Review of Shot in the Heart. The Washington Post June 13, 1994: C1. Lexis Nexis. Web. 23 October 2014.

Ruppert, James. "Textual Perspectives and the Reader in The Surrounded."Narrative Chance: Postmodern Discourse on Native American Indian Literatures. Vizenor, Gerald, ed. Albuquerque: University of New Mexico Press, 1989, 91-100. Print.

Saal, Ilka. "The Politics of Mimicry: The Minor Theater of Suzan-Lori Parks." South Atlantic Review 70.2 (Spring 2005): 57-71. JSTOR. Web. 23 October 2014.

Salamon, Julie. "Why, Big Brother, Why?" Review of Shot in the Heart (HBO). The New York Times October 21, 2001. Web. 23 Oct. 2014.

Samuels, Diane. "A Brave Life." The Guardian. The Guardian, 3 October 2008. Web. 20 July 2016.

Samuels, Shirley. Romances of the Republic: Women, Family, and Violence in the Literature of Early American Nation. New York: Oxford University Press, 1996. Print.

---. Culture of Sentiment: Race, Gender, and Sentimentality in $19^{\text {th }}$-Century America. New York: Oxford University Press, 1992. Web. Pro Quest Ebrary. 22 Feb. 2016.

Sandell, Jillian. “Telling Stories of 'Queer White Trash': Race Class, and Sexuality in the Work of Dorothy Allison." White Trash: Race and Class in America. Ed. Matt Wray and Annalee Newitz. New York: Routledge, 1997, 211-231. Print. 
Scheffler, Judith A. "The Prisoner as Creator in Norman Mailer's The Executioner's Song." Midwest Quarterly: A Journal of Contemporary Thought 24.4 (Summer 1983): 400-411. Web. 12 October 2014.

Schinko, Carsten. "Why Trash? Thirteen Ways of Looking at Poor (White) Folks." Amerikastudien/American Studies 55.1 (2010): 143-164. JSTOR. Web. 5 November 2015.

Schönfelder, Christa. Wounds and Words: Childhood and Family Trauma in Romantic and Postmodern Fiction. New York: Columbia University Press, 2013. Print.

Schor, Hilary. "Bastard Daughters and Illegitimate." The Yearbook of Research in English and American Literature: REAL (2002): 109-130. Web.

Schwab, Gabriele. Haunting Legacies: Violent Histories and Transgenerational Trauma. New York: Columbia University Press, 2010. Print.

Schwartz, Nina. Dead Fathers: The Logic of Transference in Modern Narrative. Ann Arbor: University of Michigan Press, 1994. Print.

Seltzer, Mark. "Wound Culture: Trauma in the Pathological Public Sphere." October 80 (Spring 1997): 3-26. JSTOR. Web. 31 March 2016.

Seran, Justine. "Australian Aboriginal Memoir and Memory: A Stolen Generations Trauma Narrative." Humanities 4 (2015): 661-675. Web. 7 February 2017.

Shot in the Heart. Dir. Agnieszka Holland. Perf. Giovanni Ribisi, Lee Tergesen, and Elias Koteas. HBO, 2001. YouTube. 1 February 2015.

Shumante, Dennis and James E. Robertson. "Bookshelf.” Corrections Today 56.6 (1994): 133. Criminal Justice Abstracts with Full Text. Web. 23 October 2014.

Slotkin, Richard. Gunfighter Nation: The Myth of the Frontier in Twentieth-Century 
America. New York: Maxwell Macmillan International, 1992. Print.

Smith, Rich. "Sherman Alexie Talks About Writing in the Era of Trump." The Stranger. The Stranger, 6 December 2016. Web. 25 February 2017.

Smith, Sidonie. "Performativity, Autobiographical Practice, Resistance." A/B: Auto/Biography Studies 10.1 (Spring 1995): 17-33. Print.

Smith, Sidonie and Julia Watson. Reading Autobiographies: A Guide for Interpreting Life Narratives. $2^{\text {nd }}$ ed. Minneapolis: University of Minnesota Press, 2010. Print.

---. Decolonizing the Subject: The Politics of Gender in Women's Autobiography. Minneapolis: University of Minnesota Press, 1992. Print.

Sparks, Anglea. "Resisting First Nations Stereotypes in Banned YA Novel The Absolutely True Diary of a Part-Time Indian." U.S. Studies Online, 5 December 2015. Web. 15 August 2016.

Sposato, Jessie. "The Absolutely True Interview with Sherman Alexie, an Amazing Part-Time Indian.” Sadie Magazine 4 (2009). Web. 13 August 2016.

Solomon, Alisa. "Signifying on the signifyin': The Plays of Suzan-Lori Parks." Theatre (New Haven, Conn.) 21.3 (1990): 73-80. Print.

Starobin, Paul. "Dawn of the Daddy State." The Atlantic, June 2004, np. Google. Web. 5 April 2016.

Stevens, Andrea. “A Playwright Who Likes to Ban Words Together." Rev. of The America Play, Suzan-Lori Parks. New York Times 6 March 1994 late ed.: Section 2, 5. Print.

Sweeting-Trotter, Tarah. "The Price We Pay: Motherhood, Marriage, and the Struggle to Class 
Jump in Dorothy Allison's Bastard Out of Carolina." Disjointed Perspectives on Motherhood. Ed. Catalina Florina Florescu. Lanham, MD: Lexington Books, 2013, 7389. Print.

Szeghi, Tereza M. “The Possibilities and Pitfalls in Teaching Sherman Alexie's The Absolutely True Diary of a Part-Time Indian." Multiethnic American Literatures. Ed. Helane Adams Androne. North Carolina: McFarland, 2015, 72-99. Print.

Taylor, Keeanga-Yamahtta. “No Time For Depair.” Jacobin, 1 Jan. 2017. Web. 16 Feb. 2017. Thomas, Piri. Down These Mean Streets. New York: Vintage Books, 1997. Print. Thompson, Dawn. "Educational Decisions: "Traplines" in The Absolutely True Diary of a Part -Time Indian." Knowing Their Place: Identity and Space in Children's Literature. Ed. Terri Doughty and Dawn Thompson. Newcastle Upon Tyne, UK: Cambridge Scholars Publishing, 2011, 63-79. Print.

Tonn, Horst. "Making Sense of Contemporary Reality: The Construction of Meaning in the Nonfiction Novel." Historiographic Metafiction in Modern American and Canadian Literature. Ed. Bernd Engler and Kurt Müller. Paderborn: Ferdinand Schöningh, 1994, 197-208. Print.

Trodd, Zoe. "In Possession of Space: Abolitionist Memory and Spatial Transformation in Civil Rights Literature and Photography." Representing Segregation: Toward an Aesthetics of Living Jim Crow, and Other Forms of Racial Division. Norman, Brian and Piper Kendrix Williams, eds. New York: State of New York University Press, 2010, 223244. Print.

Vickroy, Laurie. "Elusive Redemptions: Trauma, Gender and Violence in Bastard Out of 
Carolina and Paco's Story." Journal of Evolutionary Psychology 22.1-2 (2001): 37-44.

Web. 18 November 2015.

Vizenor, Gerald, ed. Survivance: Narratives of Presence. Lincoln, Nebraska: University of Nebraska Press, 2008. Print.

---. Fugitive Poses: Native American Indian Scenes of Absence and Presence. Lincoln, NE:

University of Nebraska Press, 1998. Print.

---. Manifest Manners: Narratives on Postindian Survivance. Lincoln, NE: University of

Nebraska Press, 1994. Print.

---. “Trickster Discourse: Comic Holotropes and Language Games.” Narrative

Chance: Postmodern Discourse on Native American Indian Literatures. Gerald Vizenor, ed. Albuquerque: University of New Mexico Press, 1989, 187-212. Print.

Walls, Jeanette. The Glass Castle. New York: Scribner, 2005. Print.

Weldon, Glen. "The War Over Comics for Kids is Nearly Over, and Kids are Winning." NPR. NPR.com, 5 January 2016. Web. 25 July 2016.

West, Cornel. “Examined Life.” Online Video Clip. Dir. Astra Taylor. Ontario Media Development. YouTube. YouTube, March 22, 2013. Web. 29 October 2014.

White, Hayden. The Content of the Form: Narrative Discourse and Historical Representation. Baltimore: Johns Hopkins University Press, 1987. Print.

Witchel, Alex. "How Jeanette Walls Spins Good Stories out of Bad Memories." The New York Times Magazine, The New York Time Company, November 12, 2015. Web. 30 November 2015.

Wilson, Andrew. “American Minimalism: The Western Vernacular in Norman Mailer's The 
Executioner's Song." European Journal of American Studies 4.1 (2009): 2-13.

Revues.org. Web. 9 October 2014.

Wolfe, Tom. "Son of Crime and Punishment or: How to Go Eight Fast Rounds with the Heavyweight Champ—and Lose.” Rev. of An American Dream. Book Week. (14 March 1965): 1-13. Microfilm. 28 January 2015.

Woo, Eunjoo. "Breaking the Silence of Abuse and Poverty: Mother/Daughter Conflict and Abandonment in Dorothy Allison's Bastard Out of Carolina." English Language and Literature 49.2 (2003): 689-705. Web. 5 November 2015.

Woog, Adam. "Examining the Legacy of a Murderer." Review of Shot in the Heart. The Seattle Times July 24, 1994. Web. 23 October 2014.

Worthen, W.B. "Citing History: Textuality and Performativity in the Plays of Suzan-Lori Parks." Essays in Theatre 18.1 (1999): 3-22. Web. 29 October 2014.

Yankah, Ekow. "When Addiction has a White Face." The New York Times 9 February 2016: Opinion. Web.

Yu, Ying-Wen. “'Playing Indian': Manifest Manners, Simulation, and Pastiche.” Gerald Vizenor, ed. Survivance: Narratives of Presence. Lincoln, Nebraska: University of Nebraska Press, 2008, 89-102. Print. 
Hammond 217 